\author{
Jimmy Llontop Incio
}

Funcionalização de nanopartículas magnéticas de óxido de ferro com fármacos hidrofóbicos e construção de um sistema para controle de liberação

Dissertação apresentada como requisito parcial para obtenção do título de Mestre em Física pelo Programa de Pós-Graduação em Física do Departamento de Física da PUC-Rio.

Orientadores: Profa. Sônia Renaux Wanderley Louro Prof. Antonio Carlos Oliveira Bruno 
Jimmy Llontop Incio

\title{
Funcionalização de nanopartículas magnéticas de óxido de ferro com fármacos hidrofóbicos e construção de um sistema para controle de liberação
}

\begin{abstract}
Dissertação apresentada como requisito parcial para obtenção do grau de Mestre pelo Programa de PósGraduação em Física do Departamento de Física do Centro Técnico Científico da PUC-Rio. Aprovada pela Comissão Examinadora abaixo assinada.
\end{abstract}

Profa. Sônia Renaux Wanderley Louro Orientadora Departamento de Física - PUC-Rio

Prof. Antonio Carlos Oliveira Bruno

Co-orientador Departamento de Física - PUC-Rio

Profa. Isabel Cristina dos Santos Carvalho Departamento de Física - PUC-Rio

Prof. Jefferson Ferraz Damasceno Félix de Araujo Massachusetts Institute of Technology - MIT

Prof. José Eugenio Leal Coordenador Setorial de Pós-Graduação Centro Técnico Científico - PUC-Rio

Rio de Janeiro, 27 de maio de 2014 
Todos os direitos reservados. É proibida a reprodução total ou parcial do trabalho sem autorização da universidade, do autor e dos orientadores.

\section{Jimmy Llontop Incio}

Graduou-se em Física na UNI (Universidad Nacional de Ingenieria- Lima, Perú) em 2011.

Ficha Catalográfica

Incio, Jimmy Llontop

Funcionalização de nanopartículas magnéticas de óxido de ferro com fármacos hidrofóbicos e construção de um sistema para controle de liberação / Jimmy Llontop Incio; orientadores: Sônia Renaux Wanderley Louro, Antonio Carlos Oliveira Bruno. - Rio de Janeiro : PUC-Rio, Departamento de Física, 2014.

v., 100 f.: il.(color.) ; $30 \mathrm{~cm}$

1. Dissertação (mestrado) - Pontifícia Universidade Católica do Rio de Janeiro, Departamento de Física.

Inclui referências bibliográficas.

1. Biofísica. 2. Nanopartículas magnéticas. 3. Funcionalização. 4. Magnetohipertermia. 5. Fotossensibilizante. 6. Espectrofotometria. I. Louro, Sonia R. W., Bruno, A. C. O. II. Pontifícia Universidade Católica do Rio de Janeiro. Departamento de Física. III. Título. 
Dedico a:

Minha mãe Maria Esther Incio e meu pai Pedro Llontop, que têm sido a fonte de minha inspiração, de meu esforço e dedicação. A minha família: Meu irmão Elvis e irmã Marisol Noelia, por estar sempre comigo, incondicionalmente, apoiando-me moralmente e acreditando sempre em mim. 


\section{Agradecimentos}

A Deus, por me amparar sempre nos momentos difíceis, me dar a força suficiente para vencer todas as dificuldades a serem apresentadas, por me mostrar o caminho nas horas incertas e me suprir em todas minhas necessidades.

Aos meus pais, Pedro Llontop Gonzales e Maria Esther Incio Puyen, pela minha vida, compreensão, esforço, apoio constante, e aos meus irmãos Elvis e Noelia pela ajuda nos momentos que eu precisei, muito agradecido a minha família.

À minha orientadora, a Professora Sonia Louro, por sua dedicação, ensinamentos e paciência infinita assim como a meu orientador, o professor Antonio Carlos, sempre me ajudando no que puder e confiança de ambos para mim.

Aos meus grandes amigos, Jefferson Ferraz Damasceno e João Manoel Barbosa Pereira, por me ajudar em todo o trajeto da minha dissertação, sempre me ajudando no laboratório e conhecimentos científicos. O João Manoel colaborou muito para a construção do circuito eletrônico ressonante, um agradecimento especial para ele.

Ao Prof. Dr. Kleber Thiago de Oliveira, DQ/UFSCar, pela síntese e disponibilização do fotossensibilizante derivado da ftalocianina.

Aos meus amigos e colegas da Física da PUC-Rio, pelo ótimo convívio e grande amizade, eles também acreditaram em mim, agradeço a eles. A todos os professores da Física pelos conhecimentos recebidos e pela acolhida mostrada.

Aos secretários Julinho, Giza, Márcia, e Eliane, da Física PUC-Rio, pela enorme ajuda e amplo sorriso recebido em todo este tempo.

À Coordenação de Aperfeiçoamento de Pessoal de Nível Superior (CAPES), à Fundação de Amparo à Pesquisa do Estado do Rio de Janeiro (FAPERJ) e à PUCRio, pelo apoio financeiro. 
Ao povo Brasileiro, pela qualidade de pessoas, sua amabilidade e carinho com que fui recebido e mantido até estes dias. Obrigado! 


\section{Resumo}

Incio, Jimmy Llontop; Louro, Sônia Renaux Wanderley; Bruno, Antonio Carlos Oliveira. Funcionalização de nanopartículas magnéticas de óxido de ferro com fármacos hidrofóbicos e construção de um sistema para controle de liberação. Rio de Janeiro, 2014. 100p. Dissertação de Mestrado - Departamento de Física, Pontifícia Universidade Católica do Rio de Janeiro.

Estudos com nanopartículas magnéticas têm sido realizados no âmbito da medicina tanto para tratamento de tumores e câncer, quanto para fins de diagnósticos ou ainda para transporte de fármacos. Nanopartículas magnéticas podem ser administradas a alvos específicos e mantidas no local adequado por meio de um campo magnético aplicado. Com este propósito, as nanopartículas com um núcleo de material magnético são recobertas com material adequado para sua funcionalização. Neste trabalho sintetizamos nanopartículas de óxido de ferro e funcionalizamos sua superfície com uma bicamada que permitiu criar um compartimento adequado à solubilização de fármacos hidrofóbicos. Nesse compartimento foi solubilizada uma ftalocianina que se mostrou promissora como fotossensibilizante em terapia fotodinâmica. Fotossensibilizantes são moléculas que, ao interagir com a luz, formam espécies altamente reativas, como o oxigênio singlete, que destroem células e tecidos adjacentes. Este processo é utilizado em Terapia Fotodinâmica (PDT). A geração de oxigênio singlete pela ftalocianina no compartimento hidrofóbico foi avaliada usando como sonda o 1,3-difenil isobenzofurano (DPBF), em formulações com os surfactantes não iônicos, Tween 80 e Pluronic 127. Com o objetivo de controlar a liberação de fármacos, construímos um circuito eletrônico para produzir um campo magnético AC que atua sobre as partículas magnéticas e produz um aumento local de temperatura. $\mathrm{O}$ aumento de temperatura modifica a difusão das moléculas localizadas na camada que recobre as nanopartículas, o que permite variar a taxa de liberação. Foi estudada a variação de temperatura produzida na presença do campo magnético AC. Foi estudado também o efeito da temperatura na produção de oxigênio singlete.

\section{Palavras-chave}

Biofísica; nanopartículas magnéticas; funcionalização; magnetohipertermia; fotossensibilizante; espectrofotometria. 


\section{Abstract}

Incio, Jimmy Llontop; Louro, Sônia Renaux Wanderley (Advisor); Bruno, Antonio Carlos Oliveira (Co-advisor). Functionalization of iron oxide magnetic nanoparticles with hydrophobic drugs and construction of a system for controlled release. Rio de Janeiro, 2014. 100p. MSc. Dissertation - Departamento de Física, Pontifícia Universidade Católica do Rio de Janeiro.

Magnetic nanoparticles have been studied aiming at medical applications, such as treatment of tumors and cancer, for diagnostic purposes and drug delivery. Magnetic nanoparticles can be administered to specific targets and maintained in the proper location by means of an applied magnetic field. For this purpose, nanoparticles with a core of magnetic material are coated with suitable material for functionalization. In this work, we synthesized nanoparticles of iron oxide and functionalized their surface with a bilayer that served as an appropriate compartment for hydrophobic drugs. A promising phthalocyanine derived photosensitizer was solubilized in this compartment. Photosensitizers are molecules that interact with light to form highly reactive species such as singlet oxygen, which destroy cells and surrounding tissues. This process is used in photodynamic therapy (PDT). The generation of singlet oxygen by the phthalocyanine in the hydrophobic compartment was evaluated using the probe 1,3- diphenyl isobenzofuran (DPBF) in formulations with the nonionic surfactants Tween 80 and Pluronic F-127. Aiming to control the release of drugs, we build an electronic circuit to produce an AC magnetic field which acts on the magnetic particles to produce a local temperature increase. This increase in temperature modifies the diffusion of molecules at the surface layer of the nanoparticles, and allows to control the rate of release. Temperature variation produced in the presence of the AC magnetic field was studied. The effect of temperature on the singlet oxygen production was also studied.

\section{Keywords}

Biophysics; magnetic nanoparticles; functionalization; magnetic hyperthermia; photosensitizer; spectrophotometry. 


\section{Sumário}

1 Introdução 13

1.1 Partículas magnéticas e a distribuição de fármacos 13

1.2 Terapia Fotodinâmica, Fotossensibilizantes e Ftalocianinas 15

$\begin{array}{ll}1.3 \text { Objetivos } & 18\end{array}$

$\begin{array}{ll}1.4 \text { Estrutura dos capítulos } & 18\end{array}$

2 Princípios gerais 20

2.1 Magnetismo e nanopartículas magnéticas 20

2.1.1 Diamagnetismo, Paramagnetismo, Ferromagnetismo 20

2.1.2 Domínios magnéticos, curva de histerese 23

2.1.3 Superparamagnetismo e processos de relaxação em campos

2.1.4 Ferritas e nanopartículas de óxido de ferro 30

2.2 Transporte e distribuição de fármacos 33

2.2.1 Sistema de transportes de fármacos 33

2.2.2 Interação de surfactantes com fármacos 35

$\begin{array}{ll}2.3 \text { Terapia Fotodinâmica } & 37\end{array}$

2.3.1 Mecanismo de ação e oxigênio singlete 38

2.3.2 Fotossensibilizantes $\quad 41$

2.3.3 Ftalocianinas $\quad 43$

3 Materiais e métodos $\quad 47$

3.1 Materiais $\quad 47$

3.2 Técnica de Espectrofotometria UV visível 49

3.3 Métodos 52

3.3.1 Preparação de MentaZnPc em micelas 52

3.3.2 Preparação de nanopartículas de óxido de ferro 52

3.3.3 Processo de fotodegradação $\quad 55$

3.3.4 Taxa de fotoxidação de DPBF $\quad 57$

3.3.5 Construção do circuito aquecedor por indução eletromagnética 58

3.3.6 Campo magnético no interior da bobina 63

4 Resultados e Discussões $\quad 67$

4.1 Produção de oxigênio singlete por MentaZnPc 67

4.1.1 DBPF como sensor de oxigênio singlete $\quad 67$

4.1.2 Avaliação fotodinâmica de MentaZnPc utilizando DPBF 71

4.2 Funcionalização das Nanopartículas $\quad 74$

4.2.1 Associação do fotossensibilizante hidrofóbico MentaZnPc a
nanopartículas hidrofobizadas com ácido oleico

4.2.2 Nanopartículas magnéticas funcionalizadas para dispersão em meio aquoso 
4.3 Ensaios de aquecimento por relaxação magnética para dispersão aquosa de magnetita $\mathrm{Fe}_{3} \mathrm{O}_{4}$

4.4 Influência de campo magnético AC na produção de oxigênio singlete 82

5 Conclusões $\quad 86$

6 Referências Bibliográficas $\quad 88$

$\begin{array}{ll}\text { Apêndices } & 96\end{array}$ 


\section{Abreviações}

$\begin{array}{ll}\text { CMC } & \text { Concentração micelar crítica } \\ \text { CTAB } & \text { Brometode hexadeciltrimetilamônio } \\ \text { DMF } & N, N \text {-Dimetilformamida } \\ \text { DMSO } & \text { Dimetilsulfóxido } \\ \text { DPBF } & \text { 1,3- difenil isobenzofurano } \\ \text { EtOAc } & \text { Acetato de etila } \\ \phi_{\Delta} & \text { Eficiência quântica de oxigênio singlete } \\ \phi_{f} & \text { Eficiência quântica de fluorescência } \\ \phi_{p D P B F} & \text { Eficiência quântica de fotobranqueamento do DPBF } \\ \boldsymbol{k} & \text { Taxa de fotobranqueamento } \\ \boldsymbol{k}_{\boldsymbol{p}} & \text { Taxa de fotoxidação } \\ \text { MentaZnPc } & \text { ZnPccom } 4 \text { grupos mentoxicomo } \beta \text {-substituintes } \\ \text { MNP } & \text { Nanopartícula magnética } \\ \text { MPc } & \text { Metal-ftalocianina } \\ \text { OA } & \text { Ácido oleico } \\ \text { PB } & \text { Tampão fosfato (do inglês, phosphate buffer) } \\ \text { Pc } & \text { Ftalocianina } \\ \text { PDT } & \text { Terapia Fotodinâmica } \\ \text { PF-127 } & \text { Pluronic F-127 } \\ \text { PS } & \text { Fotossensibilizante } \\ \text { SDS } & \text { dodecil sulfato de sódio } \\ \text { SPION } & \text { Superparamagnetic iron oxide nanoparticles } \\ \text { Tween 80 } & \text { Polissorbato 80 } \\ \text { ZnPc } & \text { Ftalocianina de Zinco } \\ & \end{array}$


Tenho a impressão de ter sido uma criança brincando à beira-mar, divertindo-me em descobrir uma pedrinha mais lisa ou uma concha mais bonita que as outras, enquanto o imenso oceano da verdade continua misterioso diante de meus olhos.

Isaac Newton 


\section{Introdução}

\section{1}

\section{Partículas magnéticas e a distribuição de fármacos}

$\mathrm{Na}$ última década a nanotecnologia tem sido desenvolvida a tal ponto de ser possível sintetizar, caracterizar e adequar as propriedades funcionais de nanopartículas para aplicações biomédicas e diagnósticas [Moghimi et al., 2001; Curtis et al., 2001; Wilkinson, 2003]. Nanopartículas magnéticas funcionalizadas são importantes ferramentas para o transporte de fármacos e o tratamento de diversas doenças [Kim et al., 2001; Shinkai, 2002; Pankhurst et al., 2003]. Estas têm sido utilizadas em aplicações biomédicas in vivo e in vitro para liberação controlada de fármacos, em hipertermia magnética, em entrega de drogas, etc. Estas aplicações exigem que as MNPs tenham valores elevados de magnetização garantindo assim que sejam superparamagnéticas, e uma distribuição uniforme de tamanhos, tamanhos menores do que $100 \mathrm{~nm}$ tornando-as comparáveis ao tamanho de células, bactérias, proteínas, enzimas, etc. Isto facilita que elas possam chegar o mais perto possível das células alvo e interagir com elas [Gruttner and Teller, 1999; Yu et al., 2007].

Nanopartículas magnéticas (MNPs) possuem propriedades magnéticas únicas e capacidade de funcionar a nível celular e molecular em interações biológicas, tornando-as um sistema atraente para utilização em contraste para ressonância magnética (MRI) e como veículo para a entrega de drogas. O artigo de revisão de Sun e colaboradores (2008) fornece uma base para essas aplicações de MNPs e dá uma visão geral de desenvolvimentos recentes nesta área de pesquisa. Os recentes avanços em nanotecnologia têm melhorado a capacidade de adaptar especificamente as características e propriedades de MNPs para estas aplicações biomédicas. Para direcionar melhor as necessidades clínicas específicas, MNPs com momentos magnéticos mais altos, superfícies mais 
adequadas e diferentes funcionalidades estão sendo desenvolvidas para aplicações em detecção, diagnóstico e tratamento de tumores malignos, doenças cardiovasculares e doenças neurológicas. Através da incorporação de agentes de direcionamento altamente específicos e outros ligantes funcionais, tais como fluoróforos e incrementadores de permeação, a aplicabilidade e eficácia destas MNPs têm aumentado enormemente.

$\mathrm{Na}$ área das nanopartículas magnéticas, tem ocorrido um aumento nas investigações com vários tipos de óxidos de ferro destacando-se a maghemita, $\gamma$ $\mathrm{Fe}_{2} \mathrm{O}_{3}$, e a magnetita, $\mathrm{Fe}_{3} \mathrm{O}_{4}$, com domínios individuais $\approx 5-20 \mathrm{~nm}$ de diâmetro, sendo a magnetita um candidato muito promissor devido a sua biocompatibilidade já comprovada [Schwertmann et al., 1991]. Com o revestimento adequado da superfície, estas NPs podem ser dispersas em solventes adequados, formando suspensões homogêneas chamadas de ferrofluidos [Babincova, 2001].

Como exemplo de outra aplicação, as MNPs foram recobertas com um fármaco e uma camada de um polímero biodegradável [Knobel e Goya, 2004]. O campo magnético serviria para carregá-las até as células comprometidas e elas transportariam o fármaco com menor chance de erro e com menores efeitos colaterais.

Dentre as aplicações com NPs encontra-se a magnetohipertermia, em que as MNPs são carregadas até as células cancerosas e agitadas por campo magnético alternado. Mediante processos de relaxação magnética se gera calor por perda de energia [Gupta K. e Gupta M., 2005], destruindo as células cancerígenas a temperaturas em torno de $42-46^{\circ} \mathrm{C}$. Nessa importante aplicação de SPIONs, suas propriedades magnéticas são exploradas para induzir uma resposta terapêutica por meio da hipertermia [Singh e Sahoo, 2014]. Na hipertermia, o tecido é exposto a altas temperaturas, $41-47{ }^{\circ} \mathrm{C}$, para matar células cancerosas. Na hipertermia baseada em MNPs, estas podem gerar calor sob ação de um campo magnético alternado, por flutuação de Neel e perdas de energia ao percorrer o ciclo de histerese magnética. Diferentes quantidades de calor podem ser geradas dependendo da formulação das MNPs e dos parâmetros de campo magnético. Por exemplo, MNPs com domínio único de 14-16 nm mostraram-se mais apropriada para hipertermia. Recentemente, Magforce com sede na Alemanha relatou sua terapia NanoTherm1 usando MNPs e ensaios clínicos mostraram que a hipertermia seguida de radioterapia proporcionou um tempo médio de sobrevida 
bem maior do que o do grupo de controle em pacientes com glioblastoma [MaierHauff et al., 2011].

Outra aplicação de hipertermia em desenvolvimento, descrita em recente artigo de revisão [Singh e Sahoo, 2014] é sua utilização como um estímulo externo para liberação de fármacos a partir de nanopartículas carregadas com essas drogas. A entrega controlada de fármaco, com base em hipertermia pode ocorrer por um mecanismo de quebra de ligação em que a biomolécula está ligada à MNP através de um "linker" que é quebrado quando exposto a calor ou ainda por meio de aumento da permeabilidade da cobertura das nanopartículas sob ação do campo aplicado - as MNPs são aquecidas e a cobertura de polímero termosensível, por exemplo, torna-se permeável e faz com que a droga seja liberada. Derfus et al. demonstraram a implementação bem sucedida do mecanismo de quebra de ligação para liberar DNA marcado com fluoresceína usando ativação por força eletromotriz [Derfus et al., 2007]. Da mesma forma, em 2009, Hoare e colaboradores demonstraram liberação terapêutica por permeabilização de polímero em nanogéis termossensíveis à base de poli $(\mathrm{N}$ isopropilacrilamida) e MNPs [Hoare et al., 2009]. Assim, uma investigação mais exaustiva certamente vai ajudar a sintonia fina da entrega de fármacos, com potencial para ativar remotamente sua liberação.

\section{2}

\section{Terapia Fotodinâmica, Fotossensibilizantes e Ftalocianinas}

A Terapia fotodinâmica utiliza luz de um determinado comprimento de onda para o tratamento de alguns tipos de câncer ou bactérias. Em geral, utiliza um fotossensibilizante (PS) administrado e dirigido seletivamente ao tecido tumoral, seguindo-se a irradiação com luz aplicada localmente. Assim, o fotossensibilizante gera espécies reativas que podem iniciar a oxidação e morte das células tóxicas [Bonnet, 1995].

Para o tratamento de vários tipos de câncer existem fotossensibilizantes de primeira, segunda e terceira geração (ex. porfirinas, ftalocianinas, naftalocianinas, respectivamente), estes últimos têm sido investigados para alcançar alta seletividade da droga no tumor e grandes coeficientes de absorção molar 
$\left(\varepsilon_{\lambda} \approx 10^{5} \mathrm{M}^{-1} \mathrm{~cm}^{-1}\right)$ no vermelho e regiões do infravermelho próximo, onde a luz pode penetrar o tecido biológico [Rosenthal, 1989].

A utilização de porfirinas e ftalocianinas nesta área tem merecido maior atenção de cientistas e pesquisadores. No caso das ftalocianinas estas são compostos termicamente e quimicamente estáveis, podendo suportar intensas radiações eletromagnéticas. A sua estrutura contem dois átomos de hidrogênio na cavidade central, podendo ser substituídos por diferentes metais, incorporando assim uma grande variedade de substituintes, permitindo um melhor ajuste nas suas propriedades físicas. Um destes substituintes estudado amplamente tem sido o zinco (Zn) [Sekkat et al., 2012; Camur et al., 2009; Goslinski et al., 2011].

Então, vários novos derivados de fotossensibilizantes foram sintetizados $\mathrm{e}$ suas propriedades fotoquímicas e atividades fotodinâmicas têm sido intensamente caraterizadas [Durmus e Nyokong, 2007]. Ben-Hur e Rosenthal foram os primeiros a sugerir o uso dos derivados de ftalocianina devido às suas bandas intensas de absorção, denominadas bandas $\mathrm{Q}$, nas regiões do visível e infravermelho (650-700nm) [Rio et al., 2008].

O oxigênio singlete é um fator chave para o ataque do tumor. Raab, em 1900, observou a morte de microrganismos na presença de certos corantes quando expostos à luz solar [Raab, 1900] e reportou a interação de luz com fotossensibilizantes e oxigênio, resultando em espécies reativas que induziram a inviabilização de células, causando a morte dos microrganismos observados.

Mas, o que é o oxigênio singlete? É um dos três estados eletronicamente excitados imediatamente superiores ao oxigênio molecular no estado fundamental. A ação do oxigênio singlete na inviabilização de células cancerígenas tem sido evidenciada em diferentes experiências [Kulig e Smith, 1973].

Com respeito à produção de oxigênio singlete utilizando ftalocianinas hibridizadas com MNPs, temos que a hibridização de ftalocianinas com diversos materiais sólidos tem sido estudada a fim de evitar aglomeração e adicionar novas funções [Ishii, 2012]. Estes materiais sólidos empregados são divididos em dois grupos. O primeiro grupo é o dos nanomateriais [Bechet et al., 2008; Ben-Hur e Rosenthal, 1985] anexando Pcs com nanoesferas e nanobastões de ouro sob estudos in vivo e in vitro das suas propriedades fotoquímicas e atividades fotodinâmicas. O segundo grupo é dos fotocatalisadores sólidos baseados em Pcs. 
Estes, ativados por luz vermelha, têm sido eficientes para a geração de oxigênio singlete [Wohrle et al., 1994; Gerdes et al., 1997]. A sílica gel-suportando SiPc $\left(\mathrm{SIPc}-\mathrm{SiO}_{2}\right)$ foi um fotocatalisador sólido apresentando propriedades fotofísicas monoméricas e grande capacidade de gerar oxigênio singleto [Ishii et al., 2007]. A incorporação de nanopartículas magnéticas para a $\mathrm{SiPc}_{-} \mathrm{SiO}_{2}$ e o estudo das suas propriedades fotofísicas também foram investigados [Ozawa e Ishii, 2009]. É conhecido que nanopartículas magnéticas provocam supressão de fluorescência, mas a luminescência do ${ }^{1} \mathrm{O}_{2}$ no composto $\mathrm{SiPc}-\mathrm{MNP}-\mathrm{SiO}_{2}$ foi mais intensa do que em $\mathrm{SiPc}-\mathrm{SiO}_{2}$. Isto pode ser interpretado como tendo origem no acentuado cruzamento intersistemas (ISC) devido à presença das MNPs [Corr et al., 2008; Sahoo et al., 2005; Gu et al., 2005]. Assim, o SiPc-MNP-SiO 2 é um hibrido sólido de ftalocianina que age como um gerador de oxigênio singleto, o qual pode ser coletado utilizando imãs (Fig. 1).

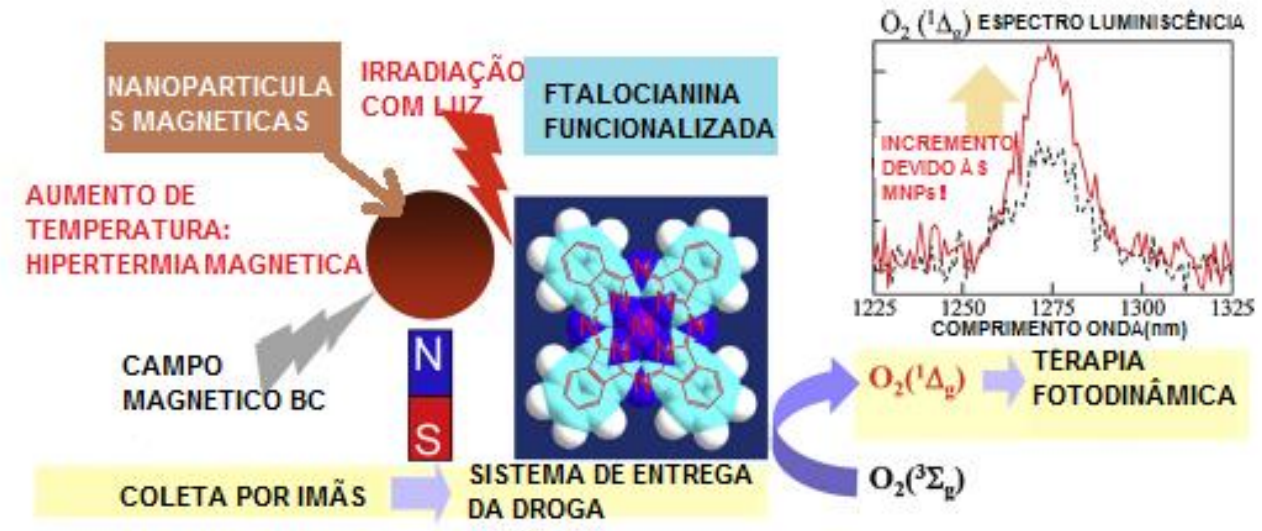

Figura 1.1. Esquema combinando hipertermia magnética e PDT. O composto SiPc-MNP-SiO pode agir como um eficiente gerador de ${ }^{1} \mathrm{O}_{2}$ coletando as MNP restantes usando ímãs. $\mathrm{O}$ conhecimento do ISC acentuado devido às MNPs é importante para o uso combinado da PDT com hipertermia magnética no sistema de entrega de droga. [Adaptado de Ishii, 2012].

Enfim, investigações recentes envolvem estudos do uso dos derivados de mentol no tratamento por terapia fotodinâmica [Romero, 2013]. Os grupos derivados da Menta têm propriedades adequadas para reduzir sua agregação em solventes apolares. Adicionando-se à $\mathrm{ZnPc}$ quatro grupos mentoxi como substituintes nas posições $\beta$, o grupo de Kleber Oliveira (UFSCar) conseguiu sintetizar o composto de MentaZnPc, solúvel em solventes apolares. Com o uso de DPBF como sonda de ${ }^{1} \mathrm{O}_{2}$ vamos avaliar sua atividade fotodinâmica em nanopartículas magnéticas hidrofobizadas com ácido oléico e implantar um 
sistema de controle da liberação de fármacos para estas nanopartículas, combinando controle de distribuição de fármacos com a terapia fotodinâmica.

\subsection{Objetivos}

O objetivo central deste trabalho é funcionalizar nanopartículas magnéticas recobrindo-as com uma camada adequada à solubilização de fármacos hidrofóbicos e avaliar como a presença de campos magnéticos alternados modifica a ação e difusão desses fármacos nas vizinhanças das nanopartículas.

Então, como objetivos específicos temos:

- Sintetizar nanopartículas magnéticas de óxido de ferro.

- Funcionalizar a superfície das nanopartículas sintetizadas, hidrofobizandoas com ácido oleico e tornando-as dispersíveis em meio aquoso com uma camada de surfactante não iônico.

- Analisar a atividade fotodinâmica de um fotossensibilizante hidrofóbico, um derivado mentolado da ftalocianina, MentaZnPc, em compartimentos micelares hidrofóbicos, semelhantes aos que revestem as nanopartículas.

- Construir um circuito eletrônico ressonante que produza um campo magnético alternado, o qual atuará sobre as nanopartículas magnéticas e, em seguida, analisar a variação da temperatura sob ação desse campo AC.

- Avaliar a influência da temperatura na atividade fotodinâmica do fotossensibilizante localizado em micelas e no revestimento das nanopartículas magnéticas.

\section{4}

\section{Estrutura dos capítulos}

No capítulo 2 se apresenta uma revisão dos principais conceitos teóricos na área de magnetismo, nanopartículas de óxido de ferro, superparamagnetismo em NPs e geração de calor por processos de relaxação em campos alternados. Na área de biofísica, aborda-se a técnica de espectroscopia de absorção, apresenta-se breve descrição da distribuição de fármacos, caracterização das ftalocianinas e sua 
aplicação na PDT. Todos estes conceitos são necessários para a compreensão do trabalho experimental desenvolvido neste trabalho de mestrado.

No capítulo 3 são apresentados os materiais e métodos empregados: a preparação de micelas contendo MentaZnPc, a síntese e técnicas de caracterização das nanopartículas. Também são descritos o espectrofotômetro utilizado, os métodos empregados nos experimentos e a construção de um circuito eletrônico de ressonância para aquecimento das nanopartículas mediante campo magnético AC. Nesta parte se faz uso dos programas de simulação OPERA 3-D e Matlab para o cálculo do campo magnético gerado pela bobina principal do circuito.

No capítulo 4 são apresentados os resultados obtidos: da estabilidade fotodinâmica da sonda de oxigênio singlete DPBF, dos estudos espectroscópicos da MentaZnPc em diferentes solventes e condições, assim como de sua avaliação fotodinâmica na geração de oxigênio singlete. Apresenta-se a funcionalização das nanopartículas com uma bicamada de ácido oleico/surfactante não iônico, permitindo criar um compartimento adequado à solubilização de fármacos hidrofóbicos como a MentaZnPc. Mostram-se também os ensaios de aquecimento das nanopartículas devido à presença do campo magnético $\mathrm{AC}$ gerado por nosso circuito eletrônico ressonante, assim como o efeito da temperatura na produção de oxigênio singlete.

No capítulo 5 são apresentadas as conclusões sobre os resultados obtidos, assim como as perspectivas para trabalhos futuros.

Finalmente no capítulo 6 , referente ao apêndice, se apresenta a calibração do sensor de platina utilizado para medir a temperatura do sistema contendo as nanopartículas, assim como também são mostradas as funções utilizadas em Matlab referentes ao circuito eletrônico de ressonância. 
2

\section{Princípios gerais}

\section{1}

\section{Magnetismo e nanopartículas magnéticas}

Quando um campo magnético externo, denotado por $\overrightarrow{\boldsymbol{H}}$, é aplicado a um material, ocorre uma mudança nos dipolos magnéticos, dando origem a uma resposta macroscópica que é a magnetização $\overrightarrow{\boldsymbol{M}}$ (momento magnético por unidade de volume).

A indução magnética $\overrightarrow{\boldsymbol{B}}$ é resultado do campo externo aplicado e do campo proveniente da própria magnetização do material. A relação, no SI, entre esses três campos é dada pela equação [Griffiths, 1999]:

$$
\overrightarrow{\boldsymbol{B}}=\mu_{0}(\overrightarrow{\boldsymbol{H}}+\overrightarrow{\boldsymbol{M}})
$$

Os materiais podem ser separados em classes de acordo com a orientação de seus momentos magnéticos em relação ao campo magnético externo. Essas classes são: diamagnéticos, paramagnéticos ferromagnéticos e superparamagnéticos.

\subsubsection{Diamagnetismo, Paramagnetismo, Ferromagnetismo}

Tanto nos materiais paramagnéticos quanto nos diamagnéticos a variação de M com H é linear: $\overrightarrow{\boldsymbol{M}}=\chi_{m} \overrightarrow{\boldsymbol{H}}$, onde $\chi_{m}$ é a susceptibilidade magnética, sendo que nos materiais diamagnéticos $\chi_{m}$ é negativa e nos paramagnéticos é positiva.

\section{Diamagnetismo}

O diamagnetismo é um fenômeno que ocorre em todos os materiais devido ao movimento orbital dos elétrons, mas frequentemente esse efeito é encoberto por outros mais fortes, como o paramagnetismo e o ferromagnetismo. Esse fenômeno nada mais é que a manifestação microscópica da Lei de Lenz, a qual diz 
que ao tentar modificar o fluxo magnético num circuito, estabelece-se uma corrente induzida no sentido de se opor à variação de fluxo que a gerou. Num circuito sem resistência, num supercondutor, ou num orbital eletrônico dentro de um átomo, a corrente induzida persiste enquanto o campo magnético estiver presente e o momento magnético induzido tem sentido oposto ao que o gerou.

A pequena susceptibilidade magnética dos materiais diamagnéticos é negativa e, em geral, independente da temperatura (com exceção do bismuto na passagem do estado sólido para o líquido), ou seja, a magnetização induzida por um campo externo é contrária e proporcional ao campo. O diamagnetismo surge da interação do campo com as cargas eletrônicas alterando sua velocidade. Como a velocidade dos elétrons é uma função dos estados eletrônicos, e estes são independentes da temperatura, isso faz com que $\chi_{m}$ também não dependa de $\mathrm{T}$.

\section{Paramagnetismo}

O paramagnetismo é uma resposta bem menos intensa a um campo magnético externo aplicado que o ferromagnetismo. Materiais paramagnéticos possuem íons cujos momentos magnéticos se alinham na presença de um campo magnético, mas não há uma interação forte entre esses momentos. Esses momentos magnéticos são provenientes de elétrons desemparelhados nos átomos ou moléculas do material.

No caso da susceptibilidade magnética o modelo clássico mostra que, em campos magnéticos fracos, a susceptibilidade magnética desses materiais cai com $\mathrm{T}^{-1}$ :

$$
\chi_{m}=\frac{\mu_{m}^{2} N_{v} \mu_{0}}{3 k_{B} T}=\frac{C}{T}
$$

onde $N_{v}$ é o número de momentos magnéticos por unidade de volume, $k_{B}$ a constante de Boltzmann e $\mu_{m}$ a magnitude dos momentos magnéticos presentes no material. Esta expressão é conhecida como Lei de Curie.

Considerando o caso de metais chega-se ao paramagnetismo de Pauli, que considera a indistinguibilidade dos spins dos elétrons livres num metal. Nesse caso a susceptibilidade é independente da temperatura:

$$
\chi_{\text {pauli }}=\frac{\mu_{m}^{2} N_{v} \mu_{0}}{k_{B} T_{f}}=\text { cte. }
$$


onde $T_{f}$ é a temperatura de Fermi. Nessa expressão não surge a temperatura, pois o modelo não leva em conta a possibilidade dos elétrons ocuparem estados mais energéticos com o aumento de $\mathrm{T}$ nem o efeito da desordem térmica no sistema.

\section{Ferromagnetismo}

Num meio linear, o alinhamento dos dipolos atômicos é mantido por um campo magnético externo. Os ferromagnetos (que são não lineares) não requerem campos magnéticos externos para manter a magnetização, os momentos magnéticos atómicos ou moleculares estão quase alinhados mesmo na ausência do campo externo. Como o paramagnetismo, o ferromagnetismo envolve os dipolos magnéticos associados aos spins dos elétrons desemparelhados. Uma característica que torna o ferromagnetismo notavelmente diferente do paramagnetismo é que no ferromagnetismo existe uma forte interação entre os momentos de dipolos vizinhos, alinhando-os $100 \%$ dos spins dos elétrons desemparelhados.

Uma variação de energia térmica produzirá uma flutuação da direção dos dipolos magnéticos em relação a uma direção particular causando um desvio do alinhamento com consequente perda de magnetização. A energia de troca que produz o alinhamento dos dipolos magnéticos é contraposta pela energia térmica, para altas temperaturas causam a redução da intensidade de magnetização. A temperatura na qual um material ferromagnético passa a ser paramagnético é denominada temperatura de Curie. Nesta temperatura o alinhamento dos dipolos magnéticos desaparece. Para temperaturas maiores que a temperatura de Curie o material se comporta como uma substância paramagnética, pois os dipolos só são levados ao alinhamento parcial ao aplicar um campo magnético. Na tabela 1.1 apresentamos alguns materiais ferromagnéticos com sua respectiva temperatura de Curie. [Faria, 2005].

Tabela 1.1. Temperatura de Curie para diversos materiais ferromagnéticos.

\begin{tabular}{lc}
\hline Material Ferromagnético & Temperatura de Curie (K) \\
\hline Ferro & 1043 \\
Cobalto & 1404 \\
Níquel & 631 \\
Cromel & 436 \\
Gadolínio & 289 \\
\hline
\end{tabular}




\subsubsection{Domínios magnéticos, curva de histerese}

O físico francês Andre-Marie Ampère, ao descobrir os efeitos dos materiais magnéticos permanentes ou temporários, propôs a teoria de que as propriedades magnéticas de um corpo fossem originadas por um grande número de minúsculas correntes internas circulares. O campo magnético total no material seria então a soma do campo gerado pela corrente externa com o campo gerado por estas correntes microscópicas. Hoje, com o modelo atômico sabemos que esses materiais são constituídos de átomos possuindo elétrons que, além de apresentarem momento angular orbital, também apresentam momento angular de spin, dando inicio à teoria dos domínios proposta por Weiss em 1907 e continuada por Heisenberg em 1928.

Os elétrons apresentam a propriedade de spin que faz com que eles se comportem como pequenos imãs. No caso de moléculas de materiais não magnéticos, os elétrons ocorrem emparelhados uns com os outros, mas com os spins em sentidos opostos, fazendo com que o campo magnético produzido por um elétron seja cancelado pelo campo do outro elétron. Isso ocorre ao longo de todo o arranjo cristalino da substância não magnética resultando num campo magnético total nulo. Nos materiais magnéticos, a maioria dos spins eletrônicos ocorre numa direção dada, portanto nem todos os campos magnéticos produzidos por elétrons são cancelados, e o campo magnético resultante total tem um valor não nulo. Esses campos magnéticos associados aos elétrons se alinham formando regiões que apresentam magnetismo espontâneo. Essas regiões da matéria com a mesma orientação magnética são chamadas de domínios magnéticos e são como ímãs microscópicos (Fig. 2.1 a). 
a)

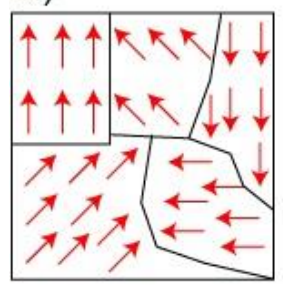

b)

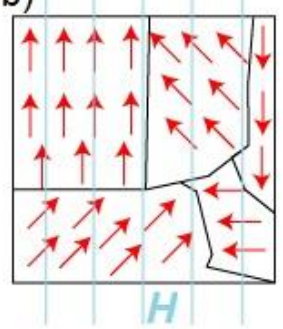

c)

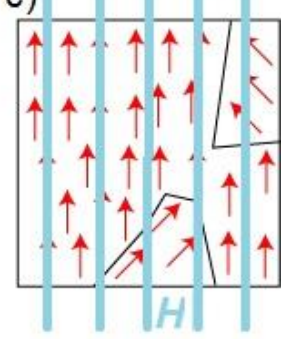

Figura 2.1. a) Domínios magnéticos orientados aleatoriamente num material desmagnetizado. b) Mudança das paredes dos domínios ante a presença de um campo magnético H. c) Quanto maior o campo $\mathbf{H}$ aplicado, os domínios adquirem uma única direção paralela ao $\mathbf{H}$ aplicado.

Num material não magnetizado não se percebe o magnetismo deste, pois seus domínios estão distribuídos de forma aleatória e o campo magnético total é zero (Fig. 2.2 a). Quando esse material sofre a ação de um campo magnético externo, os domínios que estão aproximadamente alinhados com o campo aplicado crescem à custa dos outros domínios(Fig. 2.2 b). Este processo continua até todos os domínios estejam orientados na direção de magnetização mais próxima a $\overrightarrow{\boldsymbol{H}}$, desaparecendo as paredes (Fig. 2.2 c). Aumentando a excitação, os momentos magnéticos giram até se colocar paralelamente ao campo $\overrightarrow{\boldsymbol{H}}$ (Fig. 2.2 d). Neste caso se diz que a substância encontra-se magneticamente saturada e a magnetização não cresce mesmo aumentando o campo $\overrightarrow{\boldsymbol{H}}$.

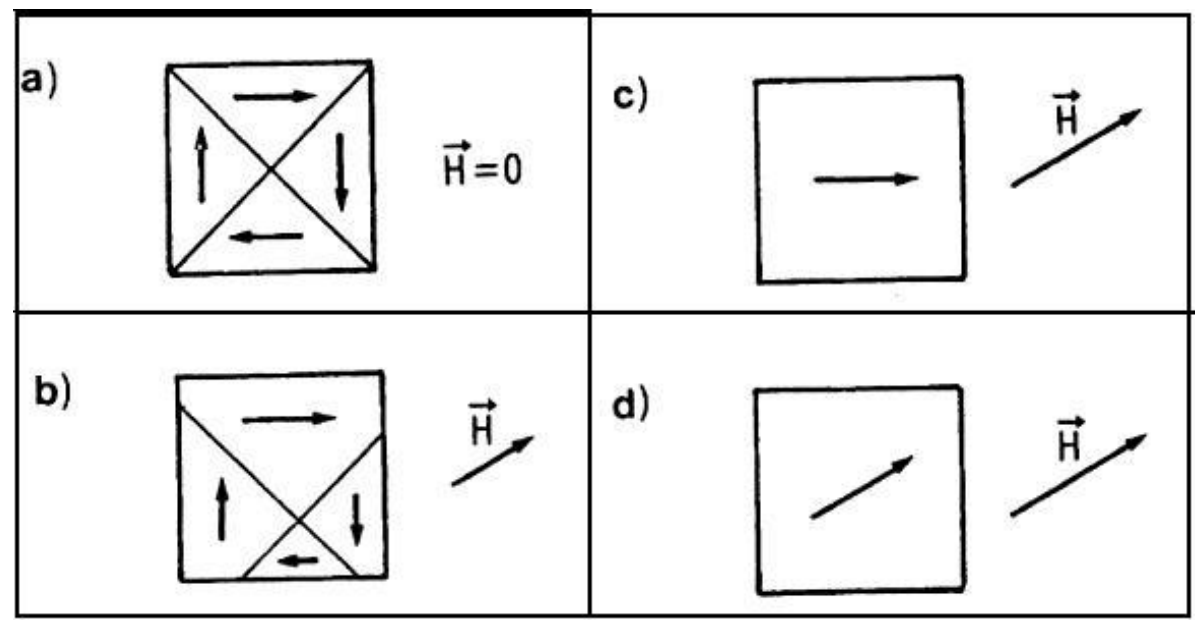

Figura 2.2. Campo magnético $\mathbf{H}$ atuando sobre um domínio magnético. Adaptado de Llinares e Page, 1997.

No entanto, há casos em que estes domínios estão arranjados naturalmente de forma que os polos ficam alinhados sem precisar de algum agente externo, e a 
soma dos seus campos magnéticos elementares gera um campo macroscópico forte, como é o caso dos imãs naturais.

Se o campo magnético externo aplicado sobre o material magnético for suficientemente intenso, ele pode reorientar estes domínios na mesma direção (Fig. 2.1 b, Fig. 2.1 c), magnetizando-o. Quando todos estiverem alinhados, qualquer aumento do campo externo não causará aumento adicional na magnetização do material, atingindo a saturação.

Quando o campo magnético externo é removido, o grau de alinhamento diminui fazendo que o campo magnético resultante no interior do material atinja um valor não necessariamente igual ao anterior, a quantidade de domínios com spins desalinhados vai depender do tipo do material. Este fenômeno é denominado histerese.

\section{Curva de Histerese Magnética}

Curvas típicas experimentais usadas para analisar a magnetização de uma amostra em função do campo magnético aplicado são as denominadas curvas de histerese (Fig. 2.3). No processo inicial a amostra encontra-se desmagnetizada. Ao aplicar um campo crescente $\overrightarrow{\boldsymbol{H}}$, a magnetização aumenta, modificando as paredes dos domínios e fazendo com que a magnetização de cada domínio se alinhe até atingir a magnetização de saturação $\overrightarrow{\boldsymbol{M}}_{\mathrm{s}}$. Nesse instante se diz que a amostra está magneticamente saturada, formando-se assim uma primeira curva denominada curva de primeira magnetização (Fig. 2.3).

Ao diminuir a intensidade do campo $\overrightarrow{\boldsymbol{H}}$ observa-se que, no instante em que a curva passa pelo eixo das ordenadas a magnetização do material não é nula. Isto pode se explicar devido a que existe certo número de domínios com magnetizações não alinhadas, nesse ponto se diz que a amostra possui uma magnetização remanente $\overrightarrow{\boldsymbol{M}}_{\mathrm{R}}$.

Se invertermos o campo $\overrightarrow{\boldsymbol{H}}$ no instante quando a $\overrightarrow{\boldsymbol{M}}_{\mathrm{R}}$. foi atingida, os domínios se reorientam até que a amostra fique desmagnetizada no ponto $\overrightarrow{\boldsymbol{H}}_{\mathrm{c}}$ (magnetização zero). Esta propriedade onde $\overrightarrow{\boldsymbol{M}}$ é zero e o campo aplicado é não nulo é denominada de coercividade do material. O campo coercivo $\overrightarrow{\boldsymbol{H}}_{\mathrm{c}}$ é o campo 
necessário para que a magnetização atinja o valor zero depois de a amostra ser magnetizada.

Se continuarmos aumentando o campo magnético negativo aplicado, observarmos que o material fica com a magnetização na direção oposta devido à mudança de sentido no campo externo, e também atinge uma magnetização de saturação $\overrightarrow{\boldsymbol{M}}_{\mathrm{s}}$ no sentido oposto.

Depois dessa saturação magnética do material, se invertemos o campo magnético aplicado aumentando-o, aumentaremos também a magnetização até atingir novamente o mesmo valor de saturação inicial $\overrightarrow{\boldsymbol{M}}_{\mathrm{s}}$, fechando assim a curva apresentada na Fig. 2.3, denominada curva de magnetização que apresenta histerese. O fenômeno de histerese é muito comum em alguns materiais e mostra a tendência para conservar suas propriedades na ausência do estímulo que as gerou.

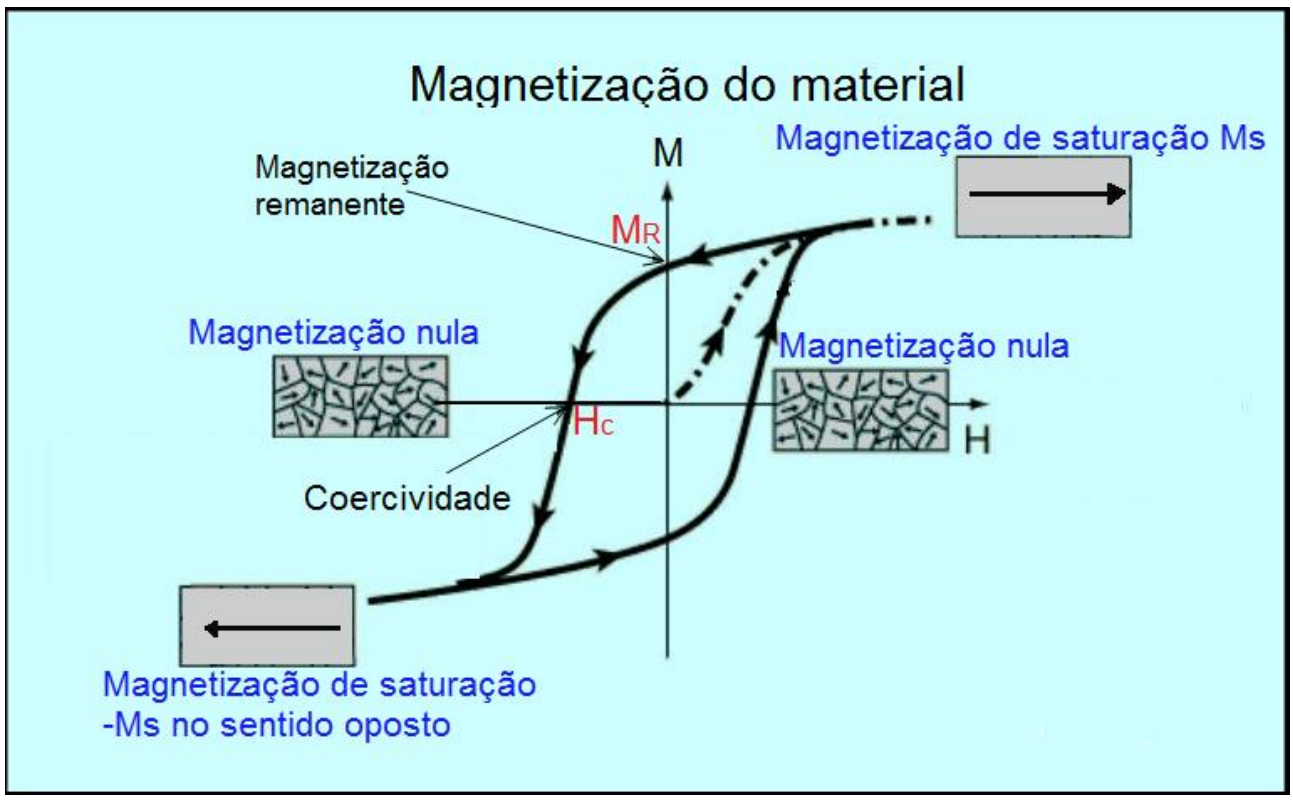

Figura 2.3. Ilustração da curva de histerese magnética. Adaptado de Young, 1992.

\subsubsection{Superparamagnetismo e processos de relaxação em campos magnéticos $\mathrm{AC}$}

Conforme dissemos antes, os domínios magnéticos são pequenas regiões do material onde os spins dos elétrons encontram-se acoplados em determinadas direções. Quando partículas magnéticas são muito pequenas em torno de um determinado tamanho crítico, o material em questão passa a ser constituído apenas 
de um domínio magnético, chamado de monodomínio, aqui a direção da magnetização pode mudar quando submetido a agitação térmica, não apresentando magnetização remanente; esse comportamento é denominado de superparamagnético. Esta denominação é dada pelo fato destes sistemas apresentarem propriedades análogas aos paramagnéticos, mas com momento magnético muito maior.

\section{Processo de relaxação de Néel}

Na primeira suposição da teoria do superparamagnetismo, considera-se que os momentos magnéticos atômicos no interior de uma partícula se movimentam coerentemente, produzindo um momento magnético total: $\mu_{t}=\mu_{a} N$ que depende do momento magnético atômico $\mu_{a}$ e do numero de átomos magnéticos $\mathrm{N}$ na partícula. No caso mais simples, a direção do momento magnético da partícula é determinada por uma anisotropia uniaxial e por um campo magnético externo onde a energia potencial deste sistema pode ser escrita como [Cullity, 1972]:

$$
E_{A}=+K_{a} V \operatorname{sen}^{2} \theta
$$

onde $K_{a}$ é a constante de anisotropia, $V$ é o volume da partícula e $\theta$ é o ângulo entre o momento magnético da partícula e o eixo de fácil magnetização. Observamos (Fig. 2.4) que o momento magnético da partícula possui dois estados de energia mínima, um para $\theta=0$ e outro para $\theta=\pi$. Vemos também que esses dois estados estão separados por uma barreira de potencial $K_{a} V$. Para passar de um estado para outro, esta barreira deve ser superada.

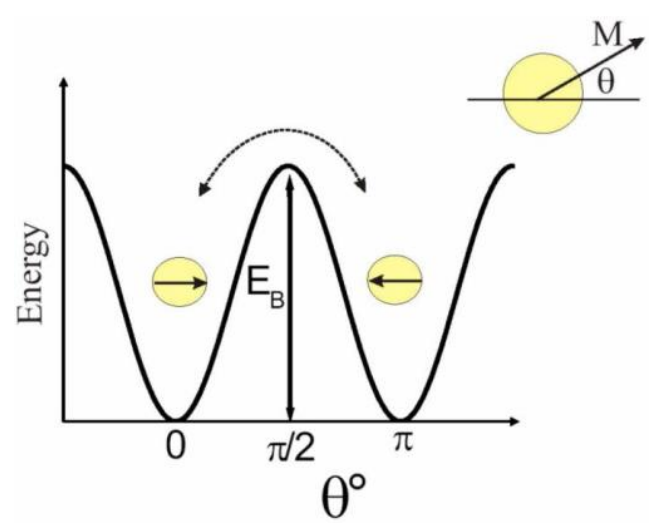

Figura 2.4. Barreira de energia que o momento magnético deve ultrapassar de um estado para outro para sofrer reversão quando não há campo magnético aplicado H=0 [Guimarães, 2009]. 
A energia térmica pode influenciar na direção dos momentos magnéticos, não permitindo que eles permaneçam fixos o tempo todo, mas oscilando constantemente (flutuação térmica), desde que seja maior do que a energia de anisotropia $K_{a} V$. A energia térmica é proporcional à temperatura absoluta, $\mathrm{k}_{\mathrm{B}} \mathrm{T}$, onde $\mathrm{k}_{\mathrm{B}}$ é a constante de Boltzmann. Quando a energia térmica for maior que a energia de anisotropia, o momento magnético terá energia suficiente para ultrapassar a barreira de energia sem dificuldade, gerando flutuações rápidas em torno dos mínimos energéticos.

O tempo que o momento magnético leva para saltar de estado mínimo a outro, em altas temperaturas, é dado por um tempo característico chamado de tempo de relaxação de Néel, $\tau_{\mathrm{N}}$ [Cullity, 1972]:

$$
\tau=\tau_{N}=\tau_{0} \exp \left(+\frac{K_{a} V}{k_{B} T}\right)
$$

onde $\mathrm{k}_{\mathrm{B}}$ é a constante de Boltzmann $\left(1,38 \times 10^{-23} \mathrm{JK}^{-1}\right), V$ é o volume da partícula, T é a temperatura absoluta, $K_{a}$ é a constante de anisotropia e $\tau_{0}$ é uma constante em torno de $10^{-9}$ s [Jiles, 1991; Klabunde, 2001; Jakubovics, 1994].

Para um dado tempo de medida é possível definir a temperatura que separa ambos os regimes, onde as flutuações térmicas da magnetização se estabilizam e que chamamos de temperatura de bloqueio. A equação que determina a temperatura de bloqueio pode ser encontrada na equação anterior quando atribuímos valores de $\tau=1 \mathrm{~s}$ e $\tau_{0}=10^{-9} \mathrm{~s}$ :

$$
T_{B}=\frac{K_{a} V_{\text {fixo }}}{21 K_{B}}
$$

Portanto, diz-se que uma partícula é superparamagnética a uma dada temperatura se o seu tempo de relaxação for menor que o tempo necessário para fazer a medida $\tau_{\mathrm{m}}$.

Se o tempo $\tau$ for maior que o tempo $\tau_{\mathrm{m}}$, a partícula se encontra no chamado estado bloqueado. Então o tempo $\tau_{\mathrm{m}}$ vai determinar se a partícula é superparamagnética ou não (por exemplo, uma medida de espectroscopia Mosbauer obtém informação em tempos da ordem de $\left.10^{-8} \mathrm{~s}\right)$. Em termos de volume, da mesma equação anterior podemos obter o volume superparamagnético $\mathrm{V}_{\mathrm{c}}$ :

$$
V_{c}=\frac{21 K_{B} T}{K_{a}}
$$


Logo, se o volume de uma nanopartícula $\mathrm{V}$ é menor do que $\mathrm{V}_{\mathrm{c}}$, não haverá histerese e o campo coercitivo será nulo, tendo uma nanopartícula superparamagnética.

\section{Processo de relaxação por movimento browniano}

Nanopartículas em fluidos magnéticos se encontram dispersas de forma estável no meio carreador. Além do mecanismo de relaxação de Néel, pode coexistir simultaneamente outro processo de relaxação denominado de relaxação por movimento browniano com um tempo característico $\tau_{\mathrm{B}}$ [Shliomis, 1974]. Este tempo característico de relaxação $\tau_{\mathrm{B}}$ depende fortemente da viscosidade do liquido, sendo descrito como:

$$
\tau_{B}=\frac{3 \eta_{i} V_{H}}{K_{B} T}
$$

onde $\eta_{\mathrm{i}}$ é a viscosidade do fluido carreador, $\mathrm{V}_{\mathrm{H}}$ é o volume hidrodinâmico da partícula, que é maior do que o volume $V$ da esfera, $\mathrm{k}_{\mathrm{B}}$ é a constante de Boltzmann e T é a temperatura absoluta. Um modelo para o volume hidrodinâmico é assumir que $V_{H}=\left(1+\frac{\delta}{R^{3}}\right) V$, onde $\delta$ é a espessura da camada de líquido adsorvido [Rosensweig, 2002].

\section{Perda de potência específica SAR (Specific Absortion Rate)}

Quando o corpo humano é exposto a radiações eletromagnéticas, cada tecido tem uma taxa de absorção de energia diferente. Esta absorção de energia pode ser caracterizada por um parâmetro conhecido como SAR: taxa de absorção específica. A taxa de absorção de energia depende da densidade de potência da radiação eletromagnética e das características do material atingido. Em outras palavras, pode-se dizer que a SAR quantifica a potência absorvida convertida em calor por unidade de massa. O valor do SAR pode ser calculado segundo a fórmula [Babincová et al., 2001]:

$$
S A R=C \frac{\Delta T}{\Delta t} \frac{1}{m_{F e}}
$$

onde $\mathrm{C}$ é o calor específico da amostra que é calculado como o valor médio ponderado em massa de magnetita e água $\left(\mathrm{J} \mathrm{g}^{-1} \mathrm{~K}^{-1}\right), \Delta \mathrm{T} / \Delta \mathrm{t}$ é taxa inicial de variação da temperatura em relação ao tempo e $m_{\mathrm{Fe}}$ é a massa de ferro por massa 
da solução aquosa de $\mathrm{Fe}_{3} \mathrm{O}_{4}$. Com tudo isto, o SAR vai ser expresso em [W/(g de $\mathrm{Fe})]$.

Dependendo da seção transversal do corpo e da condutividade do tecido, frequências baixas na faixa de 50-100 kHz devem ser usadas em seres humanos. Em nosso trabalho a frequência de operação do circuito foi de $89 \mathrm{kHz}$, o qual está conforme na gama de frequências para aplicações biomédicas.

\subsubsection{Ferritas e nanopartículas de óxido de ferro}

As ferritas, também conhecidas como $\alpha$-ferritas, são óxidos, em geral magnéticos, compostos por átomos de $\mathrm{Fe}^{3+}$ e um íon metálico $\mathrm{X}$ divalente $\left(\mathrm{X}=\mathrm{Fe}^{2+}, \mathrm{Co}^{2+}, \mathrm{Ni}^{2+}, \mathrm{Cu}^{2+}, \mathrm{Zn}^{2+}\right.$ e $\left.\mathrm{Mn}^{2+}\right)$. Sua fórmula geral é $\mathrm{XFe}_{2} \mathrm{O}_{4}$ e têm uma estrutura de empacotamento cúbico de átomos de oxigênio. Esses óxidos podem ser do tipo espinélio normal, inverso ou misto, dependendo da distribuição de cátions no cristal. A Fig. 2.5 apresenta a estrutura cristalina de um espinélio (aproximadamente duas vezes a célula unitária). De acordo com essa figura:

- Se todos os íons divalentes $\mathrm{X}^{2+}$ estiverem no sítio tetraédrico (vermelho) e os íons de $\mathrm{Fe}^{3+}$ no sítio octaédrico (verde), a estrutura cristalina será chamada de espinélio direto.

- $\quad$ Se todos os íons divalentes $\mathrm{X}^{2+}$ estiverem no sítio tetraédrico e os íons de $\mathrm{Fe}^{3+}$ estiverem colocados igualmente entre os sítios octaédricos e tetraédricos, a estrutura cristalina será chamada de espinélio inverso.

- $\mathrm{Se}$ os íons divalentes $\mathrm{X}^{2+}$ estiverem divididos em ambos os sítios tetraédricose octaédricos, chama-se de estrutura espinélio misto. 


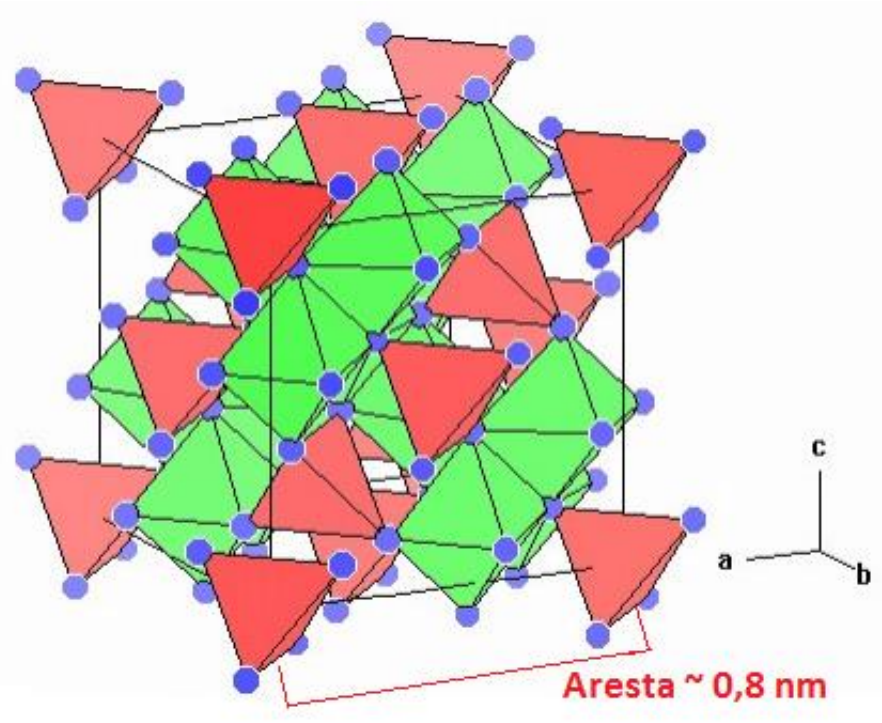

Figura 2.5. Representação da estrutura cristalina do espinélio. As esferas em azul representam átomos de oxigênio, gerando sítios espaciais tetraédricos (vermelho) e octaédricas (verde). Aresta aproximada de $0,8 \mathrm{~nm}$ (http://www.lutanho.net/drawlat/images/spinel.html).

A magnetita é um tipo de ferrita de estrutura cristalina do tipo espinélio inverso, onde os íons de $\mathrm{O}^{2-}$ formam um arranjo cúbico denso de face centrada, e os íons metálicos (com raios de 0,7 0,8 ̊) ocupam os sítios entre os íons de oxigênio. Como se pode ver na Fig. 2.6, temos dois tipos de sítios: sítio A, tetraédrico, composto por quatro íons de oxigênio nos vértices e íons férricos $\mathrm{Fe}^{3+}$ no centro, e o sítio $\mathrm{B}$, octaédrico, composto de seis íons de oxigênio nos vértices e íons $\mathrm{Fe}^{3+}$ e $\mathrm{Fe}^{2+}$ em quantidades iguais [Verwey e Haayman, 1941]. A célula unitária contém 8 íons metálicos de sítios A, 16 de sítios B e 32 oxigênios.
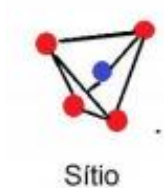
Tetraédrico
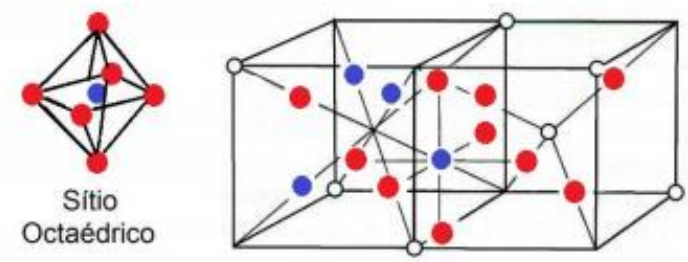

Ín Oxigênio

- Íon Tetraédrico

- İon Octaédrico

Figura 2.6. Estrutura cristalina espinélio inverso da magnetita. Adaptado de Cullity, 1972.

Para uma magnetita perfeita o número de átomos do $\mathrm{Fe}^{3+}$ é igual ao dobro de $\mathrm{Fe}^{2+}$, porém frequentemente este óxido apresenta uma estrutura não estequiométrica [Cornell e Schwertmann, 1996]. 
Nanopartículas magnéticas de óxido de ferro

As nanopartículas magnéticas desempenham um papel importante nas aplicações tecnológicas do magnetismo, assim como na medicina, em diagnóstico e tratamento de diversas doenças [Kim et al., 2001; Shinkai, 2002; Pankhurst et al., 2003]. O interesse gerado se dá porque podem ser sintetizadas em dimensões comparáveis à dos vírus $(20 \mathrm{~nm}-60 \mathrm{~nm})$, proteínas $(5 \mathrm{~nm}-50 \mathrm{~nm})$, bactérias (200 nm-6 $\mu \mathrm{m}$ ) ou genes ( $2 \mathrm{~nm}$ de espessura e 10-100 nm de comprimento). Por serem magnéticas, as nanopartículas podem ser facilmente transportadas e concentradas num local específico quando se aplica um campo magnético externo. Quando o campo magnético é removido, elas se dispersam. As nanopartículas apresentam uma grande superfície que pode ser modificada para serem funcionalizadas [Tartaj et al., 2005].

O recobrimento das nanopartículas pode ser funcionalizado através de anticorpos, mediante os quais a nanopartícula fica ligada ao tumor ou célula cancerígena. O carreamento das nanopartículas pode ser controlado magneticamente.

Outras características importantes das partículas magnéticas de óxido de ferro são as baixas toxicidades em seres humanos, a possibilidade de controlar sua magnetização, biocompatibilidade, injetabilidade e o alto nível de acumulação no tecido alvo [Ito et al., 2005].

Além da tendência para aglomerar, um problema comum nas nanopartículas magnéticas é a instabilidade com respeito à oxidação quando exposta ao ar. Devido à oxidação durante a síntese, a composição final das nanopartículas magnéticas pode ficar entre magnetita $\left(\mathrm{Fe}_{3} \mathrm{O}_{4}\right)$ e a maghemita $\left(\gamma-\mathrm{Fe}_{2} \mathrm{O}_{3}\right)$. A alta reatividade se dá obviamente devido a alta razão superfície/volume, mas a oxidação aeróbica não é o único caminho para a maghemita, dependendo do $\mathrm{pH}$ da suspensão diferentes trocas interfaciais iônicas e/ou eletrônicas podem ocorrer, conduzindo à oxidação da magnetita, seja em meio ácido (redução do oxigênio na superfície da nanopartícula) ou meio básico (íons $\mathrm{Fe}^{2+}$ superficiais são dessorvidos como complexos hexa-aquo em solução) [Jolivet et al., 2006]. 


\section{2}

\section{Transporte e distribuição de fármacos}

A partir década de 1950, juntamente com os avanços no desenvolvimento de materiais para aplicações biológicas, começou a ideia de controlar a liberação de substâncias biologicamente ativas. Na batalha contra o câncer, muitos métodos para atacar as células cancerígenas com drogas de maneira menos invasiva e mais seletiva foram investigados.

\subsubsection{Sistema de transportes de fármacos}

Konan et al. (2002) classificam o processo de distribuição de drogas em ativo ou passivo, de acordo com a presença ou ausência de alvo molecular na sua superfície. O processo ativo usa receptores do tecido alvo ou antígenos para entregar especificamente o fotossensibilizante ao tecido tumoral. $\mathrm{O}$ processo passivo implica na aplicação parenteral e distribuição passiva, como através de lipossomas, dispersões de óleos ou micelas, partículas poliméricas e conjugados hidrofílicos de polímero. Vamos nos deter em distribuição passiva.

Micelas, partículas poliméricas, lipossomas, óleos dispersores e conjugados hidrofílicos de polímeros-fotossensibilizantes são considerados transportadores passivos porque seguem um modelo de distribuição natural (difusão passiva e processos de fagocitose). A acumulação seletiva no tecido alvo é devida ao efeito de retenção pelo tecido tumoral.

\section{Surfactantes, micelas e lipossomas}

Detergentes ou surfactantes, assim como lipídios, são moléculas anfifílicas, isto é, moléculas que possuem duplo caráter, com uma região hidrofóbica e outra hidrofílica. Elas podem se autoassociar formando uma variedade de estruturas, como micelas (esféricas ou cilíndricas), vesículas, lipossomas, microtúbulos, microemulsões, etc (Fig. 2.7). O tamanho dessas estruturas varia de 0,1 nm a $1 \mu \mathrm{m}$. A associação das moléculas de surfactantes ocorre por interação de natureza entrópica, denominada interação hidrofóbica. 


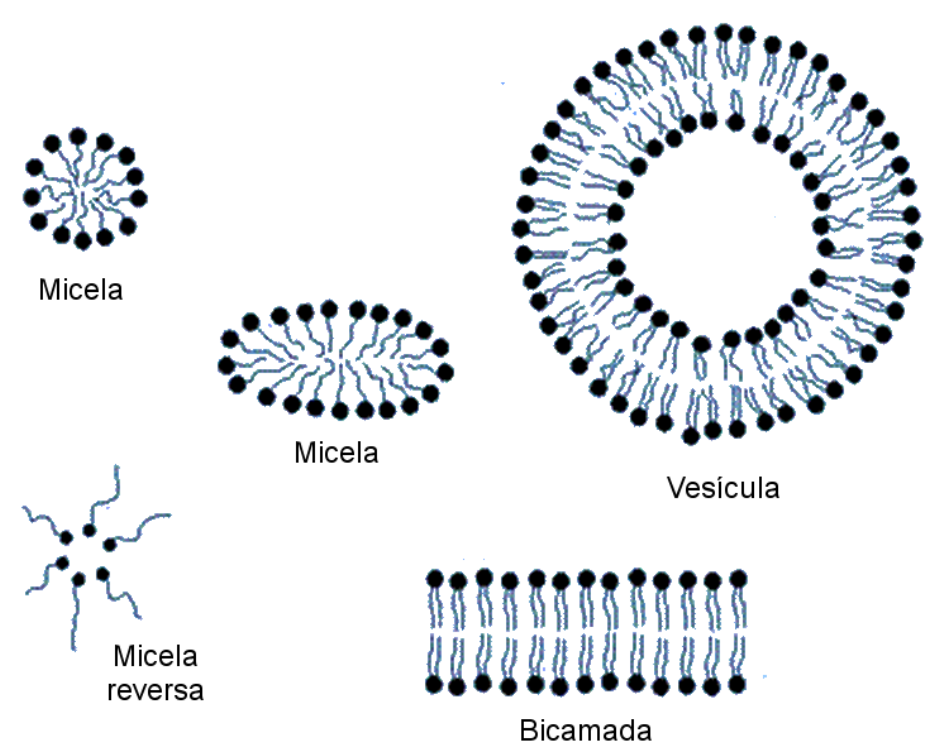

Figura 2.7. Estruturas formadas por autoagregação de surfactantes e lipídios. (modificado de http://people.umass.edu/mcclemen/Group.html)

A formação das micelas, micelização, começa a partir de uma concentração mínima chamada concentração micelar crítica, CMC (Fig. 2.8).

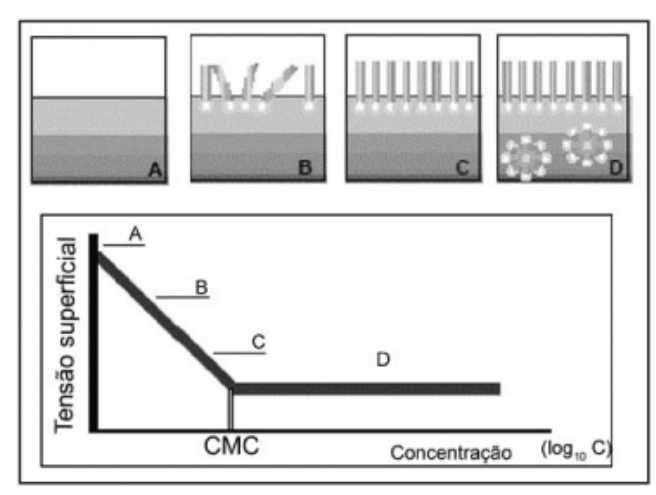

Figura 2.8. Distribuição de surfatante em solução aquosa. Efeito na tensão superficial e formação de micelas.

Lipossomas são vesículas de fosfolipídios (ver Fig. 2.7). Podem ser unilamelares ou multilamelares, e permitem incorporar drogas hidrofílicas e hidrofóbicas em sua matriz, podendo ser utilizados para transporte de diversos fármacos e biomoléculas.

Um dos objetivos de incorporar fármacos aos lipossomas é manter o estado monomérico das moléculas, para se ter um aumento do consumo de oxigênio, já que as espécies monoméricas são eficientemente mais fotossensibilizadas que as agregadas. 
Derycke e de Witte (2004), fizeram um trabalho de revisão sobre as diferentes estratégias que têm sido desenvolvidas para transportar fármacos a determinado alvo utilizando lipossomas. Canete et al. (1998), por exemplo, mostraram que a encapsulação de uma porfirina, a meso-tetrafenilporfirina, em lipossoma permitiu mantê-la na forma monomérica, aumentando sua eficiência na destruição de células cancerosas.

Alguns fotossensibilizantes têm sido encapsulados em micelas poliméricas (baixa concentração micelar critica em torno de $10^{-7} \mathrm{~mol} / \mathrm{L}$ respeito às micelas convencionais em torno de $10^{-3}$ a $10^{-4} \mathrm{~mol} / \mathrm{L}$ ) [Sibata, 2004; Nishiyama et al., 2009].

Vior et al. (2011) comprovaram que o uso de nanoemulsões de isopropyl myristate e Tween 80®, no transporte de tetrakis-(1-adamantilsulfanil) ftalocianinato de zinco(II), uma ftalocianina lipofílica, permite uma alta eficiência quântica de oxigênio singleto.

Partículas poliméricas e não poliméricas (nanopartículas)

As partículas transportadoras passivas podem ser subdivididas pela composição do material. Nanopartículas poliméricas biodegradáveis (alternativa dos lipossomas) têm como principal vantagem a grande quantidade de fármaco que se pode colocar dentro delas. Estas permitem a distribuição específica, pela incorporação de uma região sítio-específica nos polímeros. A modificação da superfície com certos polímeros tais como polietilenoglicol (PEG), polímero do ácido lático-co-glicólico (PLGA) ou poli(óxido de etileno) (PEO) pode aumentar o tempo de circulação no corpo. Alguns fotossensibilizantes encapsulados em nanoesferas poliméricas mostraram excelentes resultados em terapia fotodinâmica [Konan et al., 2003; Vargas et al., 2004].

\subsubsection{Interação de surfactantes com fármacos}

A associação de fármacos com surfactantes tem sido amplamente estudada. A incorporação de fármacos em estruturas formadas por surfactantes influenciam drasticamente seu estado de agregação e suas características espectroscópicas. Tem-se mostrado que os mecanismos de interação dependem de contribuições eletrostáticas e hidrofóbicas [Maiti et al., 1998; Gandini et al., 1999], sendo que 
estas interações dependem da cabeça polar do surfactante e do $\mathrm{pH}$ do meio [Santiago et al., 2008], assim como da carga elétrica e da hidrofobicidade de grupos químicos característicos do fármaco.

Pluronics são copolímeros em bloco baseados em óxido de etileno e óxido de propileno. Tem-se mostrado esses polímeros tribloco favorecem o transporte de fármacos através de membranas para dentro das células tumorais. Os Pluronics (PEO-PPO-PEO) são caracterizados pela sua estrutura anfifílica e são capazes de se agregar em solução aquosa e formar micelas; nesse caso, o centro hidrofóbico da micela está composto de unidades de PO e a superfície hidrofílica inclui as duas cadeias de unidades de EO (Fig. 2.9).<smiles>CC(COCCO)C(C)OCCO</smiles>

Figura 2.9. Estrutura dos Pluronics

Os pluronic diferem nas suas propriedades hidrofílicas devido à relação entre os blocos do óxido de etileno e o óxido de propileno. Os nomes dos Pluronics consistem de uma letra definindo a aparência do polímero puro ( $\mathrm{F}$ flocos, $\mathrm{P}$-pasta ou L-líquido) e dois ou três dígitos. $\mathrm{O}$ primeiro ou os dois primeiros dígitos correspondem ao grau de polimerização do bloco hidrofóbico PPO dividido por cinco, e o último dígito corresponde a um décimo da porcentagem em peso de EO no copolímero [Solovieva et al., 2009]. Por exemplo, o Pluronic F-127 vem em flocos, tem 60 unidades de PO (óxido de propileno) e $70 \%$ em peso de EO (óxido de etileno). Devido a sua baixa concentração micelar crítica, CMC, e sua toxicidade relativamente baixa, os Pluronics são candidatos adequados como nanocontêineres micelares para entrega controlada de droga.

Alguns trabalhos mostraram que os Pluronics solubilizam eficientemente tanto porfirinas hidrofóbicas [Solovieva et al., 2006] quanto hidrofílicas [Zhientaev et al., 2009] (Fig. 2.10). 


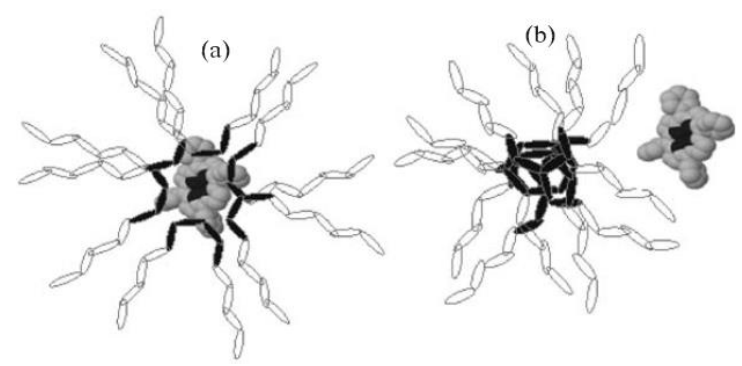

Figura 2.10. Micelas de Pluronic com a localização de porfirinas [Zhientaev T. M. et al., 2009]: (a) Porfirina insolúvel em água localizada no centro hidrofóbico micelar. (b) Porfirina hidrofílica localiza-se na superfície hidrofílica micelar.

\section{3}

\section{Terapia Fotodinâmica}

A terapia fotodinâmica, PDT, é um tratamento pouco invasivo usado tanto em doenças malignas como benignas. As drogas utilizadas no tratamento por PDT são conhecidas como fotossensibilizantes. Os fotossensibilizantes (PS) são moléculas capazes de absorver luz de modo a gerar espécies reativas de oxigênio, capazes de destruir moléculas vizinhas. O procedimento no PDT consiste na administração tópica ou sistêmica de um fotossensibilizante que, uma vez acumulado seletivamente nos tecidos ou células alvo, seja ativado localmente, afetando minimamente as células de tecidos adjacentes. Devido à natureza hidrofóbica de alguns fotossensibilizantes e à rápida absorção deste, o transportador tem que ser capaz de proteger e manter o fotossensibilizante de natureza hidrofóbica sem perda ou alteração da sua atividade, conservando sua forma monomérica e determinando, assim, a eficácia da liberação da espécie fototóxica in vivo.

A PDT é uma modalidade de tratamento de doenças, tais como infecções localizadas, infecções fúngicas, acne e o câncer, e que envolve três componentes básicos: o PS, luz de irradiação e o oxigênio reativo [Oseroff e Morgan, 2001]. No tratamento do câncer a ideia principal é administrar o PS adequado, que mostre seletividade ao tecido tumoral, seguido de irradiação local com luz cujo comprimento de onda é definido de acordo com o espectro de absorção do PS, gerando espécies reativas citotóxicas de oxigênio tal como o oxigênio singlete, para finalmente contribuir para a morte celular do tecido alvo. 
Enquanto as técnicas tradicionais de tratamento do câncer (cirurgia, quimioterapia e radioterapia) podem resultar em mutilações e alterações fisiológicas severas, alopecia (queda de cabelos), alterações gastrointestinais e prostração física, tais efeitos colaterais estão descartados na PDT, além de permitir uma destruição eficiente e seletiva do tecido cancerígeno provocando o menor dano possível ao tecido saudável.

\subsubsection{Mecanismo de ação e oxigênio singlete}

$\mathrm{Na}$ terapia fotodinâmica PDT existem três componentes básicos: o fotossensibilizante (PS), luz visível para ativar o PS e uma taxa adequada de produção de oxigênio singlete. Na Fig. 2.11 pode se resumir o processo da terapia, a qual consiste em administrar adequadamente a droga fotossensibilizante ao paciente que, uma vez concentrado no tecido tumoral, é ativado mediante radiação eletromagnética (luz) ocorrendo a fotoexcitação das moléculas da droga, gerando oxigênio reativo e produzindo finalmente a morte das células tumorais [Bonnet, 1995].

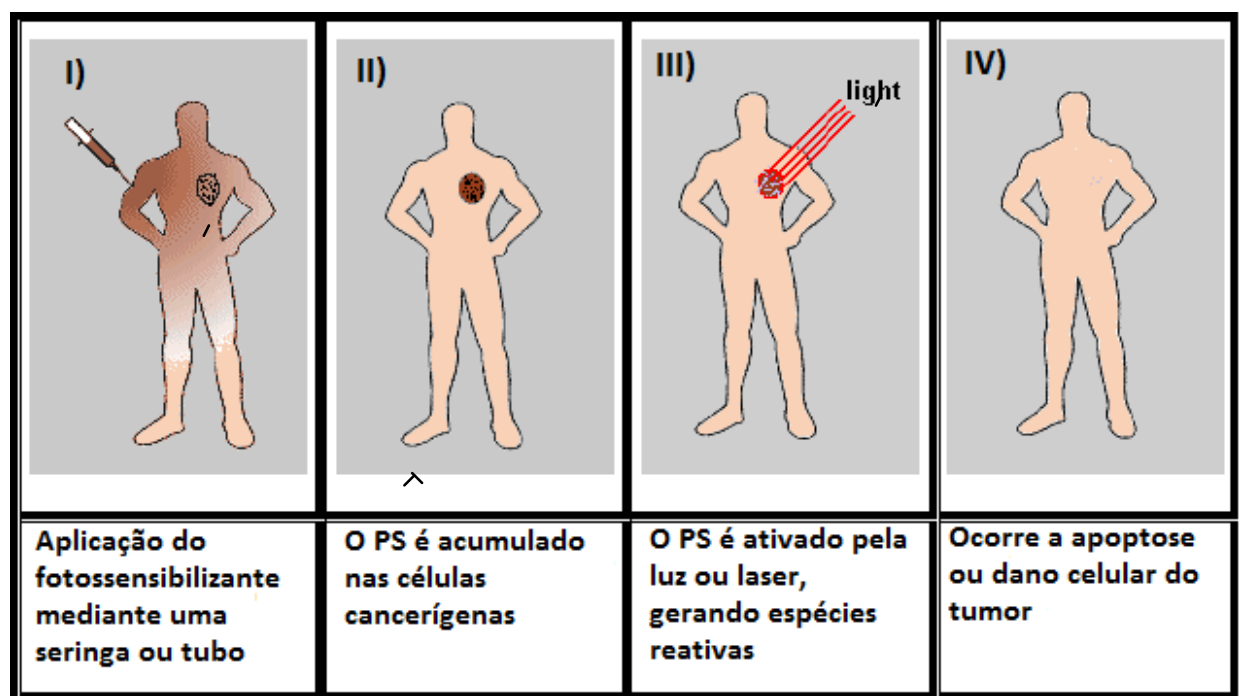

Figura 2.11. Principais estágios da terapia fotodinâmica. O fotossensibilizante (na seringa ou tubo) é aplicado localmente ou sistemicamente (estágio I), acumula-se nos tumores (estágio II) e é então ativado por iluminação externa (estágio III). Isso induz o dano ou a morte celular.

$\mathrm{Na}$ fotossensibilização ocorre uma alteração fotoquímica ou fotofísica sobre a molécula adjacente, devido à fotoexcitação do fotossensibilizante por absorção de radiação [Braslavsky et al., 2005]. O efeito fotodinâmico é explicado mediante 
dois mecanismos designados como Tipo I e Tipo II. Estes processos podem ser resumidos na Fig. 2.12 pelo diagrama de Jablonski:

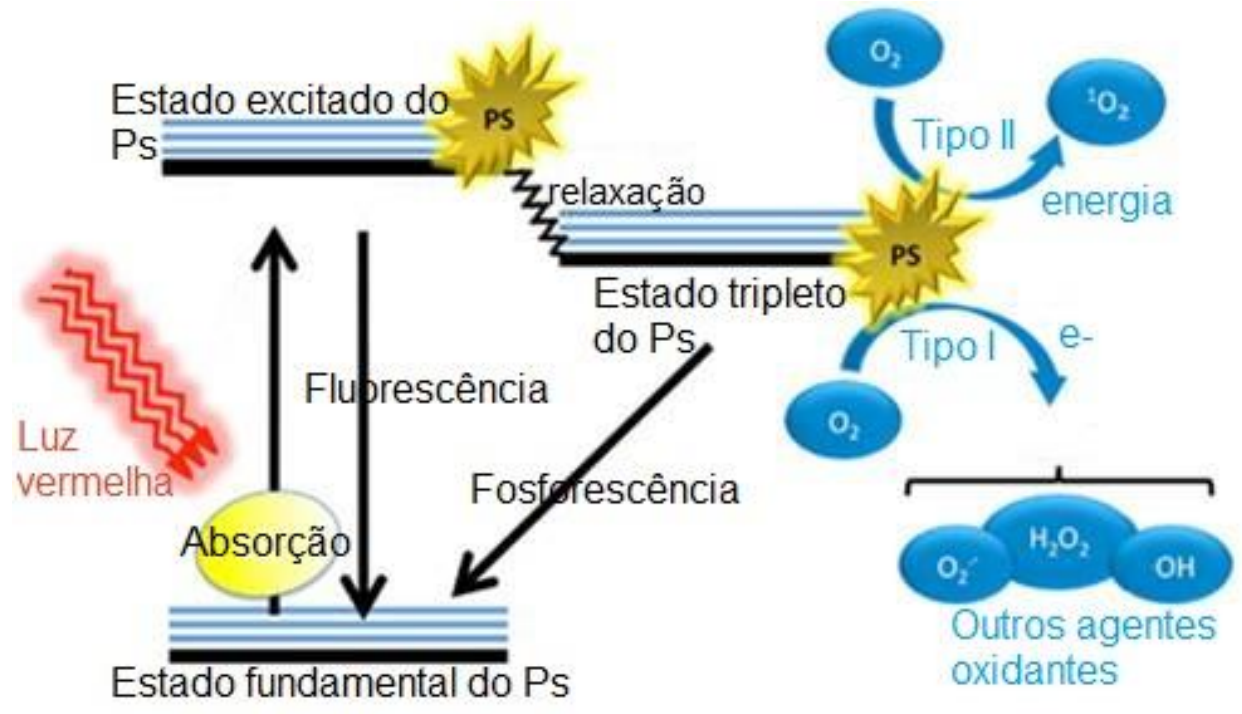

Figura 2.12. Representação do diagrama de Jablonski na geração de estados excitados de porfirina e espécies reativas de oxigênio. Adaptado de Bonnet, 1995.

Os mecanismos são ativados por combinação de luz, fotossensibilizante e oxigênio molecular. $\mathrm{O}$ estado fundamental do fotossensibilizante $S_{\mathrm{o}}$ é excitado até o estado $S_{1}$ por irradiação com luz visível. Aqui o estado $S_{1}$ pode passar para um estado excitado $T_{1}$ do fotossensibilizante, gerando radicais livres (mecanismo tipo I) e/ou oxigênio singlete (mecanismo tipo II). Estes dois mecanismos podem ocorrer simultaneamente, mas o segundo mecanismo seria o mais eficiente [Parker e Stambro, 1982; Foote, 1976; Wasserman e Murray, 1979]. Por exemplo, a transferência de energia dos estados tripletos de ftalocianinas para o oxigênio é muito rápida. Portanto a transferência de energia para outros compostos que iriam interagir com o oxigênio é menos importante, prevalecendo o mecanismo do tipo II [Bonnet, 1995].

O mecanismo tipo II caracteriza-se por envolver reações de transferência de energia entre o PS no estado $\mathrm{T}_{1}$ e o oxigênio molecular ${ }^{3} \mathrm{O}_{2}$, cujo estado fundamental também é tripleto (Fig. 2.12), permitindo a formação da espécie reativa, o oxigênio singlete ${ }^{1} \mathrm{O}_{2}$, e o PS retorna ao estado fundamental $\mathrm{S}_{\mathrm{o}}$. Com isto são oxidados prontamente os constituintes e organelas celulares das células tumorais, provocando sua morte.

O oxigênio singlete é uma espécie com tempo de vida curto, $\sim 0,04 \mu \mathrm{s}$ nos sistemas biológicos, e com um raio de penetração muito pequeno de $0,02 \mu \mathrm{m}$ 
[Thompson et al., 2001]. O dano decorrente do tratamento é minimizado e limitado localmente às células cancerosas e vizinhanças.

\section{Oxigênio singlete ${ }^{1} \mathrm{O}_{2}$}

O oxigênio singlete molecular, descoberto em 1924, foi alvo de estudo a partir de 1963 quando Khan e Kasha interpretaram a quimiluminescência da decomposição do peróxido de hidrogênio $\left(\mathrm{H}_{2} \mathrm{O}_{2}\right)$ na presença de hipoclorito (OCL'), revelando a existência de duas bandas de emissão centradas em 634 e $703 \mathrm{~nm}$, atribuídas ao decaimento para o estado fundamental do oxigênio singlete ${ }^{1} \mathrm{O}_{2}$. Atualmente, a geração de oxigênio singlete tem grande importância nos processos de fotoxidação, danos no DNA, terapia fotodinâmica, ciência de polímeros, etc [DeRosa e Crutchley, 2002].

$\mathrm{O}$ oxigênio singlete ${ }^{1} \mathrm{O}_{2}$ é um poderoso oxidante, portanto muito eletrofílico, reagindo rapidamente com ligações $\mathrm{C}-\mathrm{C}$ insaturadas, sulfetos, aminas e ânions [DeRosa e Crutchley, 2002]. Assim o ${ }^{1} \mathrm{O}_{2}$ pode reagir com inúmeros tipos de biomoléculas.

O oxigênio singlete ${ }^{1} \mathrm{O}_{2}\left({ }^{1} \Delta_{\mathrm{g}}\right)$ corresponde aos três estados eletronicamente excitados imediatamente superiores ao oxigênio molecular ${ }^{3} \mathrm{O}_{2}\left({ }^{3} \Sigma_{\mathrm{g}}\right)$, tripleto (Tabela 2.2).

Tabela 2.2. Ocupação dos orbitais moleculares para os estados eletrônicos do $\mathrm{O}_{2} . \pi^{*}$ relativa ao estado fundamental. Adaptado de Machado, 2000.

\begin{tabular}{ccc}
\hline Estado & $\begin{array}{c}\text { Orbital molecular } \\
\text { antiligante }\end{array}$ & Energia ${ }^{*}, \mathrm{kJmol}^{-1}$ \\
\hline${ }^{3} \sum \mathrm{g}$ & {$[\uparrow] \pi^{*}{ }^{*}[\uparrow] \pi^{*}{ }_{\mathrm{y}}$} & 0 \\
${ }^{1} \Delta \mathrm{x}$ & {$[\uparrow \downarrow] \pi^{*}{ }_{\mathrm{x}}[] \pi^{*}$} & 92,4 \\
${ }^{1} \Delta \mathrm{y}$ & {$[\uparrow] \pi_{\mathrm{y}}[\uparrow \downarrow] \pi^{*}$} & 92,4 \\
${ }^{1} \sum \mathrm{g}$ & {$[\uparrow] \pi^{*}{ }_{\mathrm{x}}[\downarrow] \pi_{\mathrm{y}}{ }^{*}$} & 159,6 \\
\hline
\end{tabular}

Os estados intermediários ${ }^{1} \Delta_{\mathrm{x}}$ e ${ }^{1} \Delta_{\mathrm{y}}$ são os responsáveis pela reatividade química do oxigênio singlete. Eles são degenerados e possuem uma distribuição eletrônica na qual os elétrons que ocupam um dos orbitais antiligantes $\pi^{*}$ encontram-se em planos mutuamente perpendiculares [Machado, 2000]. Por serem estados degenerados, estes intermediários são representados por conveniência como sendo o estado ${ }^{1} \Delta_{\mathrm{g}}$ [DeRosa e Crutchley, 2002]. A simetria 
destas moléculas intermediarias ${ }^{1} \Delta_{\mathrm{g}}$, que difere da do estado fundamental, lhes garante um tempo de vida considerável quando comparado com o da molécula no ${ }^{1} \Sigma_{\mathrm{g}}$, que possui a mesma simetria do estado fundamental. Na fase gasosa esses tempos são de 45s e 7-12min, respectivamente [Arnold et al., 1968] e, em solução, são de $10^{-6}-10^{-3}$ e de $10^{-11}-10^{-9}$, respectivamente [Merkel et al., 1972]. Tendo isto em consideração, o estado ${ }^{1} \Delta_{\mathrm{g}}$ é quem apresenta maior importância em reações químicas, sendo o estado ao qual se aplica o termo "oxigênio singlete" e a designação ${ }^{1} \mathrm{O}_{2}$. O orbital molecular vazio no estado ${ }^{1} \Delta_{\mathrm{g}}$ garante ao oxigênio singlete um caráter eletrofílico, favorecendo sua participação em reações químicas, principalmente, no caso em que os substratos possuem sítios ricos em elétrons [Machado, 2000].

Com respeito ao solvente, o tempo de vida $\tau$ do ${ }^{1} \mathrm{O}_{2}$ é altamente influenciado pela natureza deste. Para a água, $\tau \sim 4,0 \mu$ s [Wikinson et al., 1995], enquanto para água deuterada $\tau \sim 70,0 \mu \mathrm{s}$. Em geral, para solventes que não possuem ligações $\mathrm{C}-\mathrm{H}$ nem grupos hidroxila na sua estrutura, o $\tau \sim 30 \mathrm{~ms}$, para o clorofórmio $\tau \sim 250 \mu \mathrm{s}$ [Wikinson et al., 1995]. Já em sistemas biológicos os tempos de vida $\tau$ do ${ }^{1} \mathrm{O}_{2}$ são extremamente baixos, inferiores a $0,04 \mu \mathrm{s}$, difundindo-se menos do que $0,02 \mu \mathrm{m}$ de raio no meio celular [Redmond e Kochevar, 2006]. Como o diâmetro das células humanas varia entre 10 a $100 \mu \mathrm{m}$, o local primário de geração do ${ }^{1} \mathrm{O}_{2}$ na célula determina qual estrutura subcelular pode sofrer a ação do oxigênio singlete [Machado, 2000].

\subsubsection{Fotossensibilizantes}

Fotossensibilizantes são moléculas capazes de interagir com a luz absorvendo um fóton de modo a gerar espécies altamente reativas de oxigênio. Foi a partir do começo do século XX quando Oscar Raab envolvido num estudo sobre a toxicidade de acridina para paramécios descobriu que os seus resultados foram bastante variáveis, o qual ele suspeitou que aquela toxicidade dependesse da hora da medida, tendo uma maior variação no meio-dia. Posteriormente ele demonstrou que paramécios em soluções de acridina foram inativados de forma mais eficaz perto de uma janela clara do que se fossem mantidos no escuro. 
Com aquele começo do interesse das propriedades terapêuticas da luz, foram desenvolvidas numerosas investigações buscando novos fotossensibilizantes até o dia de hoje em numerosos países, incluindo o Brasil.

Para ser um bom fotossensibilizante deve-se ter uma substância simples, de fácil síntese de poucas etapas, com a finalidade de que a produção em maior escala seja viável. A substância deve apresentar propriedades fotofísicas adequadas, tais como elevada absorção na região da janela terapêutica, com ótima penetração da luz no tecido em torno de 600-800 nm (Fig. 2.15), capacidade de locação específica, curto intervalo de tempo entre a administração e a acumulação máxima no tecido alvo, elevado rendimento quântico de produção de oxigênio singlete, deve apresentar baixa toxicidade no escuro, não agregar em meio fisiológico, entre outros [Bonnet, 1995; Allison et al., 2004; Simplicio et al., 2002].

O comprimento de onda da radiação luminosa incidente, utilizada no processo de PDT, deve levar em conta a capacidade de penetração da luz no tecido e dos máximos de absorção do fármaco. Na região espectral do vermelho e infra-vermelho próximo $(600-850 \mathrm{~nm})$ o tecido biológico se apresenta mais transparente à radiação luminosa, sendo favorável à aplicação clínica da PDT. Este intervalo é conhecido por janela terapêutica (Fig. 2.13).

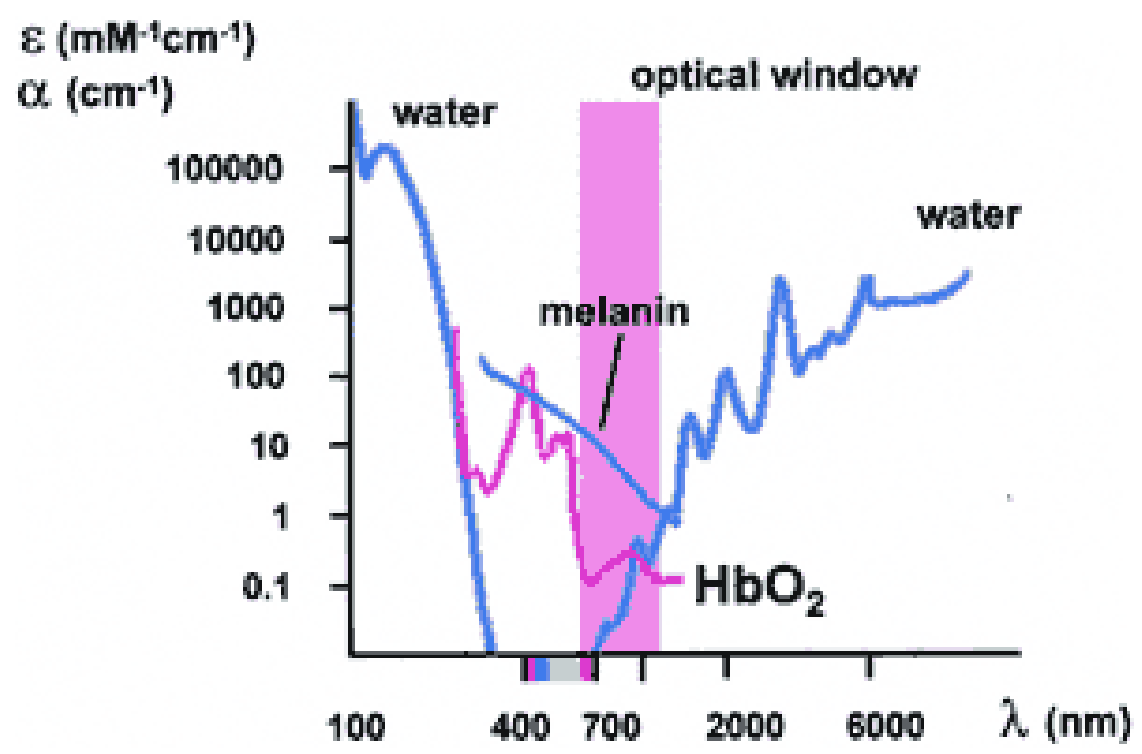

Figura 2.13. Absorção óptica de vários componentes intracelulares de tecidos, em função do comprimento de onda mostrando a janela terapêutica entre 650 e 1100 nm. [König, 2000]. 
O transporte de fotossensibilizantes até o tecido alvo é feito através de proteínas presentes no plasma sanguíneo. Um adulto possui aproximadamente 5 a 6 litros de sangue, onde se encontram hemácias, glóbulos brancos e plaquetas, o restante é o plasma constituído por $90 \%$ de água e $10 \%$ de solutos. Neste caso é preferencial o uso de fotossensibilizantes aquo-solúveis, mas eles devem possuir afinidade pelos meios hidrofóbicos, com a finalidade de serem capazes de penetrar na membrana lipídica da célula. Moléculas anfifílicas são as mais recomendáveis para a aplicação em PDT, portanto uma forma de fazer isto é incorporando o fotossensibilizante dentro de sistemas micelares para que, ao serem transportados até o tecido alvo, possa ser liberado dentro da membrana celular, produzindo a apoptose.

\subsubsection{Ftalocianinas}

As ftalocianinas $(\mathrm{Pc})$ são fotossensibilizantes promissores para ser usados em Terapia Fotodinâmica (PDT) [Garcia et al., 2011; Nishiyama et al., 2009; Vior et al., 2011; Maree et al., 2002], mas, devido a sua pouca solubilidade e tendência a agregação sua aplicação em tratamentos fotodinâmicos tem sido limitada.

As ftalocianinas mostram soluções com cor forte, dependendo dos solventes, do metal central e do substituinte no anel. As ftalocianinas são complexos macrocíclicos conjugados, simétricos e aromáticos com um sistema de 18 elétrons $\pi$ [Stillman et al., 1993] (Fig. 2.14). A estrutura dos anéis resulta em uma forte banda de absorção na região do vermelho do espectro visível. As ftalocianinas têm elevada massa molecular e podem conter no interior de seu macrociclo diferentes metais. As ftalocianinas não metálicas (Fig. 2.14) são planares e exibem uma simetria $\mathrm{D}_{2} \mathrm{~h}$ enquanto que as metaloftalocianinas exibem simetria $\mathrm{D}_{4} \mathrm{~h}$. 


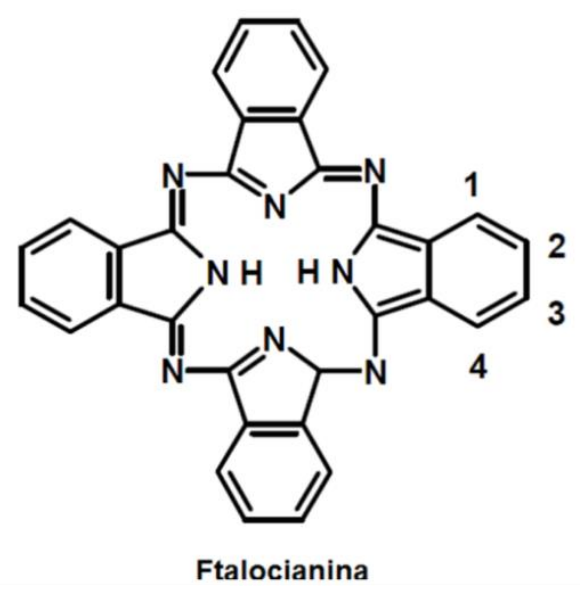

Figura 2.14. Estrutura de molécula de ftalocianina.

O interesse de metaloftalocianinas em PDT se deve a que algumas dessas ftalocianinas são eficientes fotossensibilizantes, porque absorvem luz na região entre 650 e $700 \mathrm{~nm}$ (janela fototerapêutica), apresentando um alto coeficiente de absorção molar $\varepsilon_{670} \approx 10^{5} \mathrm{M}^{-1} \mathrm{~cm}^{-1}$. Algumas características importantes são a estabilidade, baixa toxicidade, elevada seletividade e boa penetrabilidade em membranas celulares, tendendo a se localizar na região interna do tumor [Marques et al., 2002].

Moléculas de ftalocianinas sofrem auto-oxidação via ataque de oxigênio singlete $\left({ }^{1} \mathrm{O}_{2}\right)$ gerado por elas mesmas [Jonesa et al., 1994]. Tem-se observado que moléculas de metaloftalocianinas contendo grupos derivados de moléculas biológicas nas posições periféricas são mais facilmente degradadas [Hamblin et al., 1994].

As propriedades das ftalocianinas podem ser modificadas por substituintes [Stillman e Nyokong, 1989; Seotsanyana-Mokhosi et al., 2001]. Por exemplo, conseguem-se moléculas anfifílicas com substituições no anel com grupos hidrofílicos e hidrofóbicos [De la Torre et al., 1999], que também diminuem a agregação entre ftalocianinas [Maree et al., 2002]. Substituições axiais e no anel criam impedimento estérico, sendo que os ligantes mais volumosos têm efeito mais pronunciado. As substituições abrem caminho para construir estruturas complexas com fins específicos. 


\section{Caracterização espectroscópica das ftalocianinas}

Como foi dito anteriormente, a Pc exibe forte banda de absorção na região do vermelho do espectro visível $\left(\varepsilon_{670} \approx 10^{5} \mathrm{M}^{-1} \mathrm{~cm}^{-1}\right)$ e a posição dos picos vai depender da natureza da ftalocianina. O espectro de complexos metálicos da ftalocianina consiste numa intensa banda de absorção na região visível, chamada de banda $\mathrm{Q}$, com pico ao redor dos $670 \mathrm{~nm}$, produzido pelas transições $\mathrm{n}-\pi^{*}$, e uma fraca banda $\mathrm{B}$ de absorção ao redor dos $340 \mathrm{~nm}$ devida a transições $\pi$ - $\pi^{*}$ [Ough et al., 1994]. A banda B consiste em duas transições B1 e B2, todas estas transições são representadas na Fig. 2.15. Observa-se também uma banda ao redor dos $500 \mathrm{~nm}$ para alguns metais de transição, sendo atribuída à transferência de carga do metal até o ligante ou vice-versa [Fan et al., 1979]. Em altas energias (ultravioleta), transições adicionais $\pi-\pi^{*}(\mathrm{~N}, \mathrm{~L}$ e $\mathrm{C}$, em ordem crescente de energia) podem ser observadas em solventes transparentes no UV tais como o diclorometano [Nyokong et al., 1987].

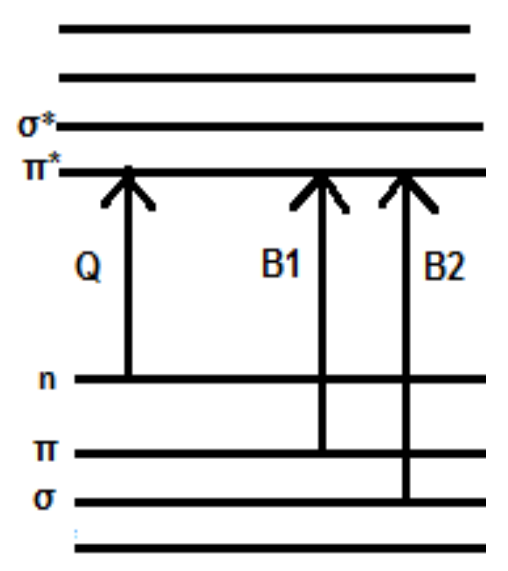

Figura 2.15. Transições orbitais envolvidas nas principais bandas de absorção. Modificado de Ough et al., 1994.

A colocação do metal, ou a substituição do anel alteram as posições dos níveis de energia do orbital ocupado de maior energia (HOMO), ou do orbital vazio de menor energia (LUMO), resultando em diferentes cores e posições dos picos de absorção [Kumar et al., 2001; Kasuga et al., 2002]. Como pode se notar na Fig. 2.16, o espectro para metalo-ftalocianinas (MPc) apresenta um pico na banda $\mathrm{Q}$, enquanto as ftalocianinas não metálicas apresentam uma banda $\mathrm{Q}$ dividida. Pcs não metalicas são de simetria $\mathrm{D}_{2 \mathrm{~h}}$, no entanto Pcs metálicas incrementam sua simetria de $\mathrm{D}_{2 \mathrm{~h}}$ para $\mathrm{D}_{4 \mathrm{~h}}$. A introdução do íon metálico vai gerar 
um pequeno deslocamento para o azul na banda $\mathrm{Q}$ devido a que a densidade eletrônica vai diminuir, fazendo que o nível de energia Eg seja degenerado, acontecendo uma única transição eletrônica desde o nível n (HOMO). Pcs não metálicas têm o nível de energia LUMO não degenerado [Stillman et al., 2002].

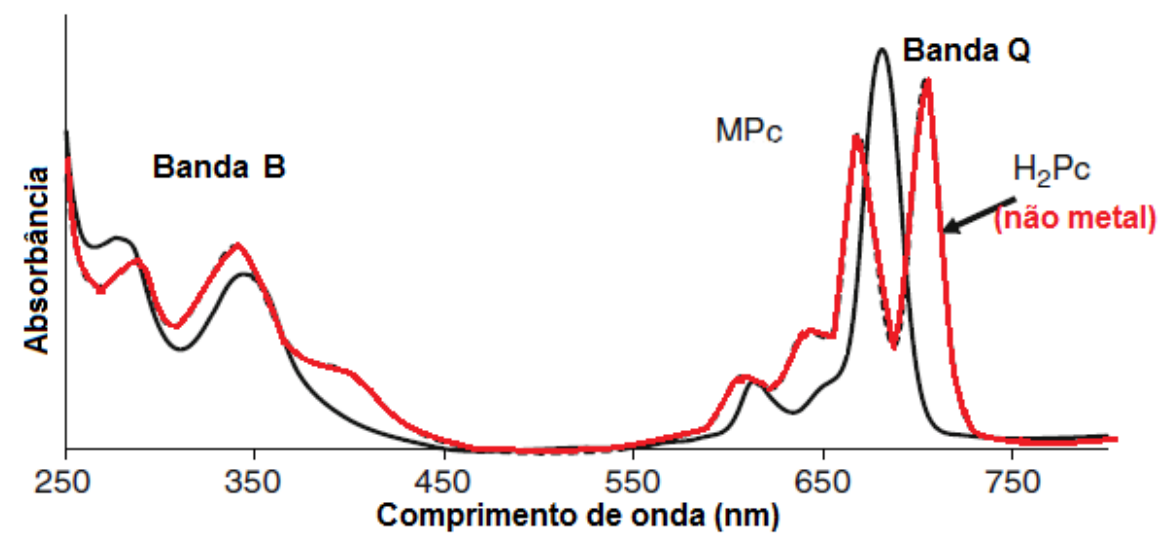

Figura 2.16. Espectro de absorção de ftalocianina sem metal (vermelho) e de metalo ftalocianina (preto).

No caso das Pcs metálicas, tem sido reportado o deslocamento da banda Q para o vermelho quando o metal está situado no meio do anel [Ogunsipe et al., 2004]. Outro fator no deslocamento da banda Q é dado pela paridade do número de protonação dos nitrogênios. Quando há uma simetria $\mathrm{D}_{2 \mathrm{~h}}$, ocorre a divisão da banda $\mathrm{Q}$, já com uma simetria $\mathrm{D}_{4 \mathrm{~h}}$, uma só banda Q é obtida [Beeby et al., 2001].

Também o espectro de absorção das ftalocianinas é afetado pela natureza do solvente [Law et al., 1997]. Solventes conjugados e aromáticos deslocam a banda Q ao vermelho [Kobayashi et al., 1999]. 


\section{3}

\section{Materiais e métodos}

\section{1}

\section{Materiais}

Foram utilizados os seguintes reagentes, adquiridos da Vetec Química Fina Ltda, para a síntese de nanopartículas magnéticas: $\mathrm{FeSO}_{4} \cdot 7 \mathrm{H}_{2} \mathrm{O}$ (Sulfato de Ferro II heptahidratado) $\mathrm{MM}=278 ; \mathrm{FeCl}_{3} \cdot 6 \mathrm{H}_{2} \mathrm{O}$ (Cloreto de Ferro III hexahidratado) $\mathrm{MM}=270 ; \mathrm{NH}_{4} \mathrm{OH}$ (Hidróxido de amônia $28 \%$ P.A.) $\mathrm{MM}=35$. Os solventes dimetilfulsóxido (DMSO), acetato de etila (EtOAc) e etanol, grau espectroscópico, também foram adquiridos da Vetec Química Fina Ltda.

Os surfactantes testados são apresentados na Tabela 3.1, mas descreveremos apenas o resultado obtido com Tween 80 , que se mostrou mais adequado.

Tabela 3.1. Surfactantes

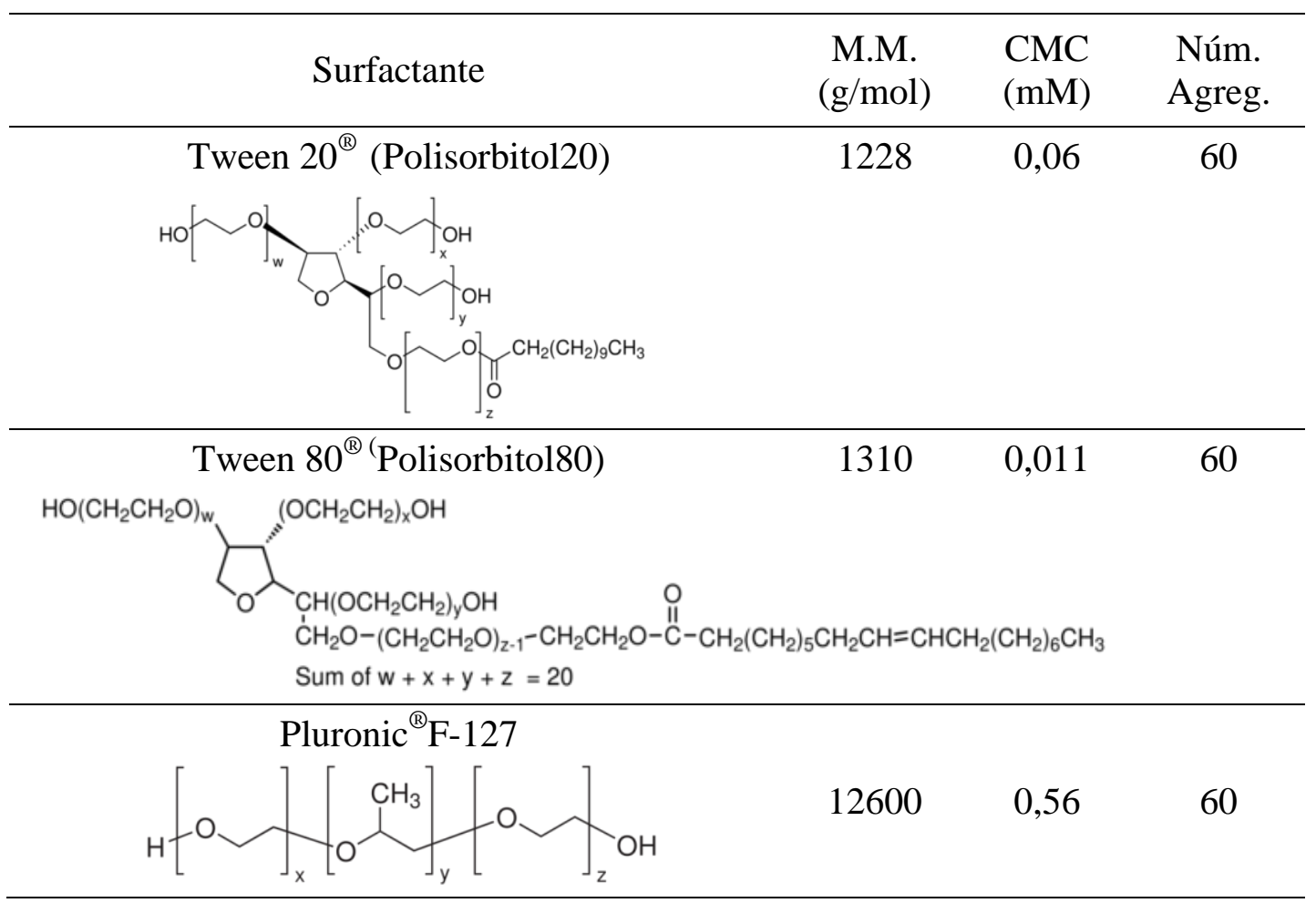


Foi utilizada água destilada e desionizada em todas as preparações. Para experimentos espectroscópicos foi utilizada água ultrapura.

\section{Fotossensibilizante MentaZnPc}

O fotossensibilizante hidrofóbico derivado da ftalocianina, MentaZnPc foi sintetizado no Laboratório Prof. Kleber Oliveira, UFSCar- São Carlos [Romero, 2013] e gentilmente disponibilizado. A Fig. 3.1 apresenta a estrutura da molécula de MentaZnPc. Essa ftalocianina é bastante solúvel em solventes orgânicos apolares.

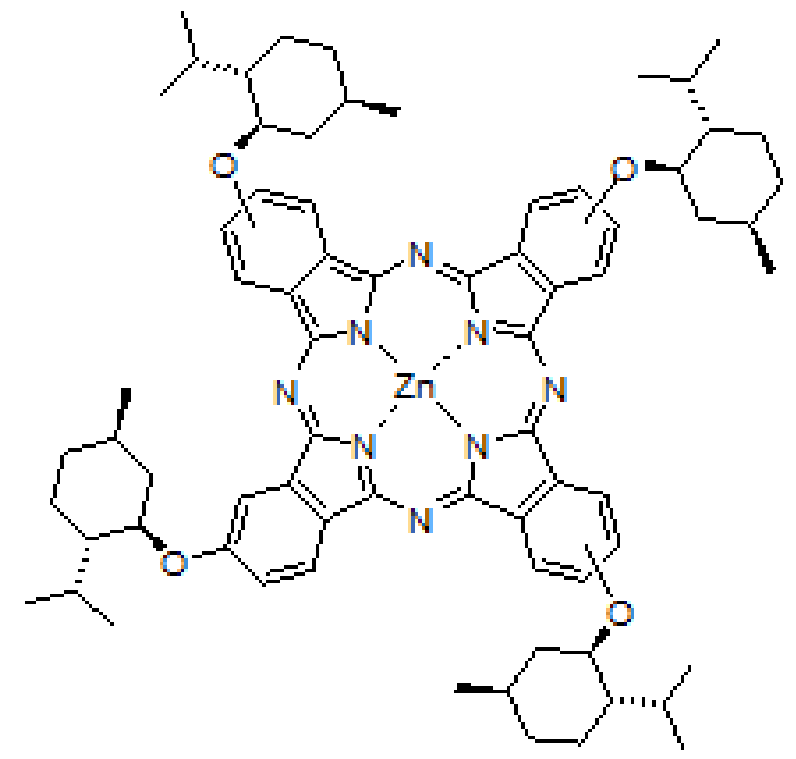

Figura 3.1. Estrutura do fotossensibilizante MentaZnPc.

Utilizou-se acetato de etila para preparar estoques $1 \mathrm{mM}$ e $3 \mathrm{mM}$ de MentaZnPc (ver Fig. 3.2), por ser bastante volátil e permitir que o solvente seja eliminado por evaporação. O acetato de etila é um éster simples, que possui alta aplicação industrial e é um ótimo solvente.

Foram também preparadas soluções estoque $1 \mathrm{mM}$ de MentaZnPc em DMSO. 


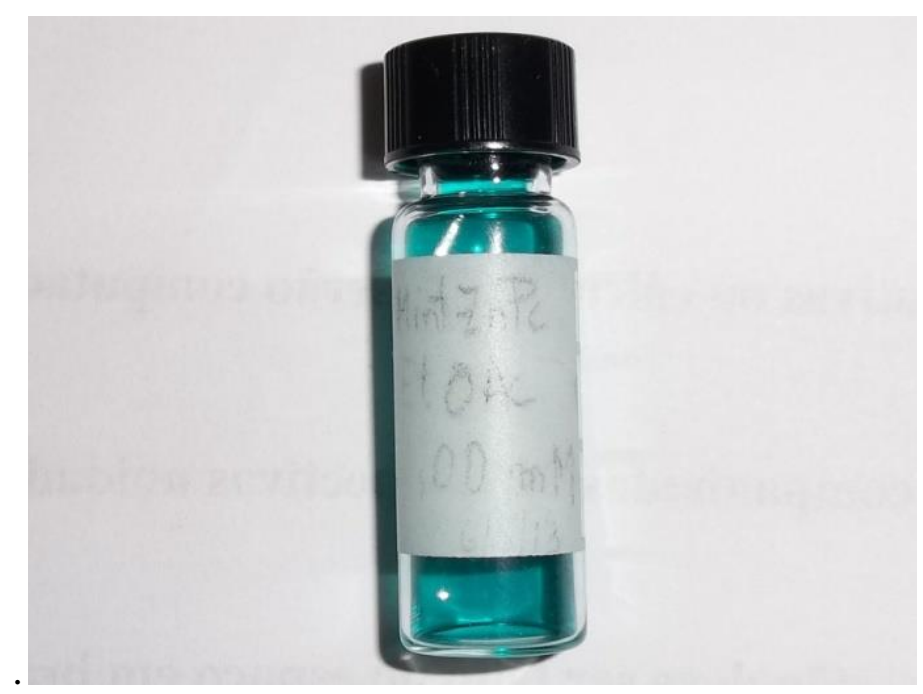

Figura 3.2. Estoque de MentaZnPc $1 \mathrm{mM}$ preparado em EtOAc.

\section{2}

\section{Técnica de Espectrofotometria UV visível}

Vários livros descrevem com distinto grau os processos fotofísicos ocorridos em moléculas. Aqui, nos basearemos principalmente no livro "Molecular fluorescence" (Valeur 2001) para introduzir alguns conceitos de absorção. A espectrofotometria ultravioleta-visível é utilizada para determinações de compostos orgânicos e inorgânicos, como, por exemplo, na identificação do princípio ativo de fármacos. Na espectroscopia de absorção molecular identificam-se os grupos funcionais de uma molécula. Mais importante, entretanto, são as aplicações para a determinação quantitativa de compostos contendo grupos que absorvem radiação nessa faixa de comprimentos de onda.

A absorção de fótons com frequências na faixa do UV-Vis por moléculas é às vezes denominada de absorção eletrônica, pois provoca transições eletrônicas, isto é, o salto do elétron desde o estado fundamental até um orbital excitado. De um ponto de vista prático, o aspecto mais importante é a determinação da quantidade de luz absorvida pela amostra, descrita pela lei de Beer-Lambert, que envolve a relação entre a intensidade de luz incidindo na solução $\left(\mathrm{I}_{\lambda}^{0}\right)$, dependente do comprimento de onda, e a intensidade que chega ao detector após atravessar a $\operatorname{amostra}\left(\mathrm{I}_{\lambda}\right)$ :

$$
A(\lambda)=\log \frac{I_{\lambda}^{0}}{I_{\lambda}}=\varepsilon_{(\lambda)} . d . c
$$


onde $\varepsilon_{(\lambda)}$ é o coeficiente de absorção molar $\left(\mathrm{L} \mathrm{mol}^{-1} \mathrm{~cm}^{-1}\right)$, c a concentração $\left(\mathrm{mol} \mathrm{L} \mathrm{L}^{-1}\right)$ da espécie absorvente e d é a distância que a luz atravessa no meio absorvente $(\mathrm{cm})$.

\section{Fatores que afetam às medidas de absorção espectral}

Existem diversos fatores que produzem mudanças no espectro de uma amostra:

- modificações químicas, tais como o $\mathrm{pH}$ do solvente, que pode mudar a estrutura da molécula.

- deslocamento do equilíbrio, quando um analito se associa, dissocia ou reage com um solvente para formar um produto cujo espectro de absorção é diferente do analito. Ex: indicador ácido-base.

- concentração sobressaturada, para soluções muito concentradas, as moléculas de soluto influenciam umas às outras devido à sua proximidade, pois quando ficam próximas entre si, a absorbância pode mudar.

\section{Instrumentação para medição da absorbância}

Os espectrofotômetros são instrumentos capazes de registrar dados de absorbância ou transmitância em função do comprimento de onda (espectros de absorção ou transmissão). O espectro de absorção é característico para cada espécie química, o qual torna possível determinar qual espécie química está presente na amostra. Também é possível detectar contaminações ou processos de decomposição de matérias-primas pela comparação dos espectros de absorção da matéria e do padrão da mesma.

Numa medida, quando a região espectral usada é a UV-visível, são necessários componentes ópticos de quartzo e detectores altamente sensíveis capazes de detectar radiação nessa extensa faixa espectral. Apesar de variarem em desenho, todos os espectrofotômetros consistem de uma fonte de luz, monocromador(es) (para a seleção dos comprimentos de onda), um porta-amostra transparente chamado de cubeta, detector(es) de luz, e um registrador para acumular os dados de saída do detector. A Fig. 3.3 mostra o esquema do espectrofotômetro utilizado (Agilent, modelo HP - 8452 A, com sistema de detecção por arranjos de diodos e resolução de $2 \mathrm{~nm}$ ). 
No caso do porta-amostra, as cubetas de vidro são suficientes quando se trabalha na região do visível. Para a região do ultravioleta, devem-se usar as cubetas de quartzo, que são transparentes à radiação ultravioleta. Uma cubeta padrão tem $1,000 \mathrm{~cm}$ de caminho óptico, para simplificar os cálculos da expressão da Lei de Beer-Lambert. As cubetas também podem ter dimensões diferentes, e esse dado deve ser considerado na hora do cálculo.

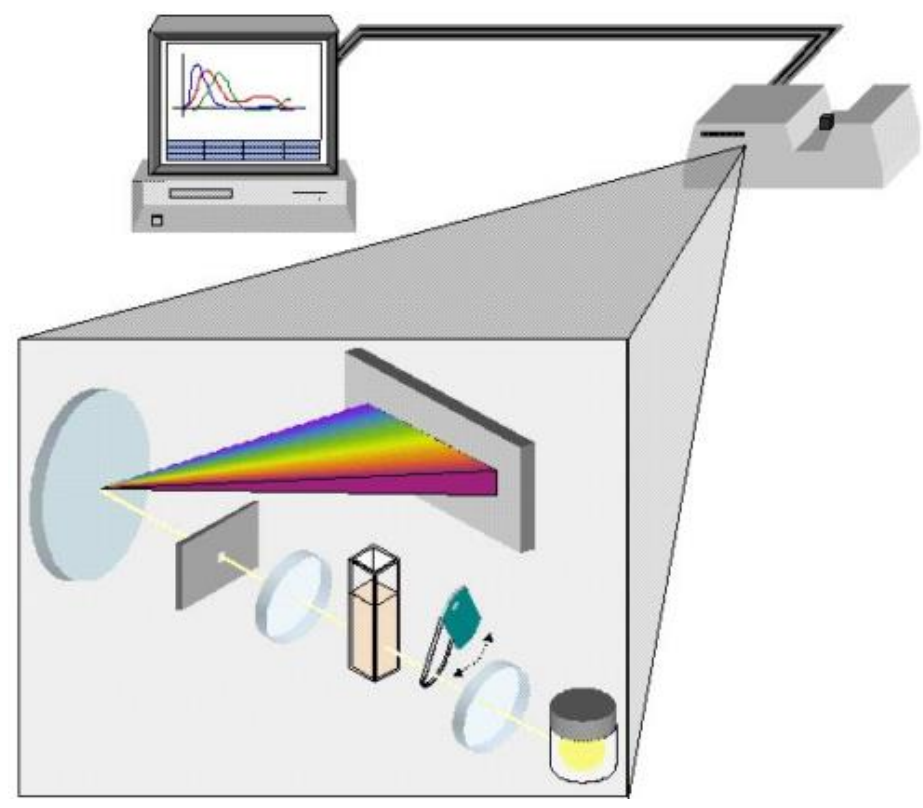

Figura 3.3. Esquema do espectrofotômetro HP-8452A. A luz da lâmpada passa através da amostra e solvente contidos em uma cubeta. Em seguida passa pela rede de difração, para seleção do comprimento de onda, e atinge o arranjo de diodos para a detecção.

Para fazer uma medição no espectrofotômetro, primeiro se obtém a medição de luz transmitida através do branco, isto é, do solvente, seguida por uma medição da luz transmitida pela amostra no mesmo solvente. O primeiro valor é, então, automaticamente subtraído do segundo para obter a fração da luz que foi absorvida pelo soluto. Isso é feito ao mesmo tempo em cada detector, para cada comprimento de onda da luz. O software permite apresentar o resultado como absorbância, derivada da absorbância, transmitância, ou ainda intensidade, sempre em função do comprimento de onda. 


\section{3}

\section{Métodos}

\subsubsection{Preparação de MentaZnPc em micelas}

Micelas do surfactante não iônico Tween 80 (Tw80) foram preparadas numa concentração $6 \mathrm{mM}$ em tampão fosfato $10 \mathrm{mM}, \mathrm{pH}$ 7,4. Observou-se que, adicionando-se alíquotas das soluções estoques de MentaZnPc às micelas já formadas, a ftalocianina não se solubilizava nas micelas. Então, optou-se por solubilizar MentaZnPc diretamente em Tw80 e, em seguida, solubilizar essa mistura no tampão para formar as micelas.

Para preparar $3 \mathrm{ml}$ de solução micelar de Tween 80 contendo MentaZnPc, tomam-se $30 \mu \mathrm{L}$ do estoque de MentaZnPc ( $2 \mathrm{mM})$ em EtOAc, evapora-se o solvente e acrescentam-se $12 \mathrm{mg}$ de Tw80. A mistura é então dissolvida em $3 \mathrm{ml}$ do tampão. A concentração final do surfactante $\left(4,0 \mathrm{mg} \mathrm{mL}^{-1}=3,0 \mathrm{mM}\right)$ é bem acima da CMC do Tw20 (16 $\left.\mu \mathrm{g} \mathrm{mL}^{-1}\right)$ e a concentração de MentaZnPc é de 20 $\mu \mathrm{M}$. A solução ficou azul ciano, bem transparente, conforme Fig. 3.4.

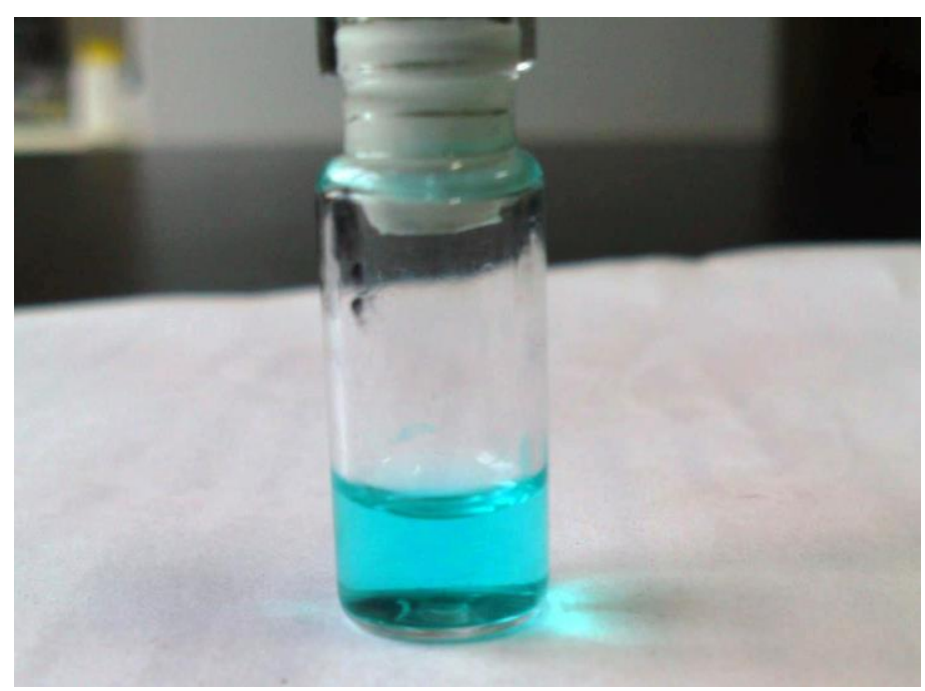

Figura 3.4. Solução micelar de Tween 80 em tampão fosfato.

\subsubsection{Preparação de nanopartículas de óxido de ferro}

Foram preparadas nanopartículas magnéticas usando o método de coprecipitação dos íons de $\mathrm{Fe}^{3+}$ e $^{2+}$ em solução aquosa por adição de uma base (hidróxido de amônia), sob atmosfera inerte à temperatura ambiente, na proporção 
de $\mathrm{Fe}^{3+} / \mathrm{F}^{2+}=2$. O tamanho das nanopartículas vai depender do tipo de solução usada, da proporção $\mathrm{Fe}^{3+} / \mathrm{F}^{2+}$, da força iônica do médio e valores do $\mathrm{pH}$ [Jolivet et al., 2006].

As soluções aquosas de $\mathrm{FeSO}_{4}, 1 \mathrm{M}$, e $\mathrm{FeCl}_{3}, 2 \mathrm{M}$, foram misturadas em iguais quantidades(dissolvidas em $200 \mathrm{ml}$ de água cada), usando o agitador magnético. A mistura foi dissolvida em $250 \mathrm{ml}$ de hidróxido de amônia 28\%, uniformizando-se com o agitador magnético. Forma-se, imediatamente, um precipitado preto. A uniformidade da solução é importante para garantir que as nanopartículas, na sua maioria, tenham um mesmo tamanho, com pequena polidispersão.

Foi colocado um pequeno imã embaixo do becker contendo esta nova mistura, para iniciar a separação magnética (Fig. 3.5). Uma vez completada a separação das partículas de cor preta, o líquido sobrenadante foi retirado e foram adicionados $250 \mathrm{ml}$ de álcool etílico ao precipitado para lavagem, uniformizando com o agitador mecânico. O processo de lavagem foi repetido, alternando lavagem com água e álcool etílico, até notar uma cor clara no líquido sobrenadante e, o mais importante, até que o líquido sobrenadante seja neutro, $\mathrm{pH}$ $\sim$, (aproximadamente 6 lavagens, alternando álcool etílico e água).

Ao final do processo, as nanopartículas de óxido de ferro precipitadas são colocadas no dessecador para secagem.

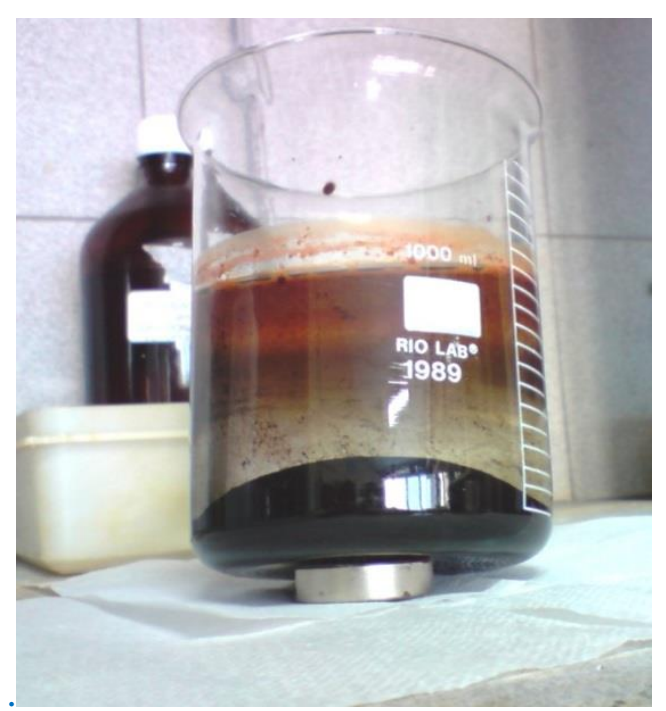

Figura 3.5. Fabricação das nanopartículas mediante co-precipitação. Nota-se o imã embaixo do becker, o liquido preto correspondem às nanopartículas de óxido de ferro. 


\section{Caracterização das nanopartículas}

As nossas nanopartículas foram preparadas da mesma forma descrita por Araújo (2013) que, analisando mediante Microscopia Eletrônica de Transmissão (MET) no Departamento de Ciência dos Materiais e Metalurgia, PUC-Rio, obteve a imagem das nanopartículas preparadas em 4,0 mol. $\mathrm{L}^{-1}$ de $\mathrm{NH}_{4} \mathrm{OH}$ (Fig. 3.6). A Fig. 3.6 (d) revela que a maioria destas nanopartículas tem um tamanho entre 5 e $10 \mathrm{~nm}$.

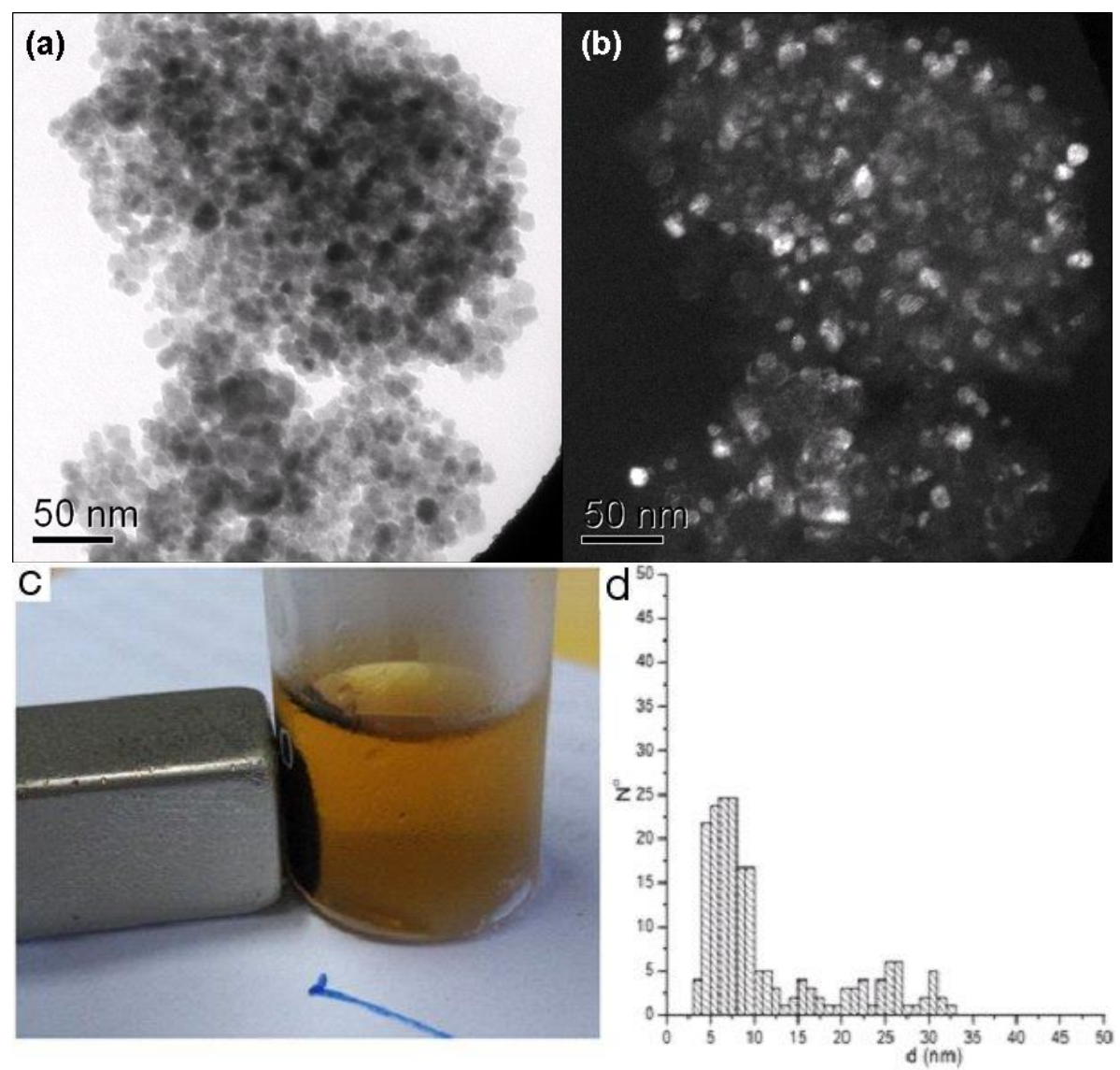

Figura 3.6. (a) e (b) Imagens mediante MET de nanopartículas magnéticas de óxido de ferro obtidas com misturas dos sais de ferro adicionadas a hidróxido de amônia $4 \mathrm{~mol} \mathrm{~L}^{-1}$, revelando somente nanopartículas de magnetitas. (c) separação magnética; (d) histograma de diâmetros feito a partir das imagens do MET [Araújo, J F D F, 2013, com permissão].

Outra forma de verificar se as NPs são superparamagnéticas é que, acima da temperatura de bloqueio, o sistema não apresenta histerese magnética. Nas análises feitas por Araújo num magnetômetro Hall (Fig. 3.7), pode-se observar que, à temperatura ambiente, a magnetização de remanência é quase nula $(0,4$ $\mathrm{Am}^{2} / \mathrm{kg}$ ), com módulo da coercividade muito pequeno de 0,6 mT a $298 \mathrm{~K}$. 
Este resultado está de acordo com a teoria do superparamagnetismo das nanopartículas magnéticas, que prevê o estado de bloqueio das nanopartículas com a diminuição da energia térmica, o qual ocorre somente para temperaturas abaixo da temperatura de bloqueio, na qual a nanopartícula deixa de ser superparamagnética e torna-se ferromagnética.

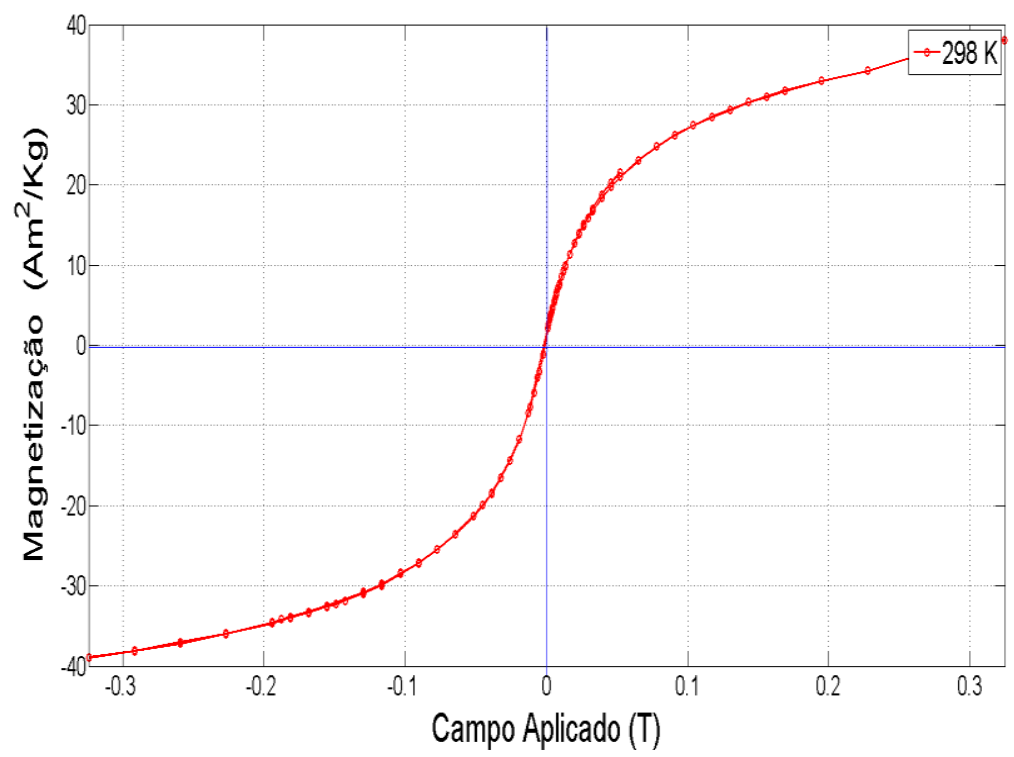

Figura 3.7. Curva de magnetização das nanopartículas de magnetita obtida no magnetômetro Hall a baixas temperaturas [Araújo, 2013, com permissão].

\subsubsection{Processo de fotodegradação}

Para o processo de fotodegradação foi utilizada a montagem descrita por Romero [Romero, 2012]. Brevemente, a fonte para fotossensibilização composta de LEDs vermelhos, foi colocada a $10 \mathrm{~cm}$ da cubeta contendo a solução do fotossensibilizante em estudo, contendo também DPBF (sonda de oxigênio singlete). A direção lâmpada-cubeta foi ajustada de modo a fazer um ângulo de $90^{\circ}$ em relação ao feixe de luz do espectrofotômetro (Fig. 3.8).

A lâmpada para irradiação das amostras (Golden Plus) é formada por 20 LEDs vermelhos ( 615-640 nm, com pico em $635 \mathrm{~nm})$. O espectro de emissão da lâmpada é mostrado na Fig. 3.9. 


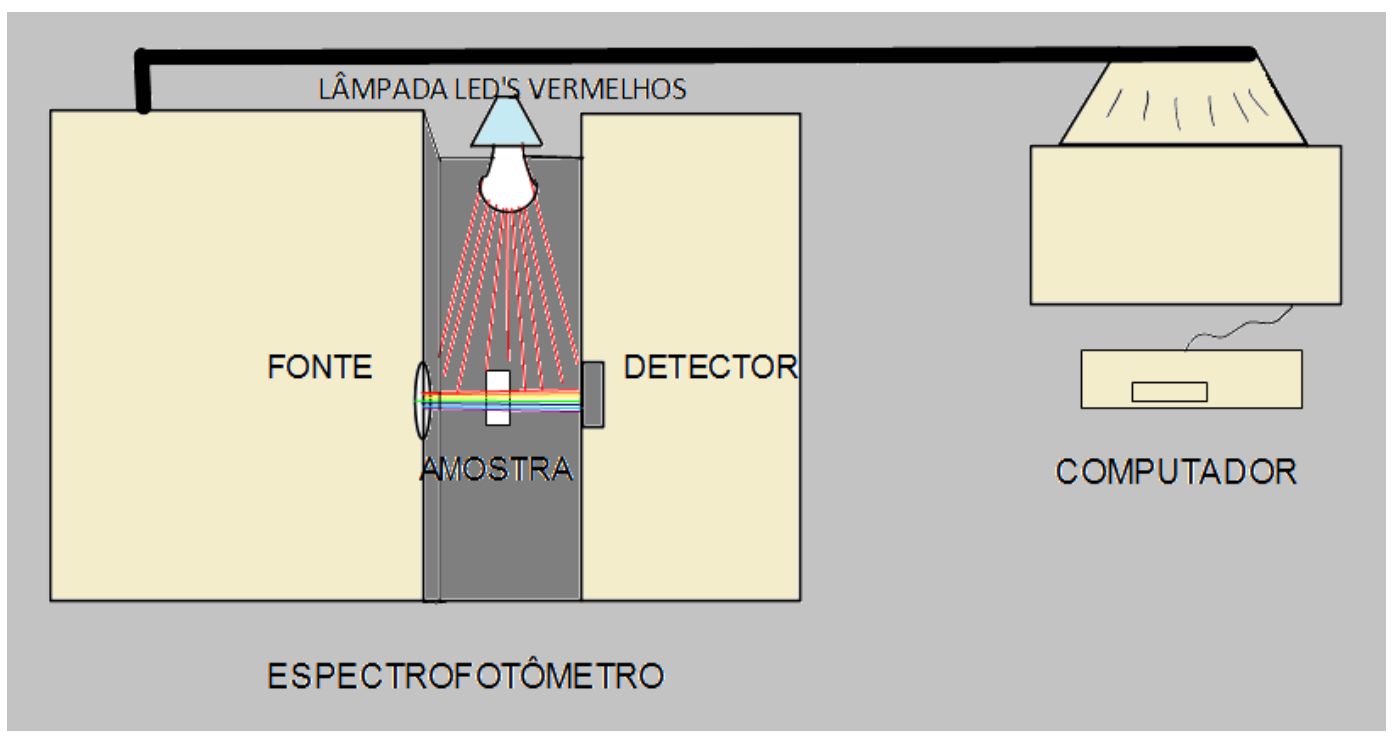

Figura 3.8. Montagem do experimento de fotodegradação. Amostra, fotoexcitada com a fonte de LEDs vermelhos, contendo DPBF como sensor de oxigênio singlete. Absorbância detectada no espectrofotômetro UV-VIS.

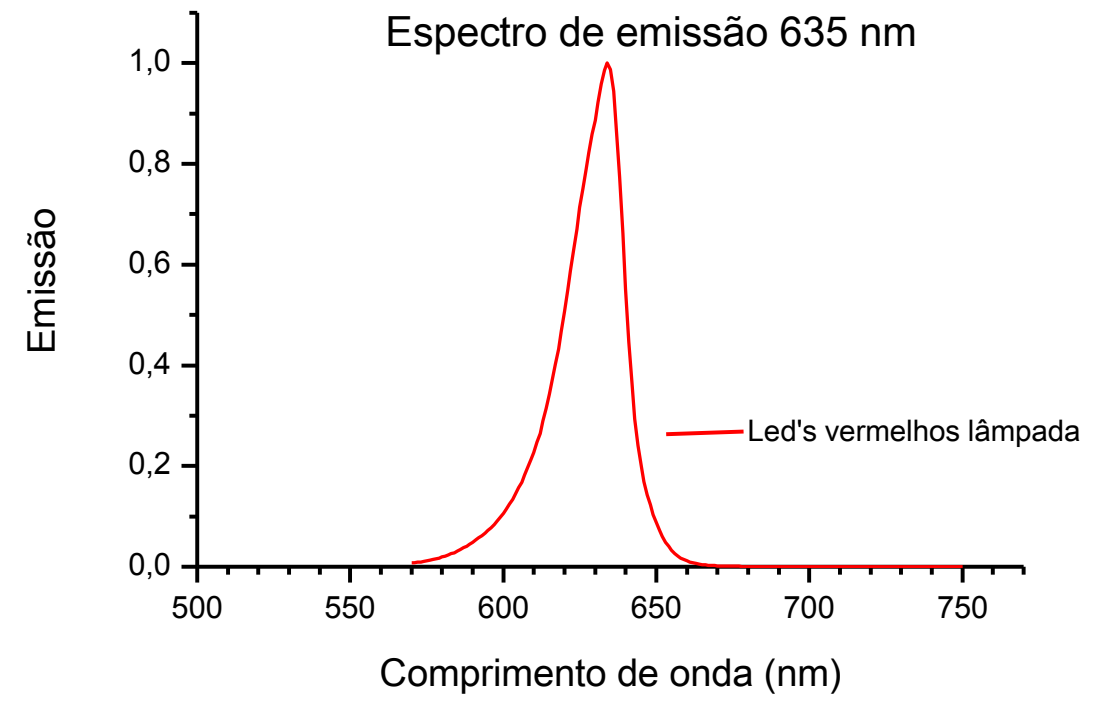

Figura 3.9. Espectro de emissão da lâmpada utilizada na produção de oxigênio singlete por MentaZnPc.

A produção de oxigênio singlete foi obtida utilizando a variação da absorção óptica de 1,3-diphenylisobenzofuran (DPBF), que é especificamente degradado pela reação com oxigênio singlete. Preparou-se um estoque de DPBF $4 \mathrm{mM}$ em etanol, protegido da luz ambiente com papel alumínio. O estoque era armazenado em geladeira e utilizado em até uma semana. Foi usado DPBF em concentrações finais da ordem de $30 \mathrm{mM}$, sendo $\epsilon_{417 \mathrm{~nm}}=2,3 \times 10^{4} \mathrm{M}^{-1} \mathrm{~cm}^{-1} \mathrm{o}$ coeficiente de absorção molar para o DPBF [Ogunsipe et al., 2003]. 
As amostras contendo o fotossensibilizante e o DPBF foram irradiadas por períodos de 1 min durante pouco mais de 30 minutos, para medir a produção de oxigênio singlete. A cubeta de quartzo de $3 \mathrm{ml}$, com 1,000 cm de caminho óptico, foi mantida a uma distância de $10 \mathrm{~cm}$ da fonte de luz. Os espectros de absorção das amostras foram obtidos a cada minuto de irradiação, com tempo de aquisição de $1 \mathrm{~s}$.

\subsubsection{Taxa de fotoxidação de DPBF}

As taxas de fotoxidação $\left(k_{p}\right)$ de DPBF e a taxa de fotobranqueamento da MentaZnPc $(k)$ foram encontradas na presença de oxigênio. Considerando que a última etapa do processo de fotodegradação, correspondente à reação de ${ }^{1} \mathrm{O}_{3} \mathrm{com}$ a sonda (DPBF) é a mais lenta, a taxa de consumo da sonda é dada pela e quação 3.2 [Da Silva A. R., 2003]:

$$
\frac{d[S]}{d t}=-k_{1}\left[{ }^{1} O_{2}\right][S]
$$

sendo $[\mathrm{S}]$ a concentração de DPBF. Se a concentração de oxigênio singlete for constante durante a reação, pode-se definir $k_{p}=k_{1}\left[{ }^{1} \mathrm{O}_{2}\right]$ e a equação (3.2) integrada vai fornecer:

$$
[S]=[S]_{0} \exp \left(-k_{p} t\right)
$$

onde $[\mathrm{S}]_{0}$ é a concentração inicial da sonda. Considerando-se a relação linear entre a concentração da sonda e a absorbância, $A$, associada a ela (absorbância de DPBF), temos a mesma função exponencial descrevendo a evolução temporal do parâmetro espectroscópico $A$ :

$$
A=A_{0} \exp \left(-k_{p} t\right)
$$

Para DPBF, toma-se a absorção em 417 nm (coeficiente de absorção molar $\left.\varepsilon_{\mathrm{DMF}}=2,30 \times 10^{4} \mathrm{M}^{-1} \mathrm{~cm}^{-1} \mathrm{em} 411 \mathrm{~nm} ; \varepsilon_{\mathrm{DMF}}=2,24 \times 10^{4} \mathrm{M}^{-1} \mathrm{~cm}^{-1} \mathrm{em} 408 \mathrm{~nm}\right)$. No entanto, a própria MentaZnPc também contribui para a absorção nesse comprimento de onda. Nesse caso, observa-se um decaimento exponencial da forma:

$$
A=A_{f}+A_{0} \exp \left(-k_{p} t\right)
$$

sendo $A_{f}$ a contribuição de MentaZnPc, que permanece constante no tempo, já que o fotobranqueamento de DPBF é muito mais rápido. 


\subsubsection{Construção do circuito aquecedor por indução eletromagnética}

\section{Circuito do Equipamento}

\section{O CIRCUITO RESSONANTE}

O circuito utilizado para testar a influência da temperatura nas nossas nanopartículas magnéticas é um circuito ressonante do tipo Royer [Jim, 1995], o qual está baseado na oscilação por relaxamento e tem as vantagens de simplicidade e operação em auto-ressonância. Utilizando o esquema da Fig. 3.10 foi montado o circuito para nossas experiências.

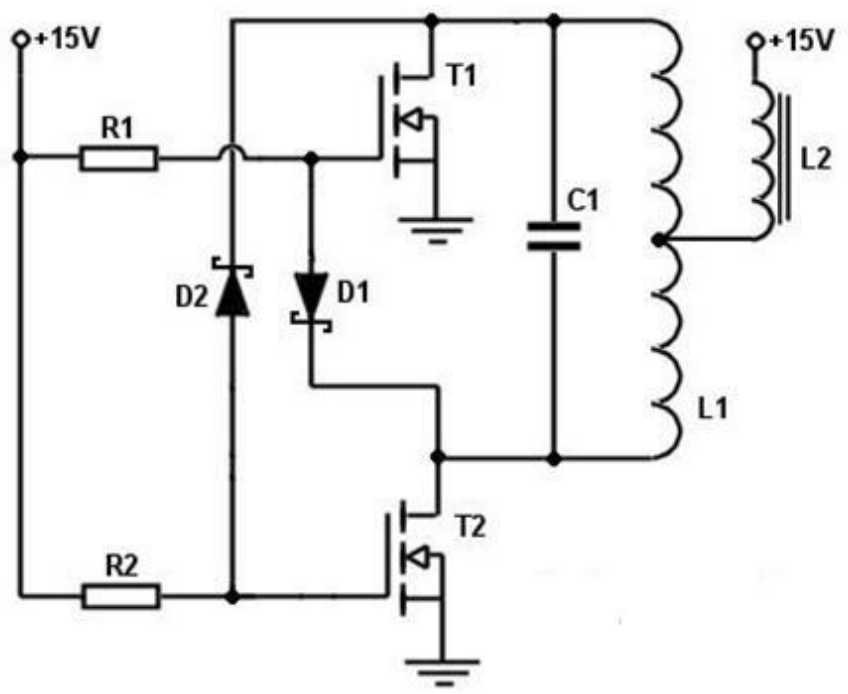

Figura 3.10. Esquema do circuito ressonante tipo oscilador Royer.

A amostra de nanopartículas em meio aquoso deve ser introduzida no meio da bobina L1 (bobina branca na Fig. 3.11), que gera o campo magnético de alta frequência. Em paralelo com a bobina L1 está ligado um banco de capacitores C1 formado por 6 capacitores em paralelo, constituindo assim o circuito tanque.

Os componentes do circuito e a geometria da bobina foram escolhidos com base nos trabalhos de Pollert et al. (2007) e Andrä et al. (1999), em que foram realizadas medidas de aquecimento de nanopartículas magnéticas em meio aquoso. Nesses trabalhos foram utilizados campo magnético $\sim 88 \mathrm{mT}$ com frequência $\sim 108 \mathrm{kHz}$ [Pollert et al., 2007] ou campo magnético $\sim 8,13 \mathrm{mT}$ com frequência $400 \mathrm{kHz}$ [Andrä et al., 1999]. 
Escolhemos trabalhar com campos magnéticos da ordem de $8 \mathrm{mT}$, projetando o tamanho da bobina para funcionar com correntes da ordem de $15 \mathrm{~A}$. O banco de capacitores foi escolhido para que o circuito ressonante tivesse frequência em torno de $90 \mathrm{kHz}$.

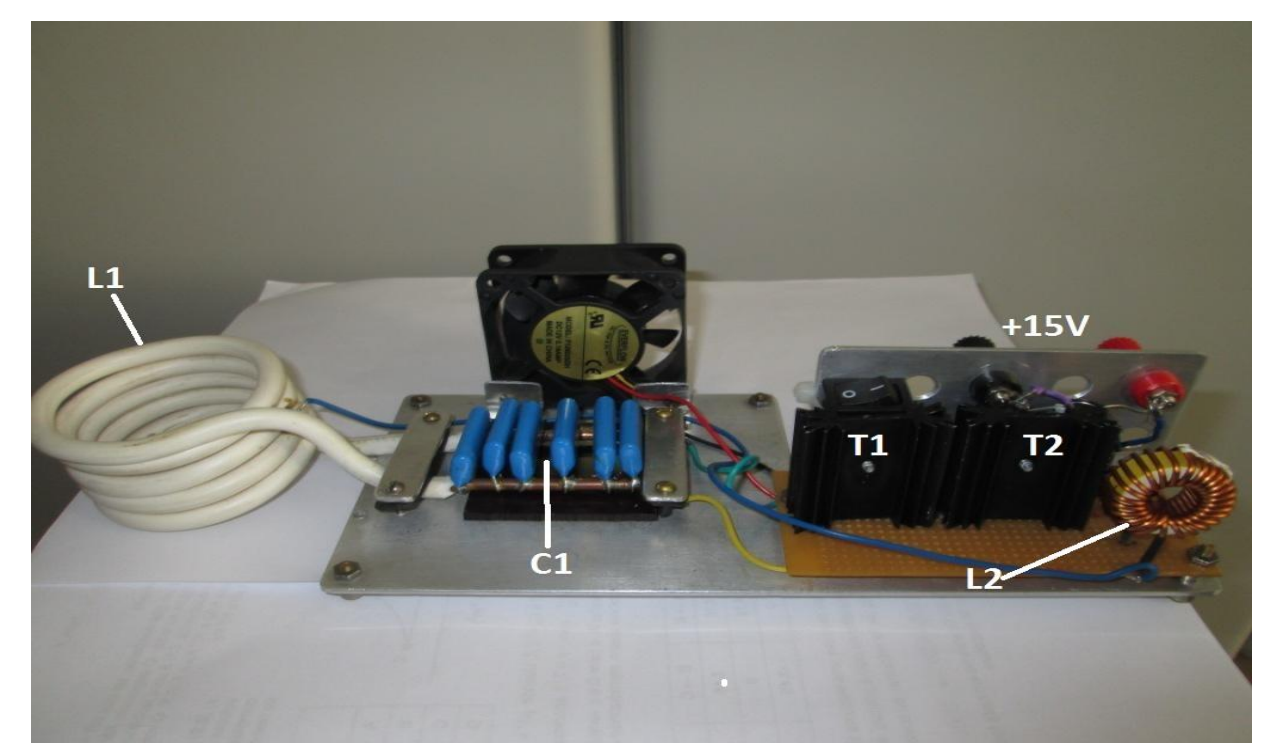

Figura 3.11. Circuito utilizado para o aquecimento das nanopartículas. A bobina branca (bobina) e capacitores formam nosso circuito tanque.

\section{Componentes utilizados}

Como mostrado na Fig. 3.10, usam-se dois resistores de baixa resistência R1 e R2, ambos de $240 \Omega$, os quais vão determinar a rapidez com que os transistores T1 e T2 são ativados. Os diodos D1 e D2 utilizados foram diodos Schottky 1N5819, por terem baixa queda de tensão e alta eficiência, de modo que quando um dos transistores esteja ligado o outro permaneça desligado.

Os transistores MOSFET $\mathrm{T} 1$ e $\mathrm{T} 2$ foram montados em dissipadores de calor, mas eles raramente esquentaram quando são executados os testes, mesmo em correntes altas.

O indutor L2 é usado para manter as oscilações de alta frequência fora da fonte de alimentação e limitar a corrente a níveis aceitáveis. Esse indutor L2 foi confeccionado enrolando cerca de 8 voltas com fio de cobre de $2 \mathrm{~mm}$ de diâmetro num núcleo toroidal de ferrite.

Um capacitor eletrolítico $2200 \mu \mathrm{F}$ foi adicionado à entrada do circuito em paralelo com a fonte de alimentação para proteção da fonte, devido à corrente 
fornecida, e evitar uma variação brusca de tensão no momento de ligar o circuito, caso contrário os transistores não funcionariam corretamente.

A derivação central da bobina L1 juntamente com dois transistores do tipo $\mathrm{N}$, permite a geração de corrente alternada a partir de uma fonte de alimentação de corrente constante. $\mathrm{O}$ centro desta bobina é conectado à alimentação positiva e os extremos são conectados alternadamente a terra por meio de dois transistores $\mathrm{T} 1 \mathrm{e}$ $\mathrm{T} 2$, de modo que a corrente flui em ambos os sentidos. A corrente na fonte de alimentação irá variar com a indutância L1 e, portanto com a condutividade do objeto a ser introduzido, para ser aquecido.

\section{O circuito tanque: a bobina e o capacitor em paralelo}

O capacitor $\mathrm{C} 1$ e a bobina L1 formam nosso circuito tanque e devem ser suficientemente capazes de resistir a grandes correntes e temperaturas. No caso do capacitor $\mathrm{C} 1$ ele foi constituído, na prática, por um banco de 6 capacitores de $0,33 \mu \mathrm{F}$ e um de $0,47 \mu \mathrm{F}$ associados em paralelo. Este banco foi colocado razoavelmente perto da bobina e conectado em paralelo, resfriado com um cooler operando a $12 \mathrm{~V}$ quando o circuito é ligado. A divisão da corrente alternada entre os capacitores do banco vai evitar uma alta corrente por um único capacitor, evitando sua danificação. A bobina L1 foi feita com 5 voltas de fio de $16 \mathrm{~mm}^{2}$ de cobre, para resistir às correntes de alta frequência fluindo nele. Mediante o circuito tanque podemos mudar a frequência de ressonância, pois ela vai depender das características da bobina e da capacitância total.

\section{Parâmetros elétricos e geométricos da bobina}

Existem diferentes formas de bobinas a serem utilizadas, mas estas devem permitir o correto acoplamento magnético com as nossas nanopartículas (amostra), e a parte interna onde vai ser colocada a amostra deve ser tal que a transferência de calor devido à bobina seja a menor possível (isolamento por condução e convecção).

A bobina do nosso circuito foi feita por 5 enrolamentos helicoidais de fio grosso de cobre cujas características são mostradas na Tabela 3.2. 
Tabela 3.2. Dimensões físicas da bobina construída com fio maciço de cobre.

\begin{tabular}{ll}
\hline Dimensões & Valores \\
\hline $\mathrm{r}=$ raio do fio & $2,2 \mathrm{~mm}$ \\
Sep = separação entre espiras & $4,1 \mathrm{~mm}$ \\
$\mathrm{~N}=$ número de voltas & 5 \\
$\mathrm{D} \_$int = diâmetro interno da bobina & $60 \mathrm{~mm}$ \\
$\mathrm{D} \_$ext = diâmetro externo da bobina & $68,4 \mathrm{~mm}$ \\
$\mathrm{R}=$ resistência & $1,37 \mathrm{~m} \Omega$ \\
$\mathrm{L}=$ indutância & $1,19 \mu \mathrm{H}$ \\
\hline
\end{tabular}

Para o cálculo da resistência $\mathrm{R}$ da bobina utilizou-se a lei de Ohm:

$$
R=\rho \frac{l}{A}
$$

onde $\rho=1,725 \times 10^{-8} \Omega \mathrm{m}$ é a resistividade do cobre, $\iota$ é o comprimento do fio e A é a seção reta do fio.

A obtenção do valor da indutância L da bobina foi feito das seguintes formas.

a) Cálculo da indutância teórica para a bobina de uma camada

Para encontrar o valor da indutância $\mathrm{L}_{\text {teor }}$ da bobina que tem espaço entre cada enrolamento, usamos uma aproximação numérica considerando cada espira como um anel, computando-se a contribuição das auto-indutâncias de cada espira $\mathrm{L}_{\mathrm{i}}$ e a contribuição das indutâncias mútuas $\mathrm{M}_{\mathrm{ij}}$ entre todas as espiras, assim a autoindutância é dada por:

$$
L_{\text {teor }}=\sum_{i}^{n} L_{i}+\sum_{i, j}^{n} M_{i j}
$$

onde a auto-indutância $\mathrm{L}_{\mathrm{i}}$ de um anel pode ser obtida com uma aproximação mais realista desprezando-se o fluxo magnético dentro do condutor [Silvester, 1968; Terman, 1943]:

$$
L_{i}=u_{\boldsymbol{o}} R\left(\ln \frac{16 \cdot R}{d}-2\right)
$$

onde $\mathrm{R}$ é o raio da bobina, $d$ é o diâmetro do fio, e $\mu_{0}$ é a permeabilidade magnética do vácuo. Como eles estão separados aproximadamente por uma mesma distância, o primeiro termo da equação 3.7 fica 5 vezes o valor da autoindutância de cada anel.

Para o cálculo das indutâncias mútuas $\mathrm{M}_{\mathrm{ij}}$ entre todas as espiras, usou-se a solução dada pela expressão [Grover, 1962, pag. 77]:

$$
M_{i j}=f_{i j} \sqrt{R_{a} R_{b}}
$$


$\operatorname{com} f$ obtido a partir da tabela13, capítulo 11 [Grover, 1962] como uma função de variável $\mathrm{k}^{2}$ :

$$
k^{2}=\frac{\left(R_{a}-R_{b}\right)^{2}+d^{2}}{\left(R_{a}+R_{b}\right)^{2}+d^{2}}
$$

onde $\mathrm{R}_{\mathrm{a}}$ e $\mathrm{R}_{\mathrm{b}}$ são os raios dos anéis (que no nosso caso são iguais), $d$ a separação entre os centros deles. Foram utilizados os valores em $\mathrm{cm}$ e o resultado da indutância mútua $\mathrm{M}_{\mathrm{ij}}$ foi obtido em $\mu \mathrm{H}$. A solução do somatório dos $\mathrm{M}_{\mathrm{ij}}$ foi implementada numericamente com auxilio do programa Matlab (Apêndice C) usando interpolação para obter os pontos que não figuravam na Tabela 13 do livro de Grover (1962), obtendo finalmente:

$$
L_{\text {teor }}=5 L_{i}+\sum_{i, j}^{n} M_{i j}=0,706+0,408=1,11 \mu H
$$

(b) Obtenção experimental da indutância

Neste caso vamos utilizar os valores dos capacitores do circuito tanque e medir a frequência de ressonância do circuito com o osciloscópio (Fig. 3.12).

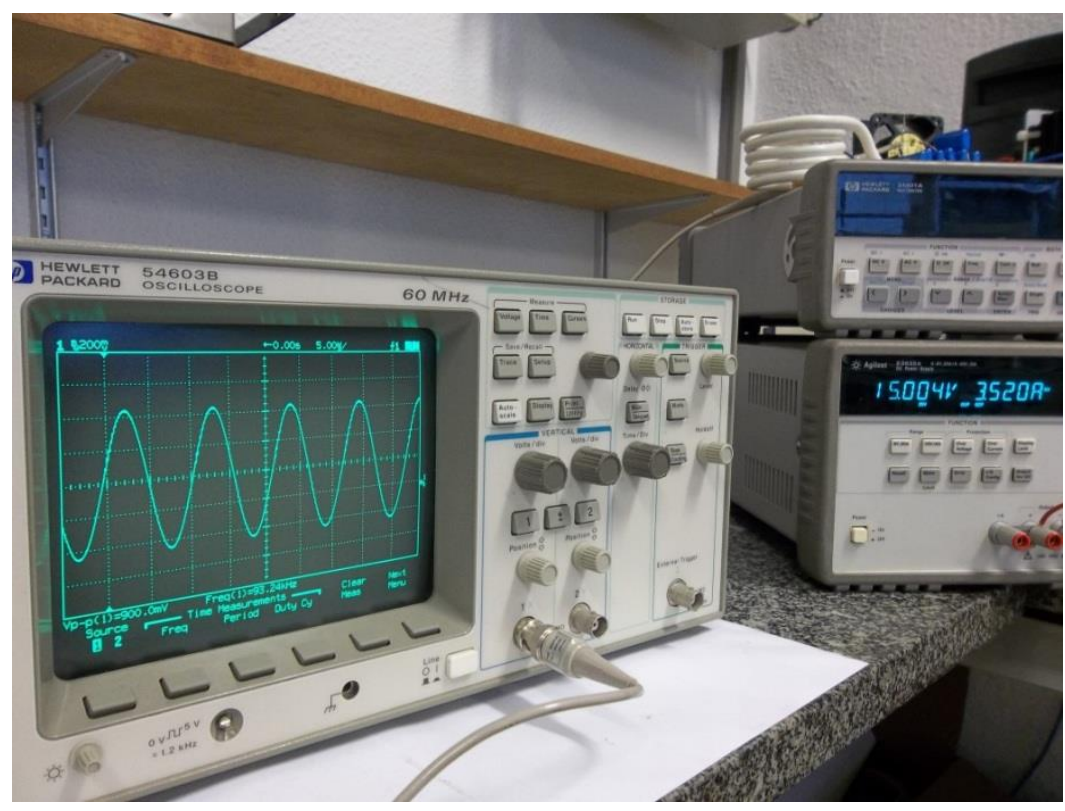

Figura 3.12. Osciloscópio utilizado para encontrar a frequência de ressonância do circuito. Pode-se apreciar a forma senoidal uniforme da onda de saída na bobina.

A frequência de ressonância para um circuito ressonante RLC é dada por:

$$
\begin{aligned}
& \omega_{0}=\frac{1}{\sqrt{L C}}=2 \pi f \\
& L=\frac{1}{4 C \pi^{2} f^{2}}
\end{aligned}
$$


A frequência de ressonância medida com o osciloscópio foi igual a $f=89$ $\mathrm{kHz}$ (Fig. 3.12). O banco de capacitores tem 6 capacitores $0,33 \mu \mathrm{F}$ e um de $0,47 \mu \mathrm{F}$ em paralelo produzindo uma capacitância total $\mathrm{C}=2,45 \mu \mathrm{F}$. Utilizando a equação 3.13, a indutância obtida foi de $1,19 \mu \mathrm{H}$, muito semelhante à calculada teoricamente.

$$
L_{1}=1,19 \mu \mathrm{H}
$$

\subsubsection{Campo magnético no interior da bobina}

Cálculo da corrente elétrica na bobina

A Fig. 3.13 ilustra o circuito tanque RLC utilizado. A corrente elétrica na bobina é obtida medindo-se a tensão no circuito tanque $\left(\mathrm{V}_{\text {tanque }}\right)$ através de um osciloscópio. Como ambas as impedâncias complexas $Z_{C}$ e $Z_{R-L}$ estão em paralelo, a impedância total $Z_{\mathrm{eq}}$ vem dada por:

$$
Z_{e q}=\frac{Z_{C} Z_{R-L}}{Z_{C}+Z_{R-L}}
$$

onde $Z_{C}=\left(\frac{-1}{\omega C}\right) j, Z_{L}=(\omega L) j$, e $Z_{\mathrm{R}}=\mathrm{R}_{\mathrm{L}}$ são as impedâncias do capacitor, indutor e resistência respectivamente, $j$ representa o numero complexo. Como o resistor e o indutor estão conectados em série:

$$
\begin{aligned}
& Z_{R-L}=Z_{R}+Z_{L}=R_{L}+(\omega L) j \\
& Z_{R-L}=\left|Z_{R}+Z_{L}\right|=\sqrt{R_{L}^{2}+\omega^{2} L^{2}}
\end{aligned}
$$

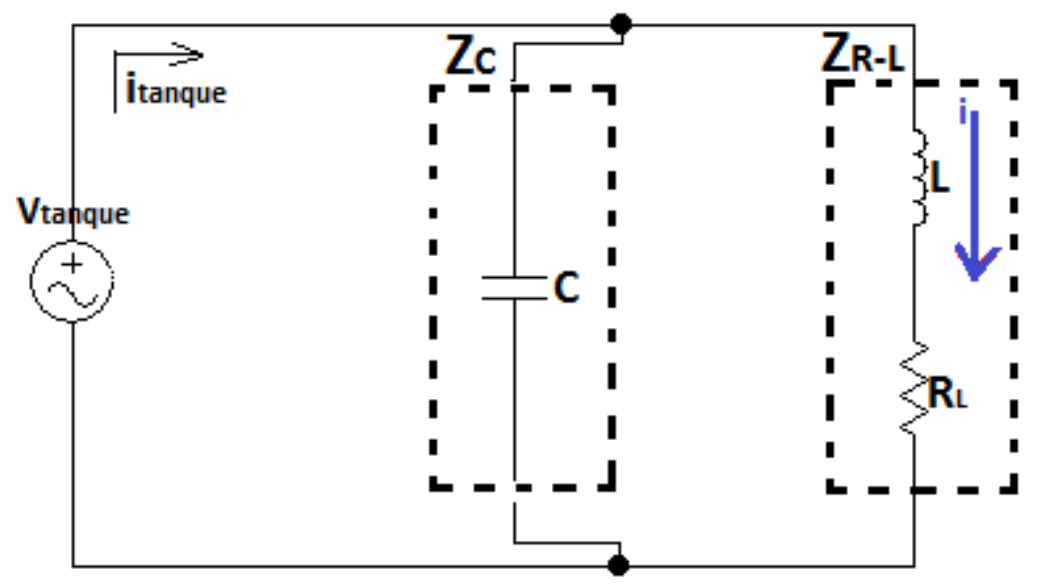

Figura 3.13. Esquema do circuito $R L C$. $R_{L}$ é a resistência própria do indutor em série com a indutância e em paralelo com o capacitor. $Z_{C}$ e $Z_{R-L}$ são impedâncias de cada componente. 
Resolvendo para o módulo da impedância complexa total, encontramos que:

$Z_{e q}=\sqrt{\frac{R_{L}^{2}+\omega^{2} L^{2}}{\left(1-\omega^{2} L C\right)^{2}+\left(\omega C R_{L}\right)^{2}}}=\frac{Z_{R-L}}{\sqrt{\left(1-\omega^{2} L C\right)^{2}+\left(\omega C R_{L}\right)^{2}}}$

Como o circuito se encontra em ressonância: $\omega=\omega_{0}=\frac{1}{\sqrt{L C}}$, obtendo enfim:

$$
Z_{e q}=\frac{Z_{R-L}}{\omega_{0} C R_{L}}
$$

Como $V_{\text {tanque }}=V_{R}+V_{L}=i\left(R_{L}+\omega L j\right)=i Z_{R-L}$, com i sendo a corrente no indutor e $j$ o numero complexo, temos em módulo que

$$
V_{\text {tanque }}=i Z_{R-L}=i_{\text {tanque }} Z_{\text {eq }}
$$

Portanto, usando as equações (3.17), (3.19) em (3.20), obtemos a corrente no indutor L1:

$$
i=\frac{i_{\text {tanque }}}{\omega_{0} C R_{L}}=Q_{0} i_{\text {tanque }}
$$

onde o fator $\mathrm{Q}_{0}$ é chamado fator de mérito do circuito.

Para obtenção da corrente $i$ circulando no indutor, usamos um divisor de tensão e, com a ajuda do osciloscópio, obtivemos a tensão $\mathrm{V}_{\text {tanque }}=38,1 \mathrm{~V}$, usando a equação (3.20) para calcular a corrente $\mathrm{i}_{\text {tanque }}$ para $\mathrm{Z}_{\mathrm{eq}}=389,0 \Omega$, obtemos que $i_{\text {tanque }}=0,098 \mathrm{~A}$. Levando tudo em consideração e usando a equação (3.21), obtivemos que o fator de mérito na ressonância $\mathrm{Q}_{0}=533$, que implicará uma corrente na bobina igual a 52,2 A.

\section{Campo magnético máximo no centro da bobina}

Em uma primeira aproximação podemos calcular o campo magnético gerado por cada anel da bobina utilizando Biot-Savart para um ponto localizado ao longo do eixo central [Reitz, Milford, Christy, 1993]:

$$
\boldsymbol{B}\left(z_{n}\right)=\frac{\mu_{0} i R^{2}}{2\left(z_{n}{ }^{2}+R^{2}\right)^{3 / 2}} \boldsymbol{k}
$$

Onde $\mu_{0}$ é a permeabilidade magnética do vácuo, $i$ é a corrente que percorre a bobina, $\mathrm{R}$ é o raio da bobina e $\mathrm{z}_{\mathrm{n}}$ é a distância de cada anel até o centro da bobina.

Calculando o campo magnético máximo no centro mediante a contribuição do campo magnético de cada anel com raios iguais e espaçados uma mesma distância, obtemos que:

$$
B(0)=\sum_{n=1}^{5} \frac{\mu_{0} i R^{2}}{2\left(z_{n}^{2}+R^{2}\right)^{3 / 2}}
$$


Utilizando a separação entre cada espira como $\mathrm{D}=0,0083 \mathrm{~m}$ obtemos $\mathrm{z}_{1}=\mathrm{z}_{5}=$ $2 \mathrm{D}, \mathrm{z}_{2}=\mathrm{z}_{4}=\mathrm{D}, \mathrm{z}_{3}=0$. Para $i=52,2$ A obtemos finalmente que: (Apêndice D)

$$
B(0)=(0,716+0,928+1,023+0,928+0,717) \times 10^{-3}=4,31 m T
$$

Campo magnético máximo no centro da bobina mediante o programa OPERA 3-D

Posteriormente, para cálculo do campo no centro da bobina, levou-se em consideração a espessura dos fios (Fig. 3.14) utilizando o pós-processador do programa OPERA-3D e utilizou-se a equação (3.21) para a corrente elétrica no indutor $i=52,2$ A. O valor obtido foi de 4,39 mT (Fig. 3.15).

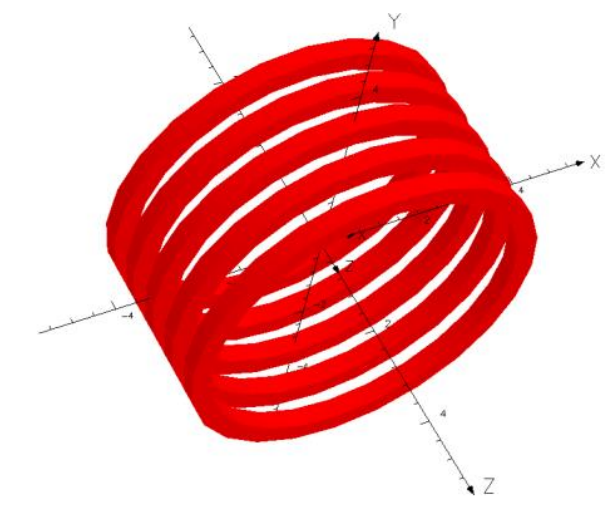

Figura 3.14. Simulação da bobina do circuito tanque como um arranjo de 5 espiras coaxiais usando o pós-processador OPERA 3-D para determinar a intensidade do campo magnético no centro dela.

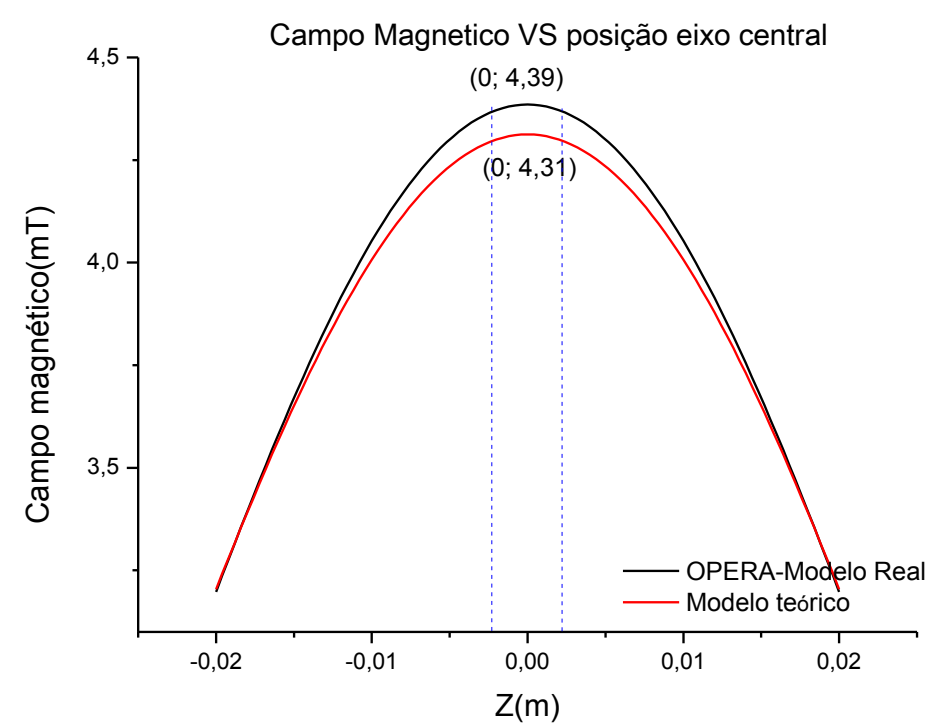

Figura 3.15. Intensidade do campo magnético $(G)$ no eixo central da bobina do circuito tanque usando o software Matlab 8,7 e o OPERA 3-D quando uma corrente de 52,25 A circula nos anéis. 
A Fig. 3.15 ilustra a dependência espacial do campo magnético ao longo do eixo da bobina, onde a faixa retangular pontilhada $[-2,5 ; 2,5] \mathrm{mm}$ é a zona do eixo central da bobina onde foram colocadas as amostras. Note-se que ambas as curvas dos campos magnéticos são muito próximas entre si.

\section{Teste qualitativo de aquecimento de materiais no centro da bobina}

Foram realizadas medidas preliminares de aquecimento com o circuito ressonante a fim de ilustrar e verificar a capacidade de nosso circuito em aquecer nanopartículas magnéticas.

Com a bobina de indução do circuito tanque, fez-se um teste colocando um pequeno alicate no seu interior. Notamos que o circuito começou a consumir mais corrente da fonte de alimentação, aquecendo o alicate em poucos segundos por ação das correntes parasitas. Veja a sequência a, b, c e d na Fig. 3.16.

Como pode ser observada na sequência das figuras, a corrente elétrica fornecida pela fonte aumenta consideravelmente ao introduzirmos mais material condutor dentro da bobina (ou seja, ao aumentar a indutância).

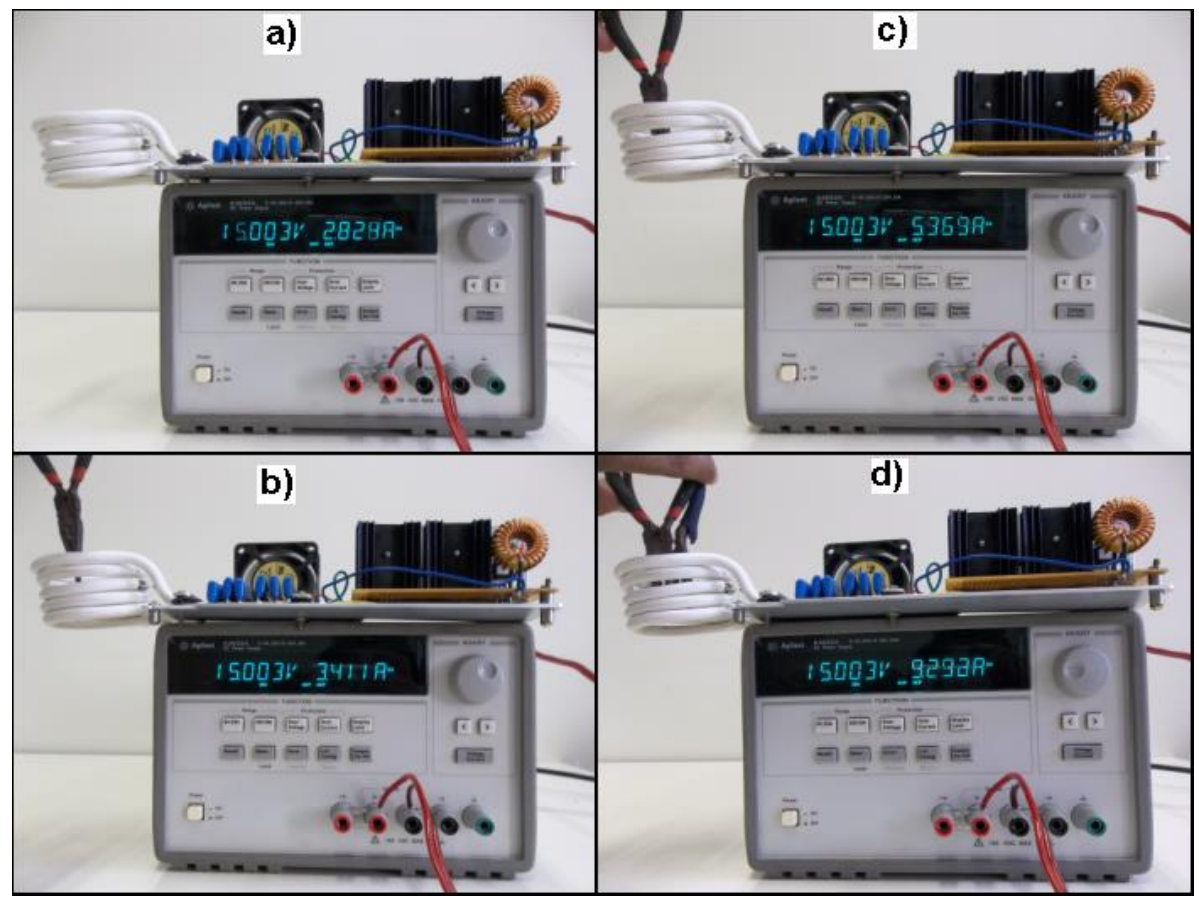

Figura 3.16. Mudança da corrente elétrica fornecida pela fonte de alimentação para cada caso. a) Circuito sem o alicate dentro b) Introduzindo uma parte do alicate. c) Introduzindo todo o alicate. d) Introduzindo dois alicates. 


\section{Resultados e Discussões}

\section{1}

\section{Produção de oxigênio singlete por MentaZnPc}

A eficiência fotodinâmica de um fotossensibilizante está associada à sua capacidade de produzir de oxigênio singlete sob iluminação com luz visível. O composto 1,3-difenilisobenzofurano (DPBF) é uma armadilha específica para oxigênio singlete. Neste trabalho o decaimento do espectro de absorção do DPBF foi utilizado como parâmetro para avaliar a produção de oxigênio singlete pelo fotossensibilizante.

\subsubsection{DBPF como sensor de oxigênio singlete}

\section{Estabilidade do DPBF em tampão e em etanol}

O composto 1,3-diphenylisobenzofuran (DPBF) foi diluído em diferentes meios a partir do estoque $4 \mathrm{mM}$ em etanol, mantido protegido da luz ambiente com papel alumínio. Os espectros de absorção ótica são apresentados na Fig. 4.1.

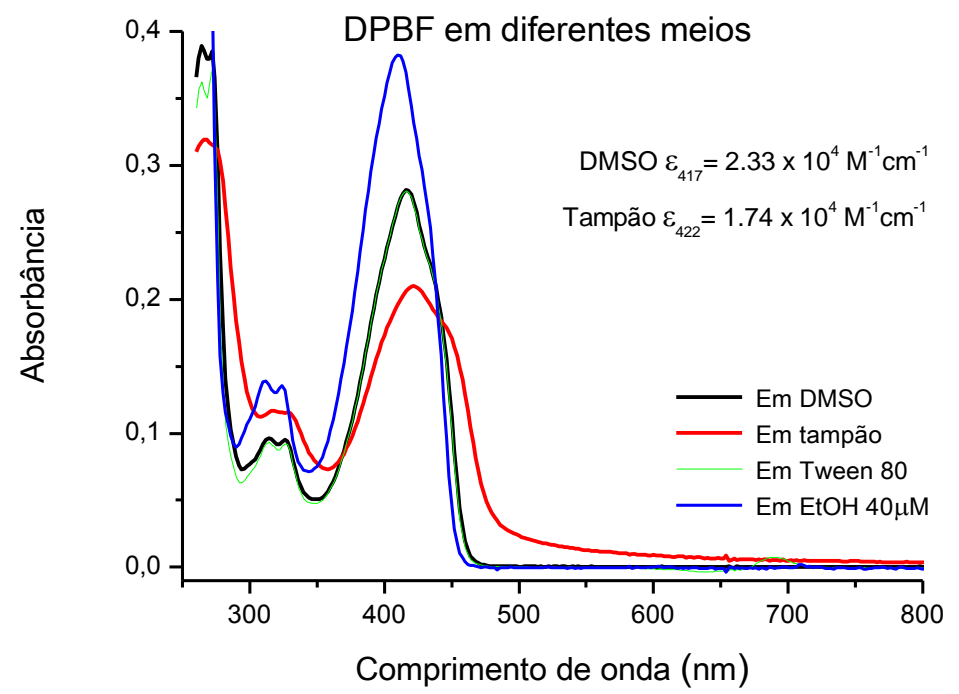

Figura 4.1. Espectros de absorção do DPBF em DMSO, Tween 80, etanol e tampão fosfato 20 $\mathrm{mM}, \mathrm{pH}$ 7,4. Medidas realizadas em ausência de luz ambiente. 
Foi obtido o coeficiente de absorção molar em tampão fosfato $20 \mathrm{mM} \mathrm{pH}$ $7,4, \varepsilon_{422}=1,74 \times 10^{4} \mathrm{M}^{-1} \mathrm{~cm}^{-1}$, calculado a partir do valor em DMSO, $\varepsilon_{417}=2,33$ $\times 10^{4} \mathrm{M}^{-1} \mathrm{~cm}^{-1}$ [Ogunsipe et al., 2003]. Observa-se que os espectros em DMSO e em Tween 80 são idênticos.

\section{Estabilidade de DPBF protegido e exposto à luz ambiente}

Para estudar a estabilidade do DPBF na luz ambiente do laboratório, tanto em tampão fosfato quanto em etanol, foram preparadas amostras pela dissolução de $15 \mu \mathrm{L}$ do nosso estoque de DPBF em 1,5 ml do respectivo solvente (cubetas com volume máximo de $2 \mathrm{ml}$ ). Logo após, foram registrados espectros em intervalos de 1 min. Os resultados são apresentados na Fig. 4.2.

As curvas de fotodegradação do DPBF em função do tempo para as duas amostras são apresentados na Fig. 4.3 e mostram que o DPBF em etanol é bem mais estável do que em tampão fosfato.

Repetiu-se a experiência anterior, protegendo-se da luz ambiente o compartimento da amostra no espectrofotômetro. Os resultados são mostrados na Fig. 4.4. Observa-se que, protegido da luz ambiente, o DPBF degrada bem menos. Decidimos então manter as amostras protegidas da luz ambiente durante os experimentos de fotodegradação. 

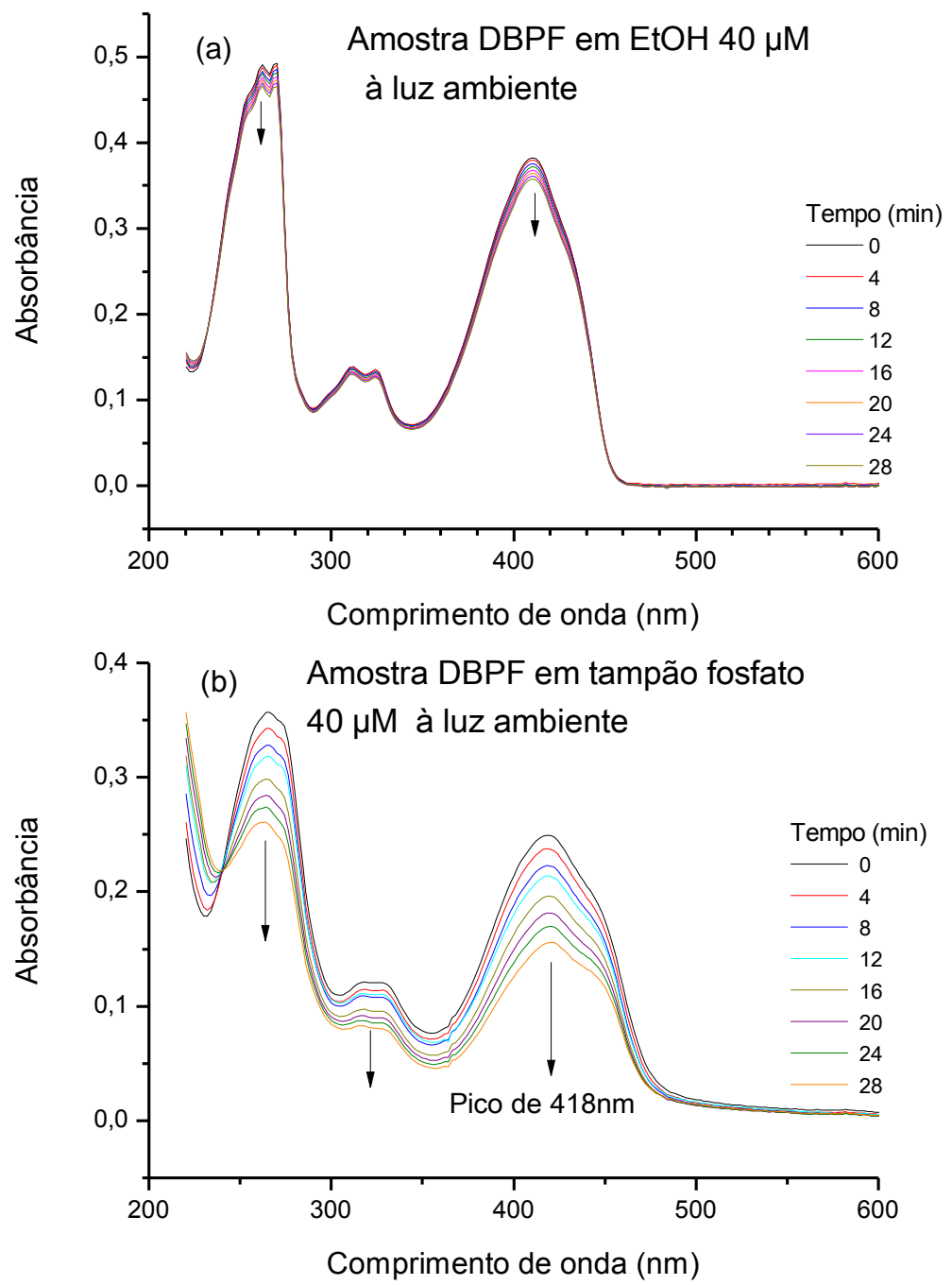

Figura 4.2. Espectros de absorção do DPBF em (a) etanol espectroscópico e (b) em tampão fosfato $\mathrm{pH} 7,4$. A concentração de DBBF na amostra foi $40 \mu \mathrm{M}$, exposto à luz ambiente.

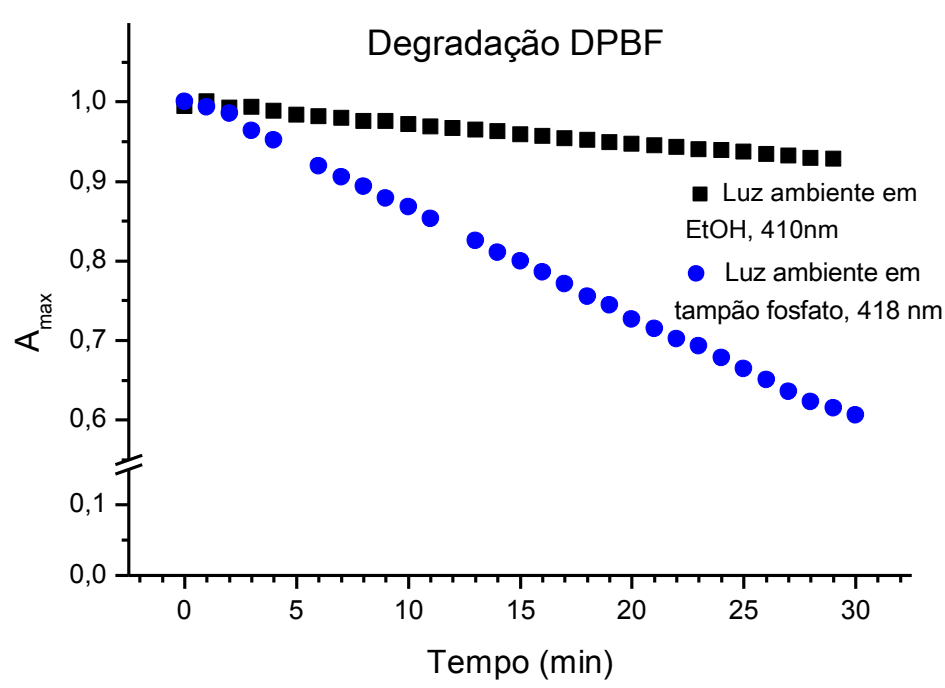

Figura 4.3. Absorbância correspondente ao pico do DPBF em função do tempo em luz ambiente. (匹) $410 \mathrm{~nm}(\mathrm{EtOH})$ ou $(\bullet) 418 \mathrm{~nm}$ (tampão fosfato $\mathrm{pH} 7,4)$. 

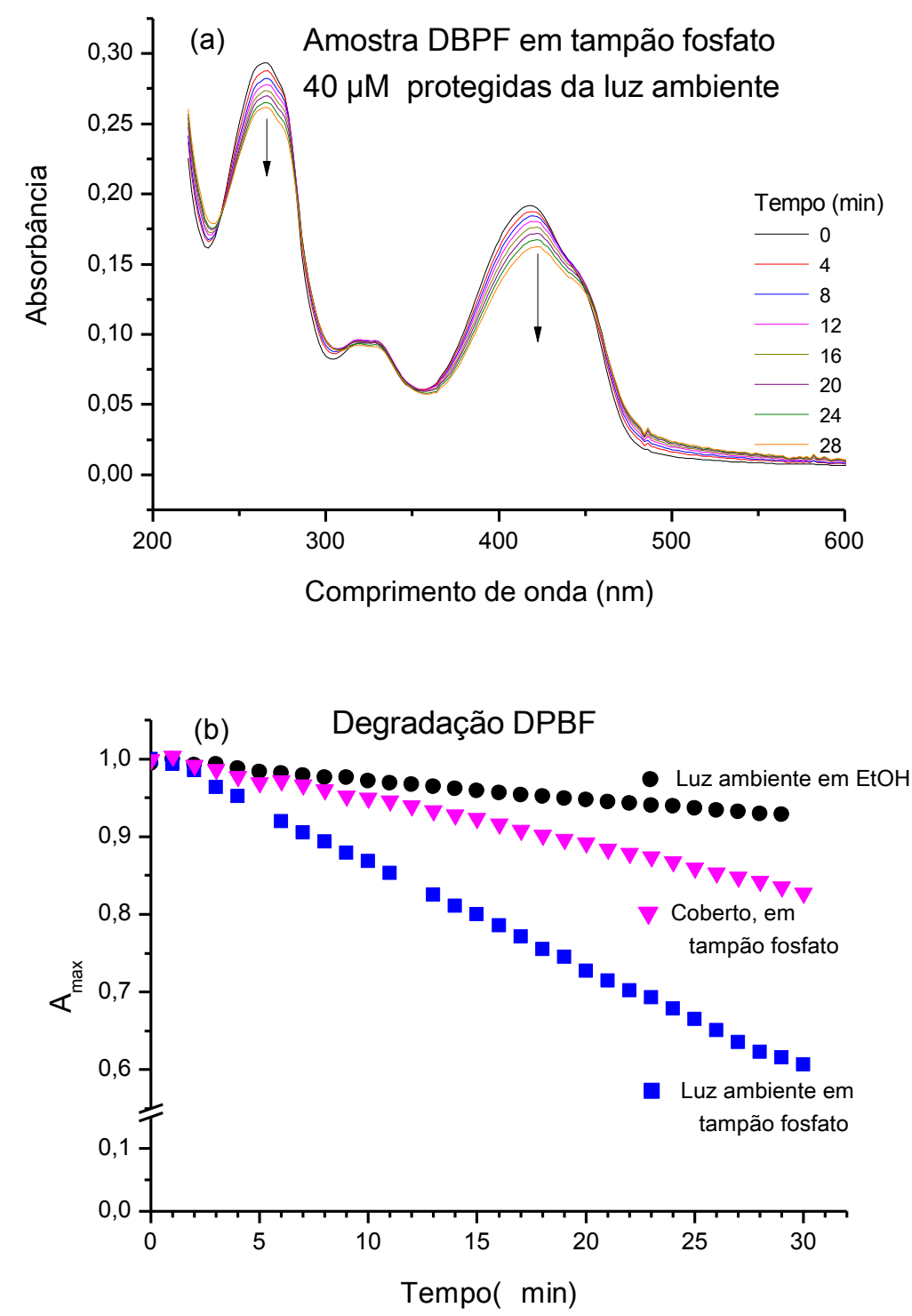

Figura 4.4. (a) Espectros de absorção do DPBF em tampão fosfato $\mathrm{pH} 7,4$, protegido da luz ambiente, em função do tempo. (b). Absorbância em $410 \mathrm{~nm}$, correspondente ao pico do DPBF, em função do tempo $(\nabla)$ em tampão com espectrofotômetro coberto. Os resultados da Fig. 4.3, à luz ambiente $(\bullet)$ em etanol e ( $\bullet$ ) em tampão fosfato também são apresentados, para comparação.

\section{Fotodegradação do DBPF sob luz vermelha (635 nm)}

Nesta experiência usou-se a lâmpada de LED's vermelhos, fazendo medidas com ela desligada e ligando-a em seguida. Os espectros são semelhantes aos da Fig. 4.4 (a). Este resultado e os resultados anteriores da variação temporal do pico do DPBF são mostrados na Fig. 4.5. Observa-se que o decaimento com iluminação vermelha é igual ao obtido em ausência de iluminação. Conclui-se que 
a luz vermelha não fotodegrada as moléculas de DPBF. Esse resultado era esperado, já que o DPBF não absorve luz nessa região do espectro (Fig. 4.1).

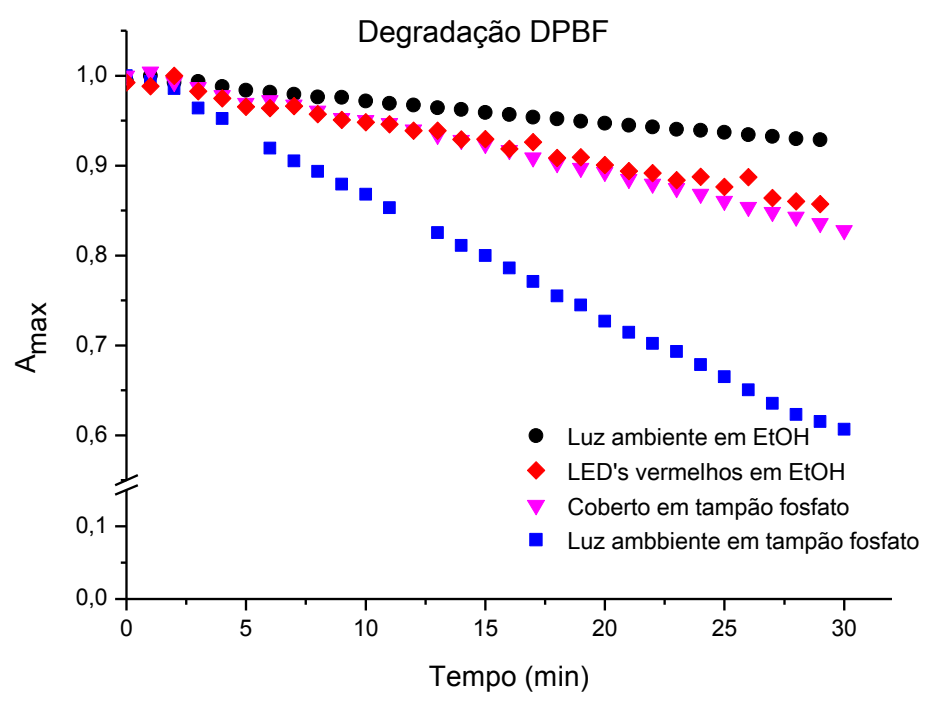

Figura 4.5. Absorbância em $410 \mathrm{~nm}$, correspondente ao pico do DPBF, em função do tempo. Comparação entre iluminação com luz ambiente, escuro e iluminação com luz vermelha de LEDs.

\subsection{2}

\section{Avaliação fotodinâmica de MentaZnPc utilizando DPBF}

O espectro de absorção de MentaZnPc em acetato de etila, EtOAc, é mostrado na Fig. 4.6. Os picos característicos do espectro UV-Vis localizam-se em 286, 350, 610, 680 e $722 \mathrm{~nm}$. O espectro é típico de espécies monoméricas. A banda de $680 \mathrm{~nm}$ é uma banda devido a monômeros. 


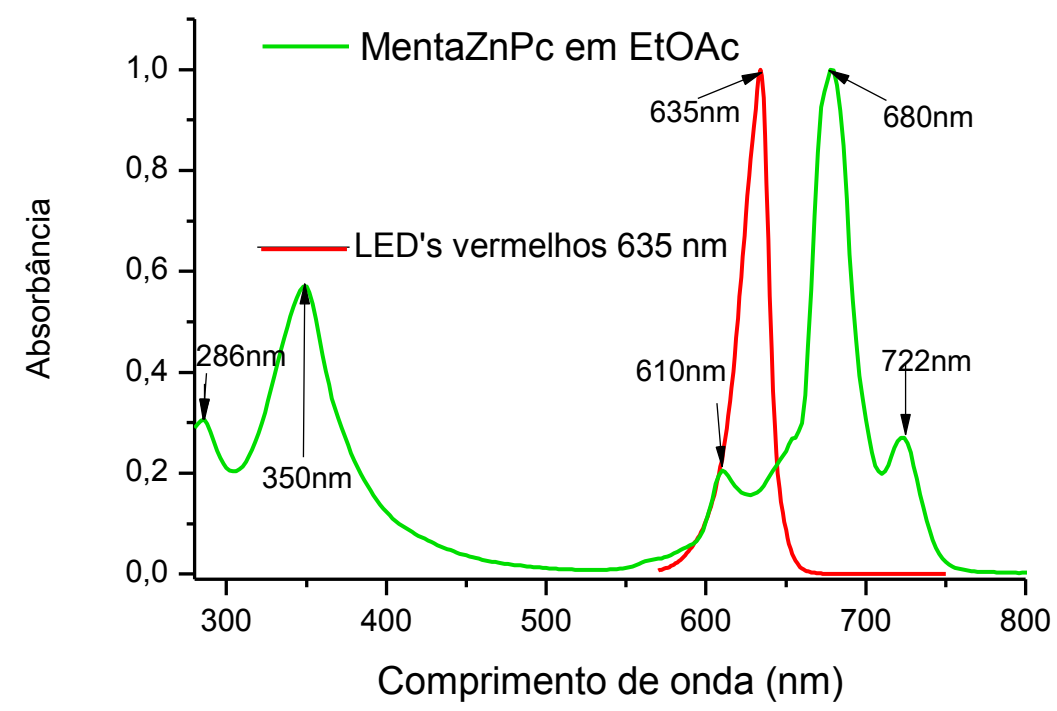

Figura 4.6. Espectro normalizado de absorção UV-Vis de MentaZnPc (6,6 $\mu \mathrm{M})$ em EtOAc (verde). Emissão da lâmpada vermelha, de LEDs (vermelho). Fonte: Tese María Paulina Romero Obando.

Em seguida, nós observamos a produção de ${ }^{1} \mathrm{O}_{2}$ por moléculas de MentaZnPc sequestradas no ambiente hidrofóbico do interior de micelas, sob iluminação vermelha. Utilizamos micelas do surfactante Tween 80, cuja CMC (12 $\mu \mathrm{M})$ é pequena, porque assim as micelas são formadas em concentrações baixas de surfactante. O Tween 80 é adequado do ponto de vista biológico, já que é usado até em alimentos e não é irritante aos olhos nem à pele.

Mediu-se a produção de ${ }^{1} \mathrm{O}_{2}$ adicionando às soluções micelares a sonda DPBF em concentração da ordem de $30 \mu \mathrm{M}$. O processo de fotodegradação foi explicado na Seção 3.3.3. Foram obtidos os espectros de absorção das soluções irradiadas em função do tempo (Fig. 4.7 a), e resultados de decaimento do pico em $412 \mathrm{~nm}$ em função do tempo são mostrados na Fig. 4.7 b.

Na Fig. 4.7 b, pode-se observar que, neste caso da solução de MentaZnPc em micelas de Tween 80, o decaimento do pico de $414 \mathrm{~nm}$, próprio do DPBF, tem a mesma tendência em ambas as concentrações. O decaimento do pico do DPBF foi ajustado por uma função exponencial do tipo $\mathrm{A}=\mathrm{A}_{1} \exp \left(-\left(\mathrm{t}-\mathrm{t}_{\mathrm{o}}\right) / \tau\right)+\mathrm{A}_{0}$, onde $\tau$ representa a constante de tempo, relacionada com a taxa de fotoxidação $\left(k_{p}=1 / \tau\right)$ de DPBF. As taxas de fotoxidação obtidas foram $\mathrm{k}_{\mathrm{p}}=3,7 \times 10^{-3} \mathrm{~s}^{-1}$ para [DPBF] $=15,49 \mu \mathrm{M}$ e $\mathrm{k}_{\mathrm{p}}=3,3 \times 10^{-3} \mathrm{~s}^{-1}$ para $[\mathrm{DPBF}]=20,86 \mu \mathrm{M}$. 

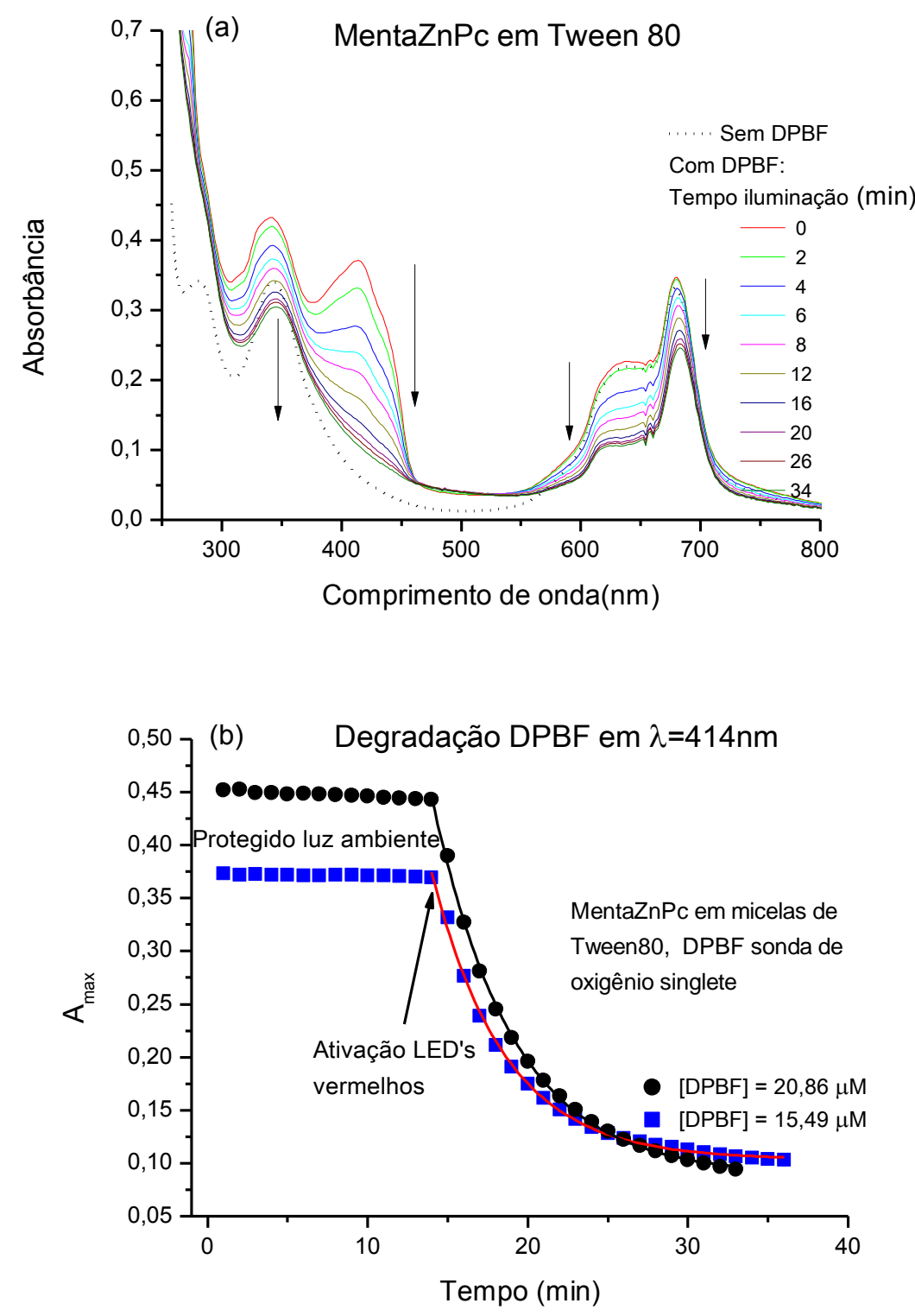

Figura 4.7. (a) Fotoxidação de DPBF $(\sim 30 \mu \mathrm{M})$ por irradiação com LED’s vermelhos na presença de MentaZnPc $(20 \mu \mathrm{M})$ em Tw80 (3 mM). (b) Decaimento da banda de $414 \mathrm{~nm}$ do DPBF na presença de MentaZnPc em micelas de Tw 80 para [DPBF] $=21 \mu \mathrm{M}$ e para [DPBF] $=15 \mu \mathrm{M}$. Linhas contínuas: ajustes exponenciais do decaimento do pico de $414 \mathrm{~nm}$ com a função $A=A_{1} \exp$ $\left(-\left(t-t_{0}\right) / \tau\right)+A_{0}$ e $\tau=4,51([D P B F]=15 \mu \mathrm{M})$ e $\tau=5,00 \min ([D P B F]=21 \mu \mathrm{M})$.

Na Fig. 4.7 a, observa-se que a região do espectro correspondente à MentaZnPc, entre 550 e $750 \mathrm{~nm}$, também decai com o tempo. Isso significa que a própria MentaZnPc é degradada por ${ }^{1} \mathrm{O}_{2}$. A Fig. 4.8 mostra o decaimento da absorção de MentaZnPc em dois diferentes comprimentos de onda: em $680 \mathrm{~nm}$, característico de monômeros, e em $636 \mathrm{~nm}$, com contribuição predominante de 
agregados. O decaimento mais rápido em $636 \mathrm{~nm}$ sugere que os agregados são mais facilmente degradados.

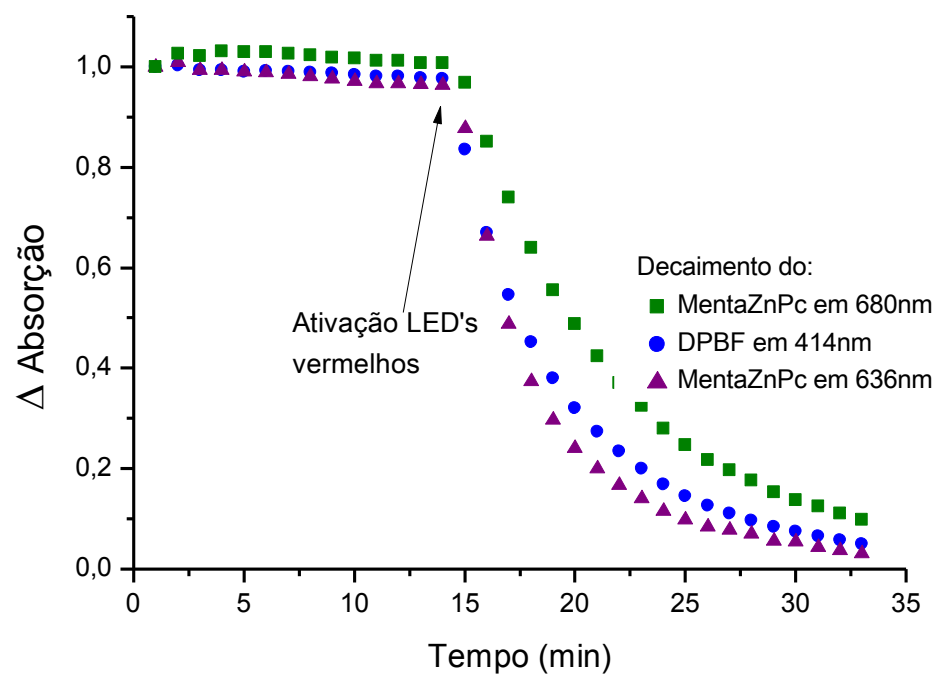

Figura 4.8. Curvas de decaimento do espectro de absorção de MentaZnPc em função do tempo. $(\boldsymbol{\nabla})$ Decaimento no pico de $636 \mathrm{~nm}$ e $(\square)$ decaimento no pico de $680 \mathrm{~nm}$ tempo. Os pontos azuis (•) correspondem ao decaimento de DPBF em $414 \mathrm{~nm}$, para comparação.

\section{2}

\section{Funcionalização das Nanopartículas}

Desenvolvemos um revestimento para as partículas magnéticas que pode ser facilmente carregado com fármacos insolúveis em água. A formulação é baseada na hidrofobização das nanopartículas com ácido oleico e recobrimento com o surfactante não iônico Tween 80. O fármaco insolúvel em água é solubilizado na camada hidrofóbica formada pelas caudas das moléculas de ácido oleico que recobre a nanopartícula. Ao adicionar Tween 80, as caudas hidrofóbicas completam o ambiente apolar da camada que envolve as nanopartículas enquanto as cabeças hidrofílicas conferem dispersibilidade em meio aquoso.

\subsubsection{Associação do fotossensibilizante hidrofóbico MentaZnPc a nanopartículas hidrofobizadas com ácido oleico}

Foi observado que o fotossensibilizante hidrofóbico MentaZnPc solubilizase bem em ácido oleico. Então uma solução em ácido oleico desse 
fotossensibilizante foi utilizada para hidrofobizar as nanopartículas magnéticas. Foi utilizada uma solução 3,00 mM de MentaZnPc em ácido oleico, preparada a partir do estoque de MentaZnPc em EtOAc, secando-se o solvente. Nessa solução, a relação molar:

$$
\frac{[O A]}{[\text { MentaZnPc }]} \sim 1000
$$

Desta solução 3,00 mM MentaZnPc/OA, 12 $\mu \mathrm{L}$ foram adicionados a $24 \mathrm{mg}$ de nanopartículas de óxido de ferro. Em seguida foram acrescentados $2 \mathrm{~mL}$ de etanol e deixou-se a mistura de um dia para outro. Em seguida, a mistura foi aquecida à temperatura de $50^{\circ} \mathrm{C}$ em estufa por uma hora. Após o processo, mediante um imã, aplicou-se separação magnética, recolhendo-se o líquido restante num primeiro frasco. As nanopartículas atraídas pelo imã foram lavadas com $2 \mathrm{~mL}$ de etanol e submetidas a ultrassom por 15 segundos. Aplicou-se novamente separação magnética, recolhendo-se o líquido em outro frasco. Como o líquido retirado já tinha uma cor clara, não houve necessidade de outra lavagem. As nanopartículas recolhidas pelo imã foram secadas com nitrogênio, e colocadas em vácuo.

A quantidade de MentaZnPc ligada à camada de ácido oleico recobrindo as nanopartículas foi avaliada por subtração. Mediu-se a concentração de MentaZnPc nos líquidos das duas lavagens, a partir dos espectros de absorção (Fig. 4.9), e obteve-se a quantidade que não se ligou às nanopartículas.

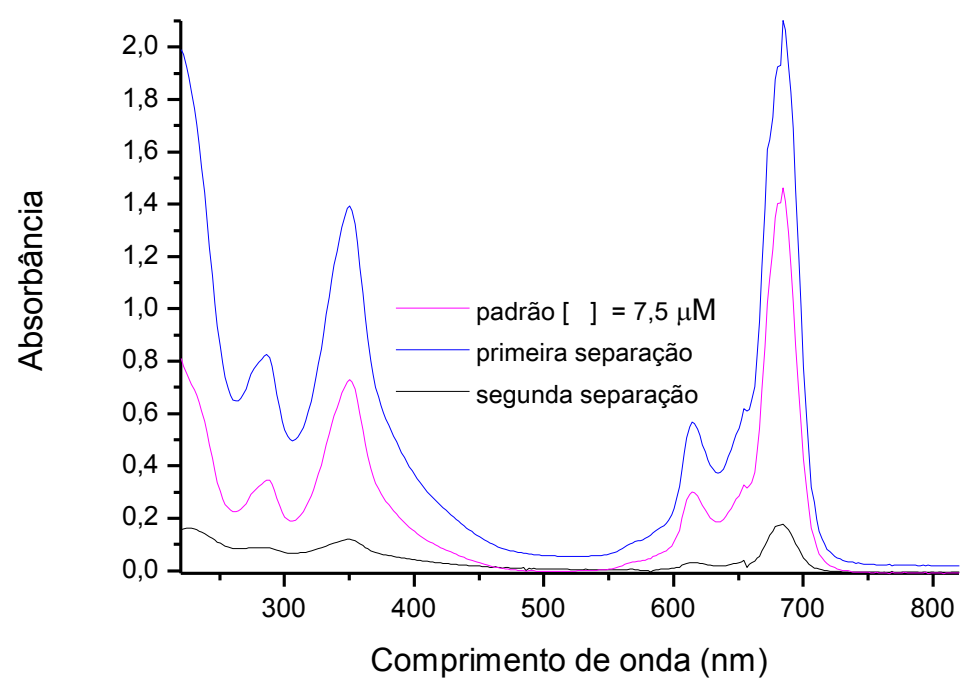

Figura 4.9. Espectros de absorção dos líquidos sobrenadantes, produto da hidrofobização das nanopartículas de $\mathrm{Fe}_{3} \mathrm{O}_{4}$. 
Para calcular a quantidade de MentaZnPc nas soluções, foram utilizados os picos em $350 \mathrm{~nm}$ e $614 \mathrm{~nm}$. O total de mols em solução foi 20,4 nmols. Como o total de MentaZnPc adicionado foi de 36 nmols, conclui-se que $43 \%$ do total se associaram às nanopartículas, localizando-se na camada de ácido oleico que as hidrofobiza. Como as partículas estão já hidrofobizadas, para que possam ser diluídas em meio aquoso devemos acrescentar um surfactante. Isso foi realizado em outra preparação, descrita a seguir.

\subsubsection{Nanopartículas magnéticas funcionalizadas para dispersão em meio aquoso}

Para aumentar ainda mais a quantidade de MentaZnPc na superfície da nanopartícula, preparou-se uma solução $6 \mathrm{mM}$ em ácido oleico $(600 \mu \mathrm{L}$ do estoque 1,00 mM em EtOAc, seca-se o EtOAc e acrescenta-se $100 \mu \mathrm{L}$ de ácido oleico: relação molar MentaZnPc:OA = 1:500). A relação OA: nanopartícula foi mantida $(24 \mu \mathrm{L}$ para $50 \mathrm{mg}$ de nanopartículas secas). Essa amostra agora foi colocada em ultrassom (probe, 20 min ao todo em modo alternado on/off, com intervalos de $10 \mathrm{~s}$ ), atingindo temperatura $\sim 50 \mathrm{C}$ no processo e também foi lavada duas vezes com $2 \mathrm{~mL}$ de etanol. Após separação magnética, recolhendo-se o etanol em cada lavagem, obteve-se aproximadamente a mesma fração de MentaZnPc associada a nanopartículas que na preparação anterior $(\sim 40 \%)$.

As nanopartículas recolhidas pelo imã foram divididas em 2 partes (acrescentando-se $\sim 100 \mu \mathrm{L}$ de etanol, e secando-se com nitrogênio e vácuo por aproximadamente 10 minutos). Adicionou-se então Tween 80 a uma das frações (4,6 x quantidade em massa de OA aderido às nanopartículas, para manter a mesma fração molar) para formar a camada que permite ressuspender em meio aquoso. A Fig. 4.10 ilustra resumidamente este processo:

Alíquotas dessa mistura são diluídas em solução aquosa para formar as suspensões para medidas de absorção e testes de fotossensibilização (concentração $25 \mathrm{mg} / \mathrm{mL})$. 


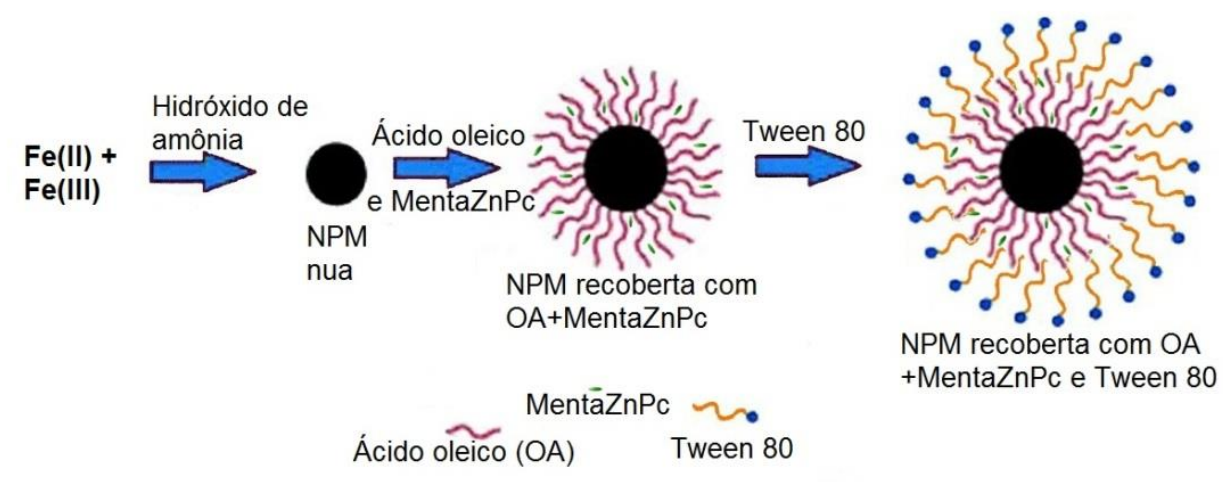

Figura 4.10. Esquema mostrando a fabricação e funcionalização das nanopartículas magnéticas.

\section{3 \\ Ensaios de aquecimento por relaxação magnética para dispersão aquosa de magnetita $\mathrm{Fe}_{3} \mathrm{O}_{4}$}

Quando se aplica um campo magnético alternado às nanopartículas magnéticas, o calor gerado está relacionado ao seu relaxamento Néel, já que as rápidas variações na direção dos momentos magnéticos causadas pelo campo magnético alternado são dificultadas pela energia de anisotropia, que tende a alinhar os momentos magnéticos da nanopartícula numa dada direção preferencial de acordo com sua estrutura cristalina. Por outro lado, o mecanismo relacionado ao relaxamento Browniano é devido à rotação física das partículas imersas no líquido, dificultada por sua viscosidade que tenta conter a rotação das partículas.

Foram realizadas medidas de aquecimento de nanopartículas de $\mathrm{Fe}_{3} \mathrm{O}_{4} \mathrm{em}$ meio aquoso com nosso circuito ressonante.

Foram usados 3 frascos contendo diferentes concentrações de nanopartículas de $\mathrm{Fe}_{3} \mathrm{O}_{4} \mathrm{em}$ água. Para isolar da transferência externa de calor, as amostras foram colocadas dentro da bobina protegidas com um pequeno tubo de isopor. As dimensões utilizadas dos frascos e do isopor são mostradas na Tabela 4.1.

A Fig. 4.11 exibe as dimensões do porta amostra para o sistema de temperatura utilizado para as nanopartículas colocadas dentro da bobina, com o porta amostra construído em acrílico, ponto de fusão $=130^{\circ} \mathrm{C}$. 
Tabela 4.1. Dimensões físicas do frasco e isopor utilizados para a experiência do aquecimento das nanopartículas.

\begin{tabular}{lcc}
\hline Medidas em mm & Frasco & Isopor \\
\hline Diâmetro ext. & 11,65 & 40,8 \\
Diâmetro int. & 10,05 & 23,0 \\
Espessura & 0,80 & 8,9 \\
Altura & 3,20 & 86,0 \\
\hline
\end{tabular}
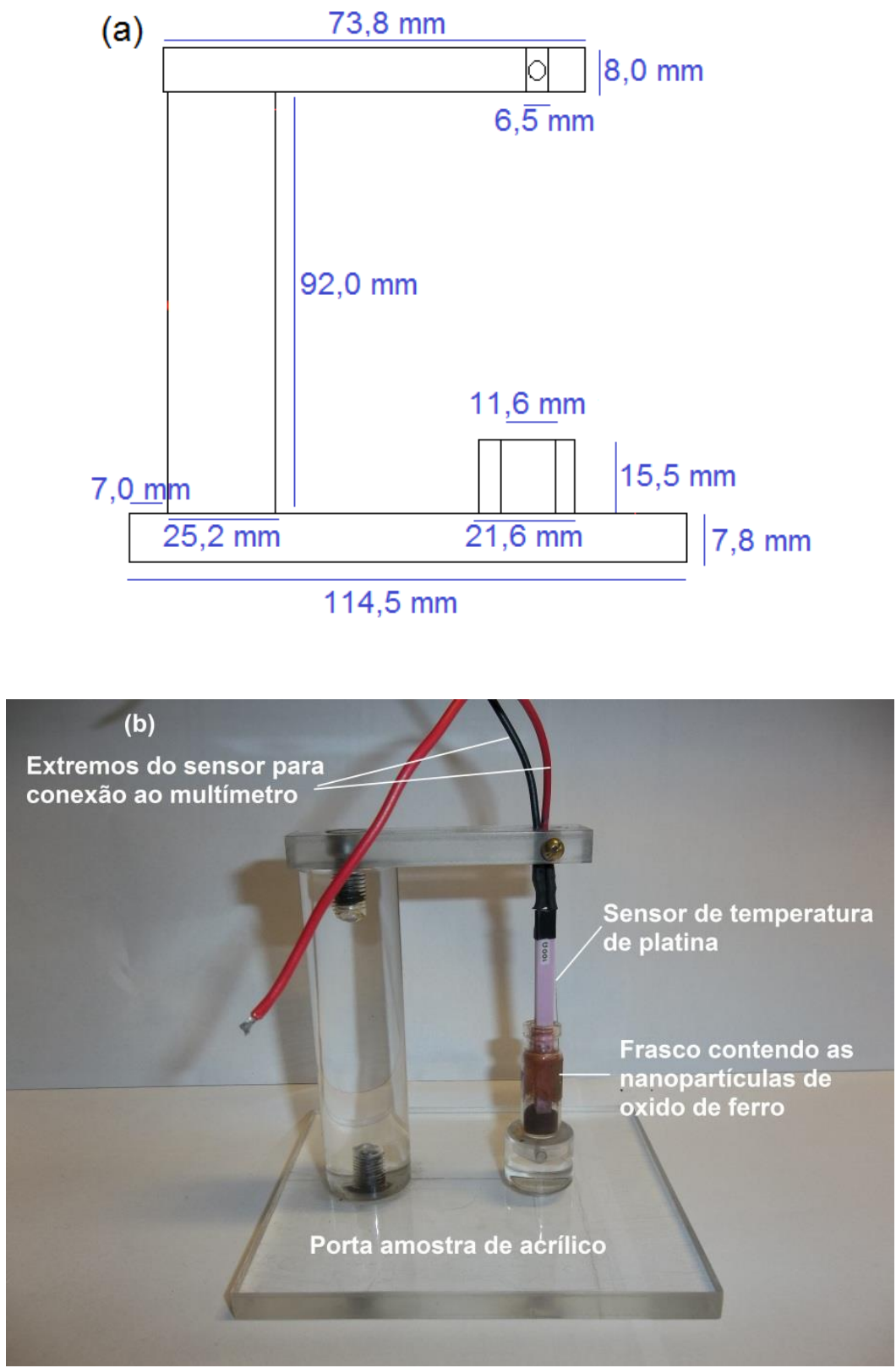

Figura 4.11. (a) Dimensões do porta amostra utilizado para o aquecimento das NP's em meio aquoso. (b) Foto do porta amostra contendo o sensor de temperatura e a amostra. 
Foram feitos testes com três frascos contendo volumes diferentes de água e nanopartículas, segundo mostrado na Tabela 4.2. Foram testadas várias configurações utilizando o isopor e sem utilizá-lo, medindo-se a temperatura com o sensor de platina colocado no centro da bobina e a meia altura, posição de máxima intensidade do campo magnético.

\section{Aquecimento de nanopartículas em água para diferentes concentrações}

O banco de capacitores do circuito foi alterado de forma a operar com duas frequências $100 \mathrm{kHz}$ e de $89 \mathrm{kHz}$. O intervalo de tempo considerado nas medidas foi de $300 \mathrm{~s}$.

Tabela 4.2. Configurações testadas para ilustrar o aquecimento das amostras devido ao campo magnético ressonante e não por transferência de calor por agentes externos

\begin{tabular}{cccc}
\hline & Volume água $(\mu \mathrm{L})$ & Massa NPs $(\mathrm{g})$ & Concentração $(\mathrm{g} / \mathrm{L})$ \\
\hline Amostra1 & 150 & 0,145 & 967 \\
Amostra2 & 200 & 0,290 & 1450 \\
Amostra3 & 300 & 0,435 & 1450 \\
\hline
\end{tabular}

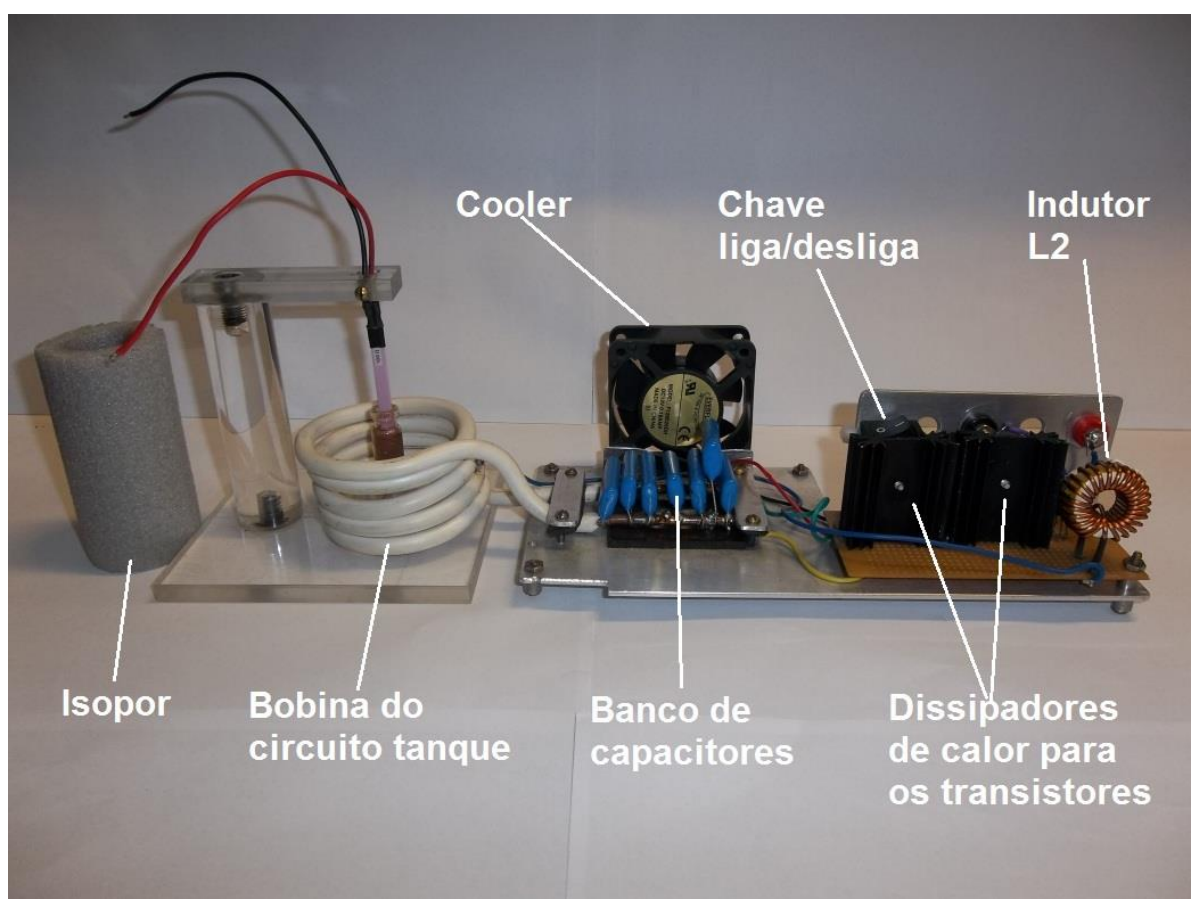

Figura 4.12. Montagem do circuito para medir a variação de temperatura das nanopartículas em meio aquoso. Veja-se no lado esquerdo o tubo de isopor usado para isolar as amostras de variações de temperatura causadas por agentes externos. 
As configurações utilizadas para a evolução temporal da temperatura das nanopartículas magnéticas submetidas ao campo magnético ressonante foram as seguintes:

Banco de capacitores configurado para que $\mathrm{f}=100 \mathrm{kHz}$ :

- Frascos 1,2 e 3 contendo água, dentro da bobina, sem usar o isopor, para uma altura $\mathrm{H}=2,9 \mathrm{~cm}$ e no centro $(1,5 \mathrm{~cm})$.

- Frascos 1, 2 e 3 contendo água, dentro da bobina, usando o isopor, para uma altura $\mathrm{H}=2,9 \mathrm{~cm}$ e no centro $(1,5 \mathrm{~cm})$.

- Frascos 1, 2 e 3 contendo as nanopartículas imersas em água, dentro da bobina, sem usar o isopor, para uma altura $\mathrm{H}=2,9 \mathrm{~cm}$ e no centro $(1,5 \mathrm{~cm})$.

- Frascos 1, 2 e 3 contendo as nanopartículas imersas em água, dentro da bobina, usando o isopor, para uma altura $\mathrm{H}=2,9 \mathrm{~cm}$ e no centro $(1,5 \mathrm{~cm})$.

Repetiu-se o mesmo procedimento para a configuração de banco de capacitores que alterasse a frequência de ressonância para $89 \mathrm{kHz}$. Os resultados obtidos mostram que a melhor configuração foi obtida usando uma frequência de $89 \mathrm{kHz}$ com campo magnético máximo de 4,39 mT. 

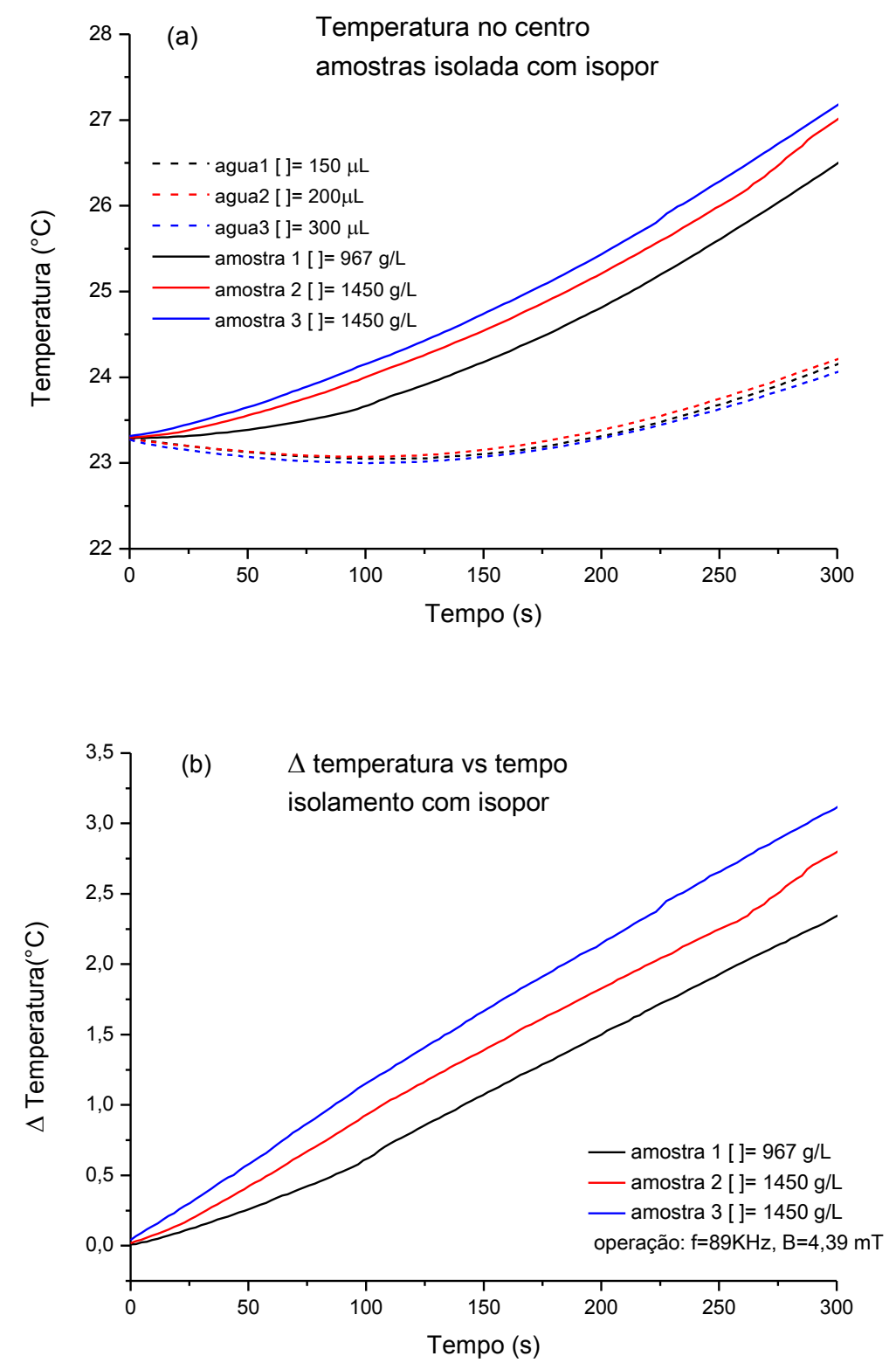

Figura 4.13. (a) Evolução temporal da temperatura para amostras aquosas de nanopartículas (linhas contínuas) e para amostras contendo apenas água (linhas pontilhadas), com o circuito operando. (b) Diferença entre as temperaturas das amostras com nanopartículas e apenas com água. Em ambos os casos a frequência foi $\mathrm{f}=89 \mathrm{kHz}$, o campo magnético alternado máximo foi $4,39 \mathrm{mT}$, e as amostras foram protegidas do ambiente com isopor.

Na Fig. 4.13 (a) pode se observar o notório incremento de temperatura (linhas contínuas) em comparação ao mesmo volume de água utilizado sem as nanopartículas (linhas pontilhadas), correspondente à frequência de $89 \mathrm{kHz}$. Em (b) temos a diferença entre as curvas de variação de temperatura das amostras com e sem nanopartículas. Nesse caso podemos observar diretamente a variação linear 
da temperatura com o tempo, para cada concentração das amostras, dando aproximadamente uma variação de $3,3{ }^{\circ} \mathrm{C}$ em 5 minutos.

Para uma comparação adicional, fez-se uma medida em um ferrofluido da Ferrotec Corporation (USA) composto de 15\% de magnetita, $25 \%$ de óleo dispersante e $60 \%$ de água por volume. Para este fim, foram utilizados $0,300 \mathrm{~g}$ do ferrofluido a uma frequência de $89 \mathrm{kHz}$ para o mesmo campo de 4,39 mT. O gráfico obtido ilustra-se na Fig. 4.14, onde podemos observar um maior incremento de temperatura de $6,5^{\circ} \mathrm{C}$ no ferrofluido em 5 minutos em comparação às nanopartículas feitas no laboratório.

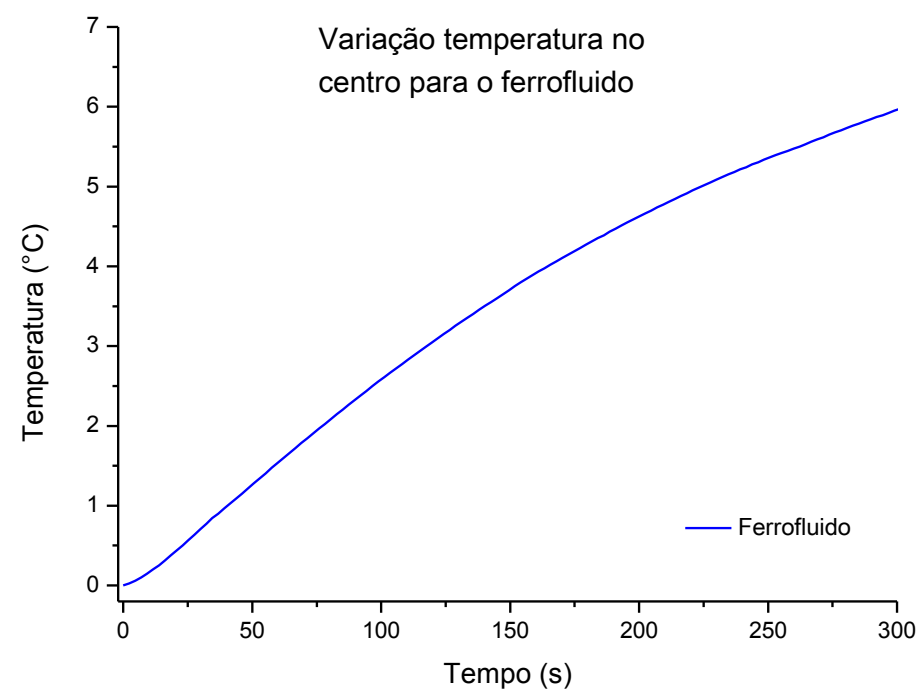

Figura 4.14. Variação da evolução temporal da temperatura para o ferrofluido quando submetido ao campo externo alternado máximo de 4,39 $\mathrm{mT}$.

\section{4}

\section{Influência de campo magnético $A C$ na produção de oxigênio singlete}

Nesta parte pretende-se avaliar a influência da temperatura na produção de oxigênio singlete produzido por MentaZnPc, detectado com DPBF. Vamos aumentar a temperatura aplicando ultrassom à MentaZnPc em amostras micelares. Vamos também aumentar localmente a temperatura das nanopartículas aplicando o campo magnético AC. 


\section{Avaliação fotodinâmica de MentaZnPc em nanopartículas hidrofobizadas}

Vamos avaliar a produção de ${ }^{1} \mathrm{O}_{2}$ por MentaZnPc na superfície de nossas nanopartículas hidrofobizadas, sob iluminação com luz vermelha, utilizando a absorção de DPBF. Inicialmente, foi avaliado o decaimento da absorção de DPBF na ausência de MentaZnPc associada às nanopartículas. Foram adicionados à cubeta $20 \mu \mathrm{l}$ do estoque de DPBF 4,0 mM em $3 \mathrm{ml}$ de água e foram tomados espectros de absorção em intervalos de 1 min com a luz vermelha ligada. A Fig. 4.15 (Decaimento 1) mostra alguns desses espectros.

Em seguida, foram adicionados $5 \mu \mathrm{l}$ da suspensão das nanopartículas funcionalizadas com MentaZnPc (OA/MentaZnPc/Tw80, concentração $25 \mathrm{mg}$ $\mathrm{NP} / \mathrm{mL}$, Seção 4.2.2) e $5 \mu 1$ da solução de MentaZnPc/OA 6mM. Observa-se na Fig. 4.15 (curva azul) absorção e espalhamento devido às nanopartículas e a aparição de um pequeno pico em 684 nm, característico de MentaZnPc. Não é possível aumentar muito a concentração de nanopartículas por causa da sua forte absorção em toda a faixa UV-Visível. Em seguida, observou-se o decaimento do pico de DPBF (Decaimento 2), indicando produção de oxigênio singlete.

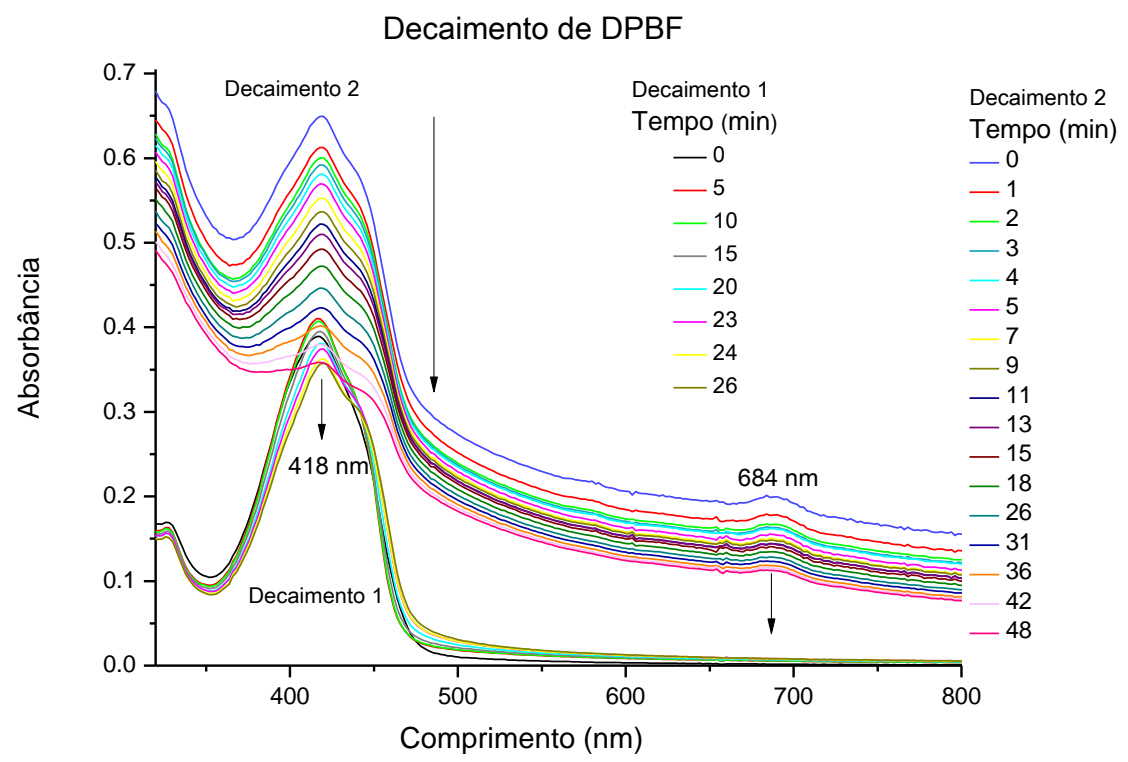

Figura 4.15. Fotoxidação de DPBF $(\sim 26,7 \mu \mathrm{M})$ em tampão fosfato $\mathrm{pH} 7,4$, na presença de nanopartículas magnéticas de óxido de ferro hidrofobizadas em micelas de Tw80. 


\section{Avaliação fotodinâmica de MentaZnPc em micelas: efeito da temperatura}

Como as NPs atrapalham o processo de absorção da luz vermelha por MentaZnPc devido ao efeito de sombra e ao espalhamento, vamos fazer a análise da influência da temperatura na ausência de nanopartículas, aquecendo a amostra com aplicação de ultrassom fisioterápico.

O aparelho utilizado é um sonicador II, modelo ME 702, utilizado em terapia ultra-sônica. Foram utilizadas soluções micelares de MentaZnPc/OA 6 mM e Tw80 (1:4, em massa) solubilizadas em água. Adicionaram-se alíquotas da solução MentaZnPc / OA / Tw80 a 3 ml de água ultrapura.
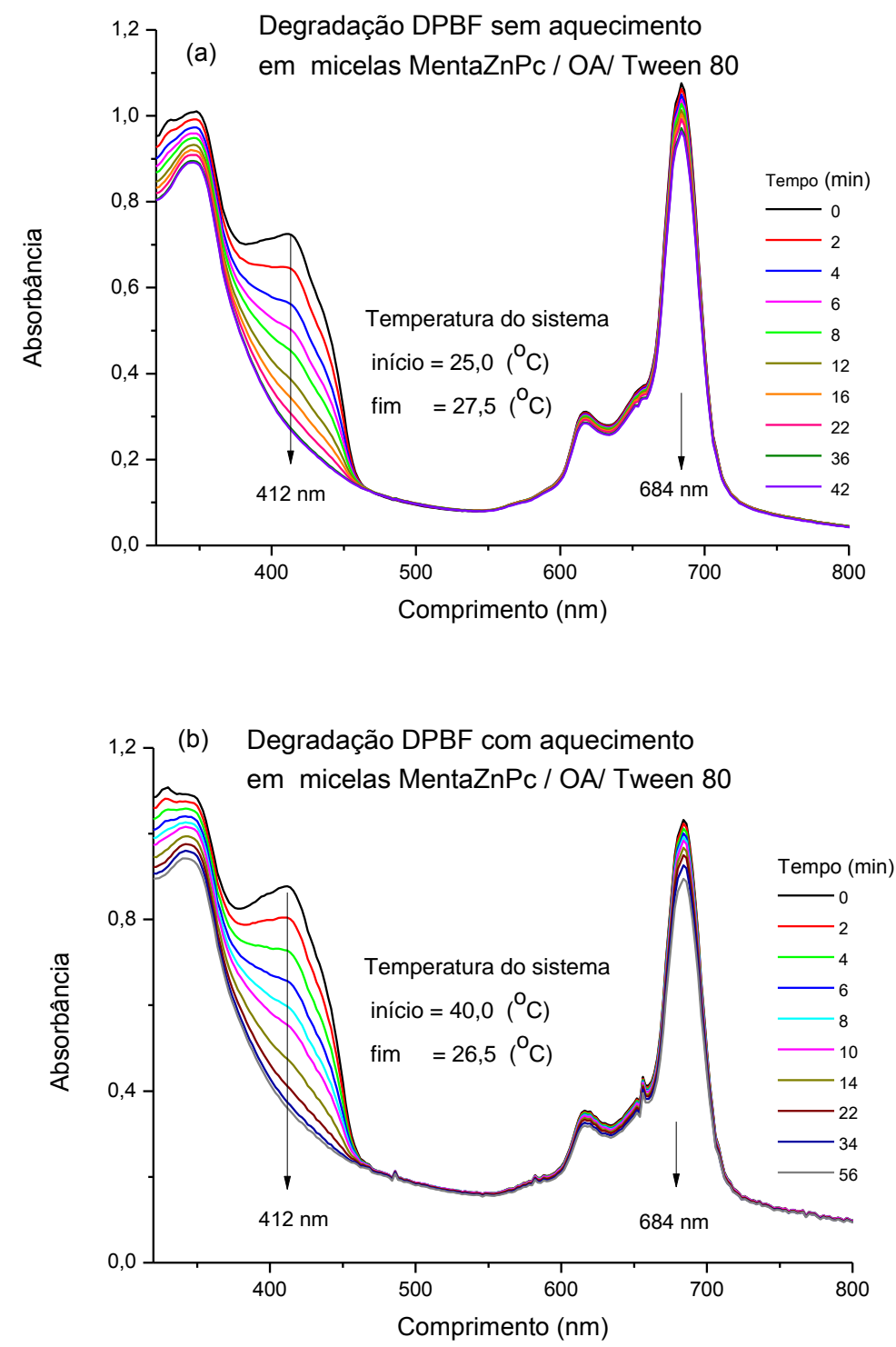

Figura 4.16. Espectros de absorção de DPBF para (a) amostra contendo MentaZnPc / OA / Tween 80 em água ultrapura, sem aplicação de ultrassom, e (b) mesma amostra aplicando sonicação antes de adicionar o DPBF. Todas as experiências foram à exposição com luz vermelha. 
Para a avaliação fotodinâmica utilizou-se DPBF e manteve-se acesa a luz vermelha. Para medida da temperatura com o sensor de platina. Os resultados são mostrados na Fig. 4.16, obtidos em temperatura ambiente (a) e após aquecimento por sonicação (b).

O resultado do decaimento do pico em 412 nm é mostrado na Fig. 4.17.

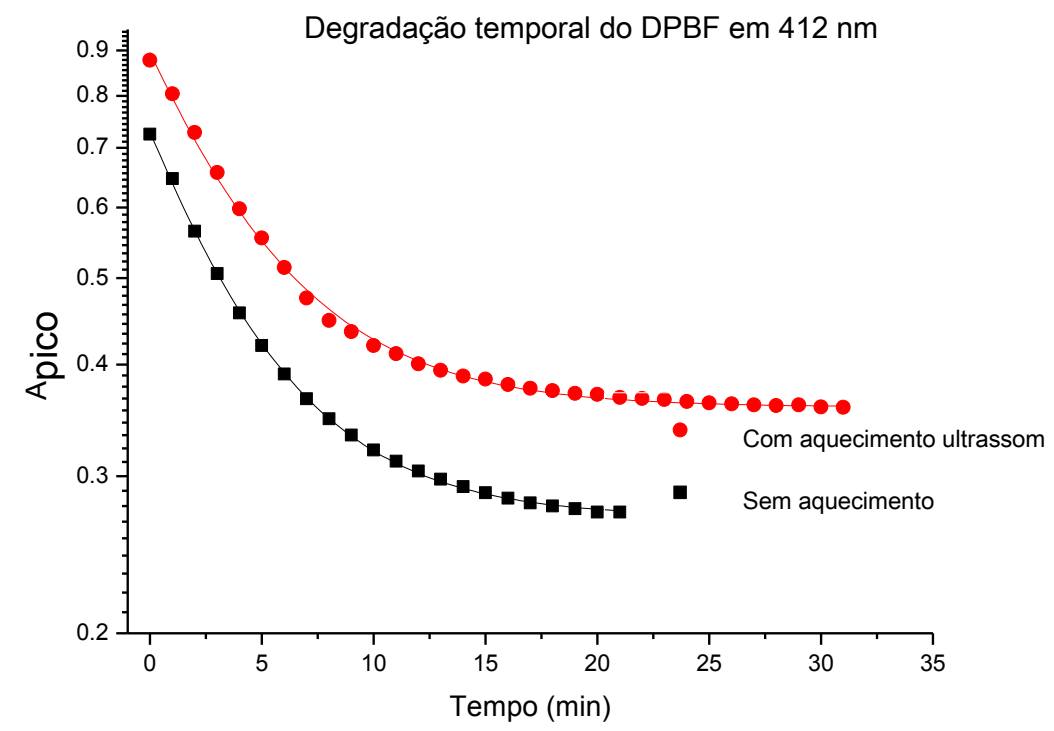

Figura 4.17. Decaimento da banda de $412 \mathrm{~nm}$ do DPBF na presença de MentaZnPc / OA / Tween 80 para medidas sem aquecimento (curva preta) e aplicando ultrassom para aquecimento inicial a $40^{\circ} \mathrm{C}$ (linha vermelha).

$\mathrm{Na}$ Fig. 4.17, fizeram-se ajustes exponenciais do decaimento do pico de $412 \mathrm{~nm}$, próprio do DPBF. O decaimento do pico de DPBF foi ajustado por uma função exponencial do tipo $\mathrm{A}=\mathrm{A}_{1} \exp \left(-\left(\mathrm{t}-\mathrm{t}_{0}\right) / \tau\right)+\mathrm{A}_{0}$, onde $\tau$ representa a constante de tempo, relacionada com a taxa de fotoxidação $\left(\mathrm{k}_{\mathrm{p}}=1 / \tau\right)$ de DPBF. As taxas de fotoxidação obtidas para as experiências sem aplicação de ultrassom foram $\mathrm{k}_{\mathrm{p}}=3,69 \times 10^{-3} \mathrm{~s}^{-1} \mathrm{e}$ com aplicação de ultrassom $\mathrm{k}_{\mathrm{p}}=3,44 \times 10^{-3} \mathrm{~s}^{-1}$. Conclui-se que o aumento de temperatura produzido pela aplicação de ultrassom não modificou significativamente a produção de oxigênio singlete. 


\section{Conclusões}

Neste trabalho, sintetizamos nanopartículas magnéticas de óxido de ferro com diâmetros da ordem de $10 \mathrm{~nm}$, pelo método de coprecipitação, para aplicação em distribuição de fármacos.

Desenvolvemos um revestimento de ácido oleico e Tween 80, capaz de carregar fármacos insolúveis em água, mantendo as nanopartículas dispersíveis em água (Fig. 4.10). Esta formulação pode ser utilizada como transportador de fármacos para administração sistêmica, possibilitando ao mesmo tempo direcionamento magnético.

Dentre fármacos insolúveis em meio aquoso encontram-se agentes anticancerígenos e fotossensibilizantes usados em terapia fotodinâmica. Escolhemos um fotossensibilizante derivado da ftalocianina, MentaZnPc, para adicionar à camada hidrofóbica da cobertura das nanopartículas. Utilizamos uma razão molar de MentaZnPc:ácido oleico 1:500. Calculamos em 18\% em massa a camada de MentaZnPc-ácido oleico associada às nanopartículas. Para dispersar em meio aquoso essas nanopartículas hidrofóbicas foi adicionado o surfactante Tween 80 na mesma proporção molar que o ácido oleico.

Mediante aplicação de campo magnético alternado, as nanopartículas magnéticas geram calor. Este aumento de temperatura pode modificar localmente a taxa de liberação de fármacos localizados na cobertura da MNP. Construímos um circuito eletrônico ressonante utilizando componentes eletrônicos básicos, o qual resultou prático. A corrente foi fornecida por uma fonte de alimentação operando em 15 V e corrente máxima de 10A. Este circuito oscila em ressonância, em frequências da ordem de $100 \mathrm{kHz}$, e gera campos magnéticos da ordem de $4 \mathrm{mT}$.

Foram realizados cálculos do campo magnético gerado pela bobina do circuito utilizando dois modelos, com resultados muito próximos entre si (discrepância de 1,7\%, Fig. 3.15). 
Usando o circuito construído, operando em duas frequências diferentes (100 e $89 \mathrm{kHz}$ ), conseguimos medir o aumento de temperatura produzido em soluções contendo diferentes concentrações de nanopartículas de óxido de ferro.

Para testarmos a produção de oxigênio singleto por MentaZnPc utilizamos DPBF como sonda. Seu pico de absorção na faixa visível desaparece ao reagir com oxigênio singlete. Vários testes de fotodegradação desse sensor foram realizados para utilização adequada. Foi necessário trabalhar em ambiente protegido da iluminação natural, iluminando-se apenas com luz vermelha, pois esta sensibiliza as ftalocianinas sem fotodegradar diretamente as moléculas de DPBF. Avaliamos a atividade do fotossensibilizante MentaZnPc no ambiente hidrofóbico da cobertura de nanopartículas sob iluminação vermelha em $635 \mathrm{~nm}$ e sob aquecimento. Observou-se que nesse ambiente micelar a MentaZnPc se comporta como fotossensibilizante adequado. No entanto, um aumento de temperatura de $25^{\circ} \mathrm{C}$ até cerca de $40^{\circ} \mathrm{C}$ não pareceu afetar consideravelmente a produção de oxigênio singlete. 


\section{Referências Bibliográficas}

Allison R. R., Downie G. H., Cuenca R., Hu X. H., Childs C. e Sibata C. H. Photosensitizers in clinical PDT. Photodiagnosis and Photodynamic Therapy. 27-42, 2004.

Andrä W., D’Ambly C. G., Hergt R., Hilger I., Kaiser W. A. Temperature distribuition as function of time around a small spherical heat source of local magnetic hyperthermia. Journal of Magnetism and Magnetic Materials. 194, 197-203, 1999.

Araújo F. D. F. J. Construção de um magnetômetro Hall a baixas temperaturas para caracterização de nanopartículas magnéticas. Tese de Doutorado. Departamento de Física, Pontifícia Universidade Católica do Rio de Janeiro. 2013.

Arnold S., Kubo M., Ogryzlo E. Relaxation and Reactivity of Singlet Oxygen. Adv. Chem Ser. 77, 133-142, 1968.

Babincová M., Leszczynska D., Sourivong P., Cicmane P., Babinec P. Superparamegnetic gel as a novel material for electromagnetically induced hyperthermia. Journal of Magnetism and Magnetic Materials. 225, 109-112, 2001.

Bechet D., Couleaud P., Frochot C., Viriot ML., Guillemin F., Barberi-Heyob M. Nanoparticles as vehicles for delivery of photodynamic therapy agents. Trends Biotechnol. 26, 612, 2008.

Beeby A., FitzGerald S. and Stanley C.F. A photophysical study of protonated (tetra-tert-butylphthalocyaninato)zinc. J. Chem. Soc. Perkin Trans 2. 10, 19781982, 2001.

Ben-Hur E., Rosenthal I. The phthalocyanines: a new class of mammalian cells photosensitizers with a potential for cancer phototherapy. Int. J. Radial Biol. Relat. Stud Phys. Chem. Med. 47(2), 145-7, 1985.

Bonnet R. Photosensitizers of the porphyrin and phthalocyanine series for photodynamic therapy. Chem. Soc. Rev. 24, 19-35, 1995.

Braslavsky S. E., Houk K.N., and Verhoeven J. W. Glossary of terms used in photochemistry. International Union of pure and applied chemistry. 3rd Edition, 2005.

Çamur M., Bulut M., Kandaz M., Güney O. Synthesis, characterization and fluorescence behavior of new fluorescent probe phthalocyanines bearing coumarin substituents. Polyhedron. 28, 233-238, 2009.

Canete M., Villanueva A., Dominguez V., Pólo S., Juarranz A., Stockert J.C. Int. J. Oncol. 13, 497-504, 1998. 
Cornell R. M and Schwertmann U. Iron oxides in the laboratory. VCH, New York. 1996.

Corr S. A., Rakovich Y. P., Gun'ko Y. K. Multifunctional magnetic-fluorescent nanocomposites for biomedical applications. Nanoscale Res Lett. 3:87-104, 2008 .

Cullity B. D. Introduction to Magnetic Materials. Addison Wesley Publishing Co. Reading, Massachusetts, 1972.

Curtis A. S. G., Wilkinson C. Nanotechniques and approaches in biotechnology. Trends Biotech. 19:97-101, 2001.

Da Silva A. R. Análise das propriedades fotossensibilizantes do In (III)mesotetrafenilporfirina para uso em Terapia Fotodinâmica. Dissertação de mestrado. Instituto de Química UNICAMP. 2003.

De la Torre G., Martinez-Diaz M. V. and Torres T. Synthesis of fused polynuclear systems based on phthalocyanine and triazolehemiporphyrazine units. J. Porphyrins Phthalocyanines. 3: 560-568, 1999.

Derfus, A. M., Von Maltzahn G., Harris T. J., Duza T., Vecchio K. S., Ruoslahti E., Bhatia S. N. Remotely triggered release from magnetic nanoparticles. Adv. Mater. 19, 3932-3936, 2007.

DeRosa M.C., Crutchley R. J. Photosensitized singlet oxygen and its applications.Coordination Chemistry Reviews. 233- 234, 351-371, 2002.

Derycke A. S. L., de Witte P. A. M. Lipossomes for photodynamic therapy. Adv. Drug Deliver. Rev. 56, 17-30, 2004.

Durmus M., Nyokong T. Synthesis, photophysical and photochemical properties of aryloxy tetra-substituted gallium and indium phthalocyanine derivates. Tetrahedron. 63, 1385, 2007.

Fan F R., Faulkner L. Phthalocyanine thin films as semiconductor electrodes. J. Am. Chem. Soc. 101, 4779-4787, 1979.

Faria R. N., Lima L. F. C. Introdução ao Magnetismo dos Materiais. Livraria da Física, 2005.

Foote C. S. Photosensitized Oxidation and Singlet Oxygen: Consequences in Biological Systems. Free Radicals in Biology. 2, 85-133, 1976.

Gandini C. M., Yushmanov V. E., Borissevitch I. E., Tabak M. Interaction of the tetra(4-sulfonatophenyl) porphyrin with Ionic Surfactants: Aggregation and location in Micelles. Langmuir. 15, 6233-6243, 1999.

Garcia A. M., Alarcon E., Muñoz M., Scaiano J. C., Edwards A. M. and Lissi E. Photophysical behaviour and photodynamic activity of zinc phthalocyanines associated to liposomes. Photochem. Photobiol. Sci. 10, 507- 512, 2011.

Gerdes R., Wöhrle D., Spiller W., Schneider G, Schnurpfeil G., Schulz-Ekloff G., Photooxidation of phenol and monochlorophenols in oxygen-saturated aqueous solutions by different photosensitizers, J. Photochem. Photobiol. A: Chemistry. 111, 65-74, 1997.

Goslinski T., Osmalek T., Konopka K., Wierzchowski M., Fita P., Mielcarek J. Photophysical properties and photocytotoxicity of novel phthalocyanines- 
potentially useful for their application in photodynamic therapy. Polyhedron. 30, 1538-1546, 2011.

Griffiths D. J. Introdution to electrodynamics, 3ed, Prentice Hall, Upper Saddle River NJ., 1999.

Grover W. F. Indutance Calculations: Working formulas and tables. Second Edition, New York, Dover Publication inc., 1962.

Gruttner C., Teller J. New types of silica-fortified magnetic nanoparticles as tools for molecular biology applications. Journal of Magnetism and Magnetic Materials. 194, 8-15, 1999.

Gu H. W., Yang Z. M., Gao J. H,. Chang C. K. and Xu B. Heterodimers of Nanoparticles: Formation at a Liquid-Liquid Interface and Particle-Specific Surface Modification by Functional Molecules. J. Am. Chem. Soc. 127, 34, 2005.

Guimarães A. P. Principles of Nanomagnetism. First Edition, New York, Springer Ed., 2009.

Gupta K. A., Gupta M. Synthesis and surfasse engineering of iron oxide nanoparticles for biomedical applications. Biomaterials. 26, 3995, 2005.

Hamblin M. R., Newman E. L. New trends in photobiology: On the mechanism of the tumour-localising effect in photodynamic therapy. Journal of Photochemistry and Photobiology B-biology. 23, 3-8, 1994.

Hoare T., Santamaria J., Goya G.F., Irusta S., Lin D., Lau S., Padera R., Langer R., Kohane D. S. A magnetically triggered composite membrane for on-demand drug delivery. Nano Lett. 9, 3651-3657, 2009.

http://people.umass.edu/mcclemen/Group.html

http://www.lutanho.net/drawlat/images/spinel.html

Ishii K., Shiine M., Kikukawa Y., Kobayashi N., Shiragami T., Matsumoto J., Yasuda M., Suzuki H., Yokoi H. Silica-gel supported photofunctional silicon phthalocyanine complexes: Photodesorption of molecular oxygen by singlet oxygen generation. Chemical Physics Letters. 448, 264, 2007.

Ishii K. Functional singlet oxygen generators based on phthalocyanines. Coodination Chemistry Reviews. 256, 1556-1568, 2012.

Ito A., Shinkai M., Honda H., Kobayashi T. Medical application of functionalized magnetic nanoparticles. J. Bioscience and Bioeng. Vol 100( 1), 1-11, 2005.

Jakubovics J. P. Magnetism and magnetic materials. 2 ed. Institute of Materials. London, 1994.

Jiles D. Introduction to Magnetism and Magnetic Materials. Second Edition. Chappman \& Hall. New York NY., 1991.

Jim W. A fourth Generation of LCD Backlight Technology. Linear Technology. Application Note 65, 1995.

Jolivet J-P., Tronc E., Chanéac C. Iron oxides: from molecular clusters to solid. A nice example of chemical versatility - Compte Rendue Geoscience. 338:488497, 2006. 
Jonesa. L. R., Grossweine L. I. Singlet oxygen generation by Photofrin ${ }^{\circledR}$ in homogeneous and light-scattering media. Journal of Photochemistry and Photobiology B: Biology. 26, 249-256, 1994.

Kasuga K., Matsura N., Inoue K., Handa M., Sugimori T., Isa K. and Nakata M. Unusual Absorption Spectra Found for Some Phthalocyaninatozinc(II) Complexes Bearing Dendritic Substituents at $\alpha$ Positions. Chem. Lett. 3, 352-353, 2002.

Khan A. U., Kasha M. Red Chemiluminescence of Molecular Oxygen in Aqueous Solution. J. Chem. Phys. 39, 2105, 1963.

Klabunde K. J. Nanoscale materials in chemistry. Sorensen C. M.: CRC. 189$221,2001$.

Kim DK., Zhang Y., Voit W., Kao KV., Kehr J., Bjelke B., Muhammed M. Superparamagnetic iron oxide nanoparticles for bio-medical applications. Scripta Materialia. 44(8), 1713-1717, 2001.

Knobel M., G. F. Goya. Ferramentas magnéticas na escala do átomo. Scientific American Brasil. 58-66, 2004.

Kobayashi N. and Konami H. In Phthalocyanines: Properties and applications. Vol. 4, VCH Publishers. New York, 1999.

Konan Y. N., Gurny R., Allémann E. State of the art in the delivery of photosensitizers for photodynamic therapy. Journal of Photochemistry and Photobiology B: Biology. 66, 89-106, 2002.

Konan Y. N., Berton M., Gurny R., Allemann E. Enhanced photodynamic activity of meso-tetra(4-hydroxyphenyl)porphyrin by incorporation into sub-200 nm nanoparticles. Eur. J. Pharm. Sci. 18, 241-249, 2003.

König K. Multiphoton microscopy in life sciences. Journal of Microscopy. 200(2), 83-104, 2000.

Kulig M. J., Smith L. L. Sterol Metabolism. XXV. Cholesterol Oxidation by Singlet Molecular Oxygen. J. Org. Chem. 38, 3639, 1973.

Kumar G. A., Thomas J., Unnikrishnan N. V., Nampouri V. P. N. and Vallabhan C. P. G. Optical absorption and emission spectral studies of phthalocyanine molecules in DMF. J. Porphyrins Phthalocyanines. 5, 456-459, 2001.

Law W. F., Liu R. C. W., Jiang J. and D. K. P. N. Synthesis and spectroscopic properties of octasubstituted (phthalocyaninato)titanium(IV) complexes. Inorg. Chim. Acta. 256, 147-150, 1997.

Llinares J., Page A. Eletromagnetismo y semiconductores. Editorial Universidad Politécnica de Valencia. 370-373. 1997.

Machado A. Terapia Fotodinâmica: Princípios, potencial de aplicação e perspectives. Química Nova. 23, 237-243, 2000.

Maier-Hauff K., Ulrich F., Nestler D., Niehoff H., Wust P., Thiesen B., Orawa H., Budach V., Jordan A. Efficacy and safety of intratumoral thermotherapy using magnetic iron-oxide nanoparticles combined with external beam radiotherapy on patients with recurrent glioblastoma multiforme. J. Neurooncol. 103, 317-324, 2011. 
Maiti N.C., Mazumdar S., Periasamy N. J and H. Aggregates of porphyrinsurfactant complexes: Time-Resolved Fluorescence and other Spectroscopic Studies. J. Phys. Chem. B. 102, 1528-1538, 1998.

Maree S., Phillips D. and Nyokong T. Synthesis, photophysical and photochemical studies of germanium and tin phthalocyanine complexes $\mathbf{J}$. Porphyrins Phthalocyanines. 6, 17-25, 2002.

Marques A. D. S., Takahata Y., Junior J. R. L., Souza M. C., Simões S. S., Azevedo W. M., As G. F. The species of 8-methoxy-psoralen in hydrophobic and hydrophilic environments and its solubilization in neutral and charged micelles. J. Luminesc. 97, 237-249, 2002.

Merkel P., Kearns D. Remarkable solvent effects on the lifetime of 1.DELTA.g oxygen. J. Am. Chem. Soc. 94, 1029-1030, 1972.

Moghimi S. M., Hunter A. C. H., Murray J. C. Long-circulating and targetspecific nanoparticles: theory to practice. Pharm Rev. 53:283-318, 2001.

Nishiyama N., Morimoto Y., Jang W-D., Kataoka K. Design and development of dendrimer photosensitizer-incorporated polymeric micelles for enhanced photodynamic therapy. Advanced Drug Delivery Reviews. 61, 327-338, 2009.

Nyokong T., Gasyna Z. and Stillman M. J. Phthalocyanine .pi.-cation-radical species: photochemical and electrochemical preparation of $[\mathrm{ZnPc}(-1) .+$ in solution Inorg. Chem. 26, 548-553, 1987.

Ogunsipe A., Maree D., Nyokong T. Solvent effects on the photochemical and fluorescence properties of zinc phthalocyanine derivatives. J Molecular Structure. 650, 131-140, 2003.

Ogunsipe A., Nyokong T. Effects of substituents and solvents on the photochemical properties of zinc phthalocyanine complexes and their protonated derivatives. J Molecular Structure. 689, 89-97, 2004.

Oseroff A. F., Morgan J. Mitochondria-based photodynamic anticancer therapy. Advanced Drug Delivery Reviews. 49, 71-86, 2001.

Ough E. A. and Stillman M. J. Analysis of the absorption and magnetic circular dichroism spectra of iron(II) phthalocyanine. Inorg. Chem. 33: 573-583, 1994.

Ozawa K., Ishii K. photophysical and magnetic properties of magnetic silica gelsupported silicon phthalocyanine complexes. Physical Chemistry Chemical Physics. 11, 1019, 2009.

Pankhurst Q. A., Connolly J., Jones S. K., Dobson J. Applications of magnetic nanoparticles in biomedicine. Journal of Physics D: Applied Physics. 36(13), R167-R181, 2003.

Parker J. P., Stanbro W. D. Optical determination of the lifetime of singleto molecular oxygn. Journal of American Chemical Society. 104, 2067-2069, 1982.

Pollert E., Knízek K., Marysko M., Kaspar P., Vasseur S. New Tc-tuned magnetic nanoparticles for self-controlled hyperthermia. Journal of Magnetism and Magnetic Materials. 316, 122-125, 2007.

Raab O. Ueber die Wirkung fluoreszierender Stoffe auf Infusioren. Z. Biol. 39, $524,1900$. 
Redmond R. W., Kochevar I. Spatially Resolved Cellular Responses to Singlet Oxygen. Photochemistry and Photobiology. V82, 1178-1186, 2006.

Reitz J., Milford F., Christy R. Foundations of electromagnetic Theory. Fourth edition. Addison-Wesley Publishing Company, 1993.

Rio Y., Rodriguez-Morgade M. S., Torres T. Modulating the electronic properties of porphyrinoids: a voyage from the violet to the infrared regions of the electromagnetic spectrum. Org. Biomol. Chem. 6:1877, 2008.

Romero O. María Paulina. Estudo da interação de fotossensibilizantes derivados de ftalocianinas com sistemas de distribuição de fármacos para terapia fotodinâmica. Tese de Doutorado. Departamento de Física, Pontifícia Universidade Católica do Rio de Janeiro. 2012.

Rosensweig R. E. Heating magnetic fluid with alternating magnetic field. Journal of Magnetism and Magnetic Materials. 252, 370-374, 2002.

Rosenthal I. Phthalocyanines as photodynamic sensitizers. Photochem Photobiol. 53(6), 859-870, 1991.

Sahoo Y., Goodarzi A., Swihart M. T., Ohulchanskyy T. Y., Kaur N., Furlani E. P., Prasad P. N. Aqueous ferrofluid of magnetite nanoparticles: Fluorescence labeling and magnetophoretic control. Journal Of Physical Chemistry B. 109(9), 3879, 2005.

Santiago P., Sousa D., Gandini S., Tabak M. On the localization of water-soluble porphyrins in micelar system evaluated by static and time-resolved frequencydomain fluorescence techniques. Colloids Surf B Biointerfaces. 65, 247-256, 2008 .

Schwertmann U., Cornell R. M. Iron oxides in the laboratory: preparation and characterization. Weinheim, Cambridge: V. C. H.; 1991.

Sekkat N., Bergh H., Nyokong T., Lange N. Like a Bolt from the Blue: Phthalocyanines in Biomedical Optics. Molecules. 17, 98-144, 2012.

Seotsanyana-Mokhosi I., Kuznetsova N. and Nyokong T. Photochemical studies of tetra-2,3-pyridinoporphyrazines Photochem. Photobiol. A: Chem. 140, 215$222,2001$.

Shinkai M. Functional magnetic particles for medical application. Journal of Bioscience and Bioengineering. 94(6), 606-613, 2002.

Shliomis M. I. Magnetic fluids. Soviet Physics Uspekhi. 17: 153-169, 1974.

Sibata M., Tedesco A., Marchetti J. Photophysicals and photochemicals studies of zinc(II) phthalocyanine in long time circulation micelles for Photodynamic Therapy use. European Journal of Pharmaceutical Sciences. 23, 131-138, 2004.

Silvester P. Modern Electromagnetic Fields. Englewoods Cliffs NJ. 1968.

Simplicio F. I., Maionchi F. e Hioka N. Terapia Fotodinâmica: Aspectos Farmacológicos, Aplicações, e Avanços Recentes no Desenvolvimento de Medicamentos. Química Nova. 25 (5), 801-807, 2002.

Singh A., Sahoo S. K. Magnetic nanoparticles: a novel platform for cancer theranostics. Drug Discovery Today. 19 (4) 475-481, 2014. 
Solovieva A. B., Melik-Nubarov N. S., Aksenova N. A., Glagolev N. N., Vstovskii G. V., Bugrin V. S., Luzgina V. N., Olishevskaya V. A., Belkova G. V. Porphyrin photosensitizers solubilized with pluronics in the oxidation of tryptophan. Russian Journal of Physics Chemistry. 80, 124-130, 2006.

Solovieva A. B., Melik-Nubarov N. S., Zhiyentayev T. M., Tolstih P. I., Kuleshov I. I., Aksenova N. A., Litmanovich E. A., Glagolev N. N., Timofeeva V. A., Ivanov A. V.. Development of novel formulations for photodynamic therapy on the basis of amphiphilic polymers and porphyrin photosensitizers. Pluronic influence on photocatalytic activity of porphyrins. Laser Physics. 19, 817-824, 2009.

Stillman M.J. and Nyokong T., In Phthalocyanines: Properties and applications. Vol. 1, VCH Publishers, New York, 1989.

Stillman J. M., Ough E. A., Creber K. A. M., Can. J. Chemistry. 71, 1898, 1993.

Stillman M., Mack J. and Kobayashi N. Theoretical aspects of the spectroscopy of porphyrins and phthalocyanines. J. Porphyrins Phthalocyanines. 6, 296-300, 2002.

Sun C., Lee J. S. H., Zhang M. Magnetic nanoparticles in MR imaging and drug delivery. Advanced Drug Delivery Reviews. 60, 1252-1265, 2008.

Tartaj P., Morales M. P., Gonzáles-Carreño T., Veitemillas-Verdaguer S. C. J. Advances in magnetic nanoparticles for biotechnology applications. J. Magnetism and Magnetic Materials. 290-291, 28-34, 2005.

Terman F. E. Radio Engineering Handbook. New York: McGraw-Hill. 1943.

Thompson M. S., Gustafsson L., Palsson S., Bendsöe N. et al. Photodynamic therapy and diagnostic measurements of basal cell carcinomas using esterified and non-esterified delta-aminolevulinic acid. Journal of Porphyrins and Phthalocyanines. 5, 147-153, 2001.

Valeur B. Molecular Fluorescence: Principles and Applications. Wiley-VCH Verlag Gmbh ISBNS: 3-527-299919X .

Vargas A., Pegaz B., Debefve E., Konan-Kouakou Y., Lange N., Ballini J. P., Bergh H. V. D., Gurny R., Delie F. Improved photodynamic activity of porphyrin loaded into nanoparticles: an in vivo evaluation using chick embryos. Int. J. Pharm. 286, 131-145, 2004.

Verwey E. J. W. and Haayman P. W. Electronic conductivity and transition point of magnetite (" $\mathrm{FE}_{3} \mathrm{O}_{4}$ "). Physica. 8, 979, 1941.

Vior M. C. G, Monteagudo E., Dicelio L. E., Awruch J; , Comparative study of a novel lipophilic phthalocyanine incorporated into nanoemulsion formulations: photophysics, size, solubility and thermodynamic stability. Dyes and Pigments. 91, 208-214, 2011.

Young Hugh D.University Physics. 8th Ed. Addison-Wesley. 1992.

Yu C. H., Tam K. Y., Lo C. C. H. and Tsang S. C., Functionalized Silica Coated Magnetic Nanoparticles With Biological Species for Magnetic Separation. IEEE Trans. Magn. 43, 2436-2438, 2007.

Wasserman H. H., Murray R .W. Singlet Oxygen. Academic Press, $1^{\text {st }}$ edition. 139-167, 1979. 
Wilkinson F., Helman W. and Ross B. Rate constans for the decay and reaction of the lowest electronically excited singlet state of molecular oxygen in solution. An expanded and revised compilation. J. Phys. Chem. Ref. Data. 24, 663-677, 1995.

Wilkinson J. M. Nanotechnology applications in medicine. Med. Device Technol. 14(5):29-31, 2003.

Wohrle D., Wendt A., Weitemeyer A., Stark J., Spiller S., Muller S., Michelsen U., Kliesch H., Heuermann A., Ardeschipur A. Metal chelates of porphyrin derivates as sensitizer in photooxidation processes of sulfur compounds and in photodynamic therapy of cancer. Russ. Chem. Bull. 43, 1953-1964, 1994.

Zhientaev T. M., Melik Nubarov N. S., Litmanovich E. A., Aksenova N. A., Glagolev N. N., and Solovieva A. B. The effect of pluronics on the photocatalytic activity of water_soluble porphyrins. Polymer Science. 51, 502-511, 2009. 


\section{Apêndices}

\section{Funções em Matlab}

Neste apêndice são mostrados os códigos e o algoritmo em Matlab usados para a construção da bobina que forma o circuito aquecedor por indução.

Inicialmente o programa cria a primeira espira para o Opera-3D, indicando as coordenadas da sua seção reta quadrada, raio da bobina e o centro desta primeira espira. Em seguida se criam as outras espiras da bobina, indicando o número de voltas desejadas, o espaçamento entre cada espira e a corrente que a percorre.

Com a corrente elétrica indicada e o intervalo de varredura do campo magnético, o Matlab interpola e gera o campo magnético e o solenóide no Opera3D, salvando os dados da curva no Matlab. Finalmente o Matlab chama e mostra a curva do campo magnético da bobina.

\section{A. Programa para gerar o solenoide e encontrar o campo magnético nele.}

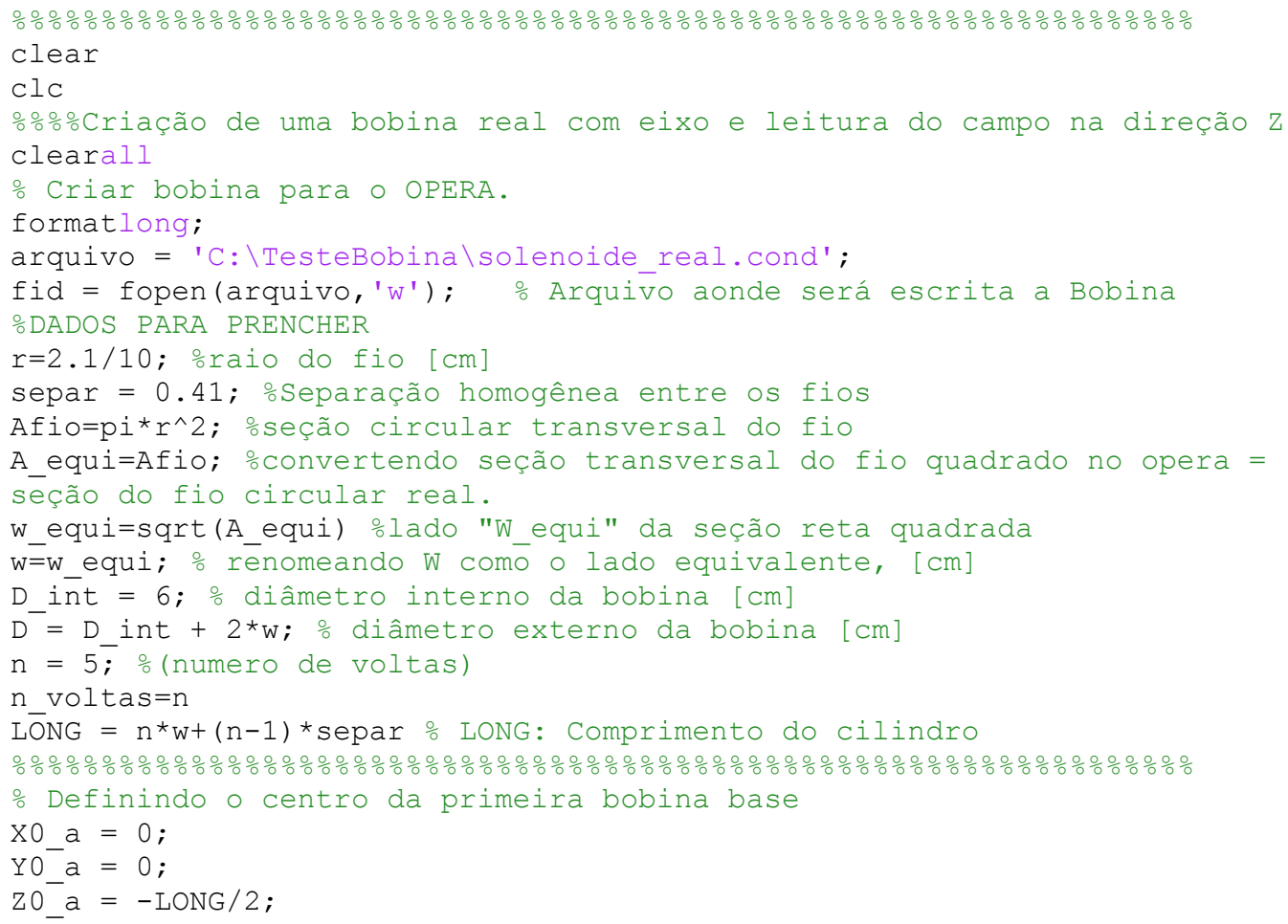




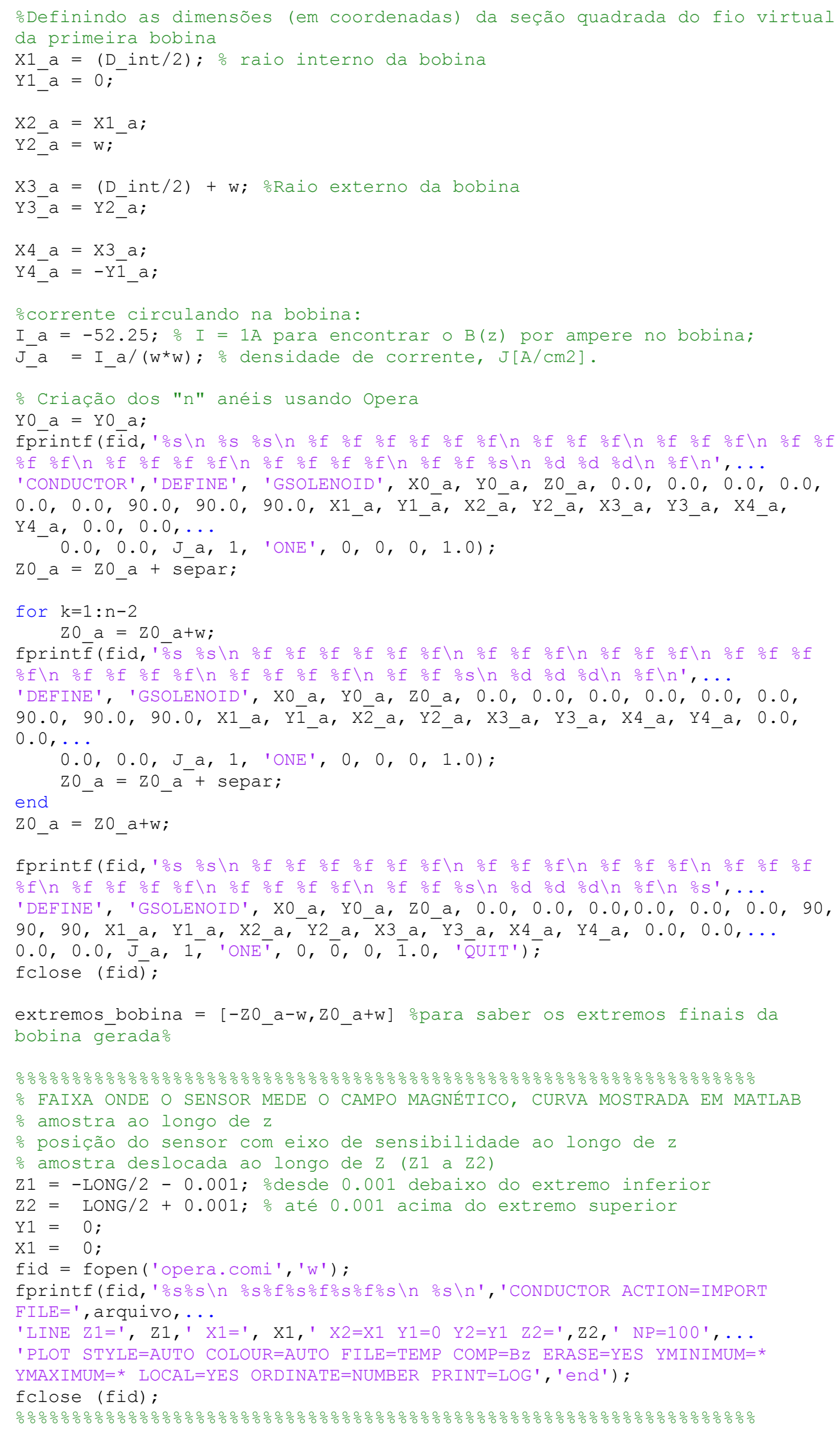




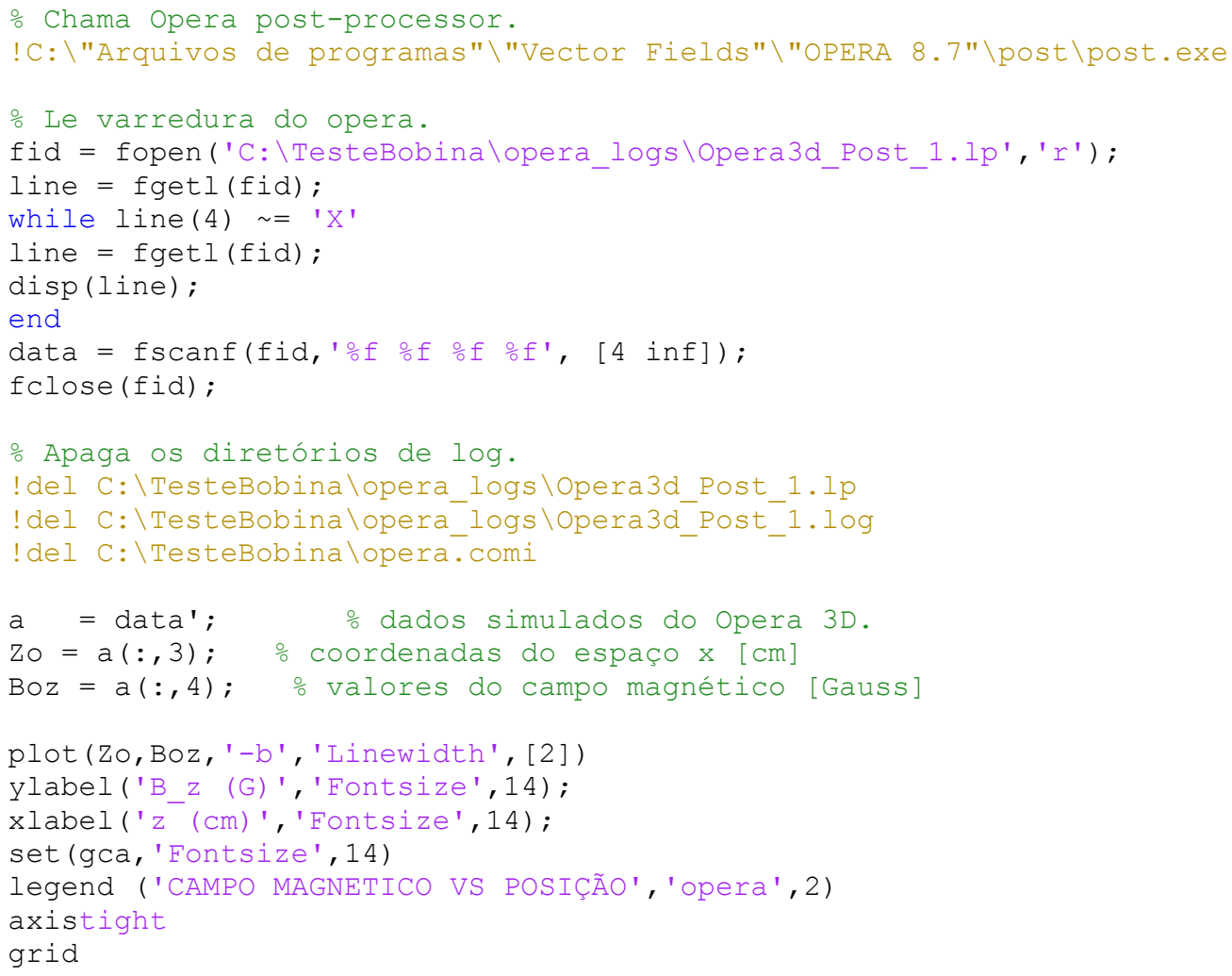

\section{B. Programa para calcular as impedâncias e corrente no bobina.}

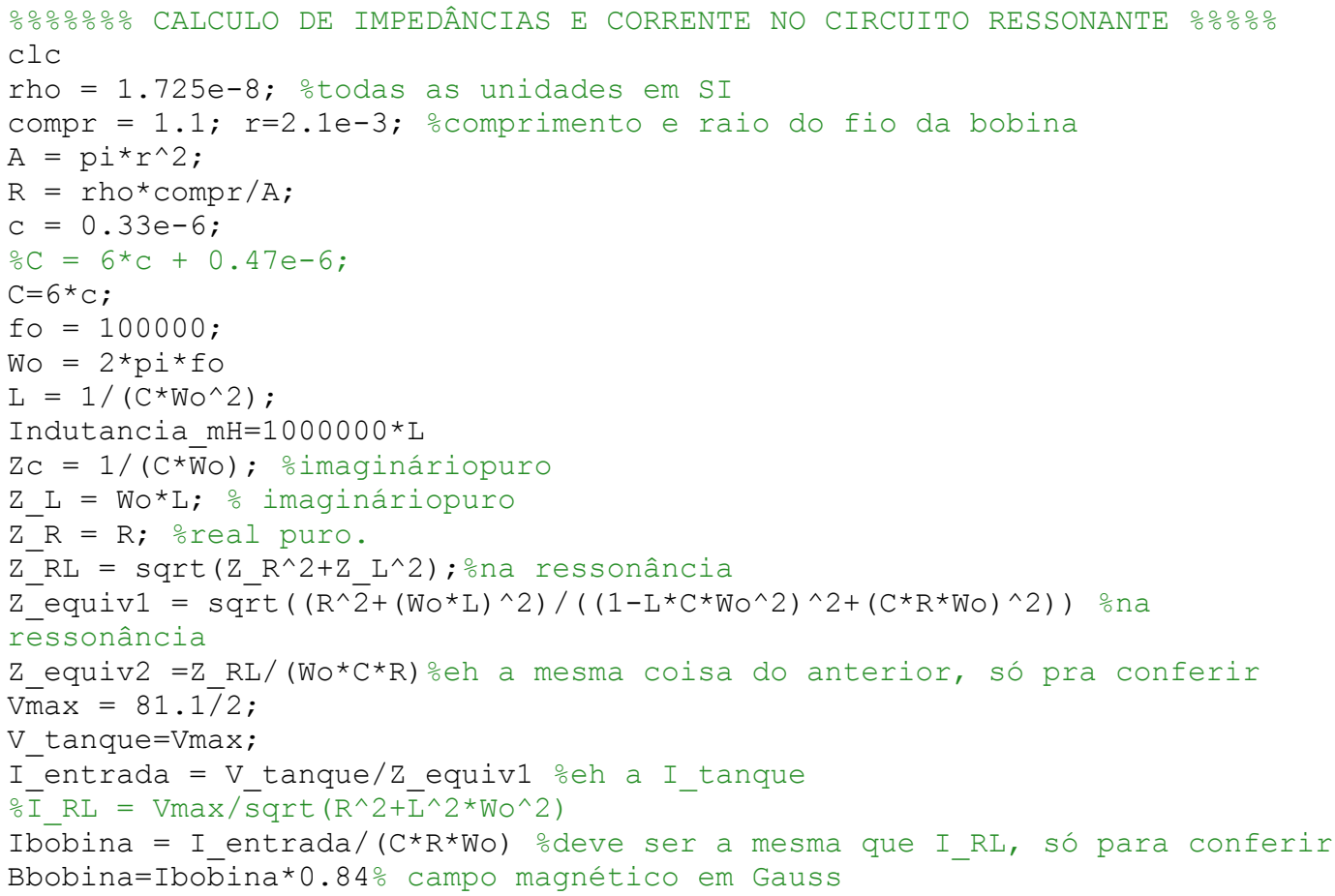

\section{Programa para calcular a indutância da bobina.}

$r=2.1 / 1000 ;$

$\mathrm{n}=5$;

$s=4.1 / 1000 ;$ oseparação entre extremos dos anéis

$\mathrm{D}=(\mathrm{s}+2 * r)$; 


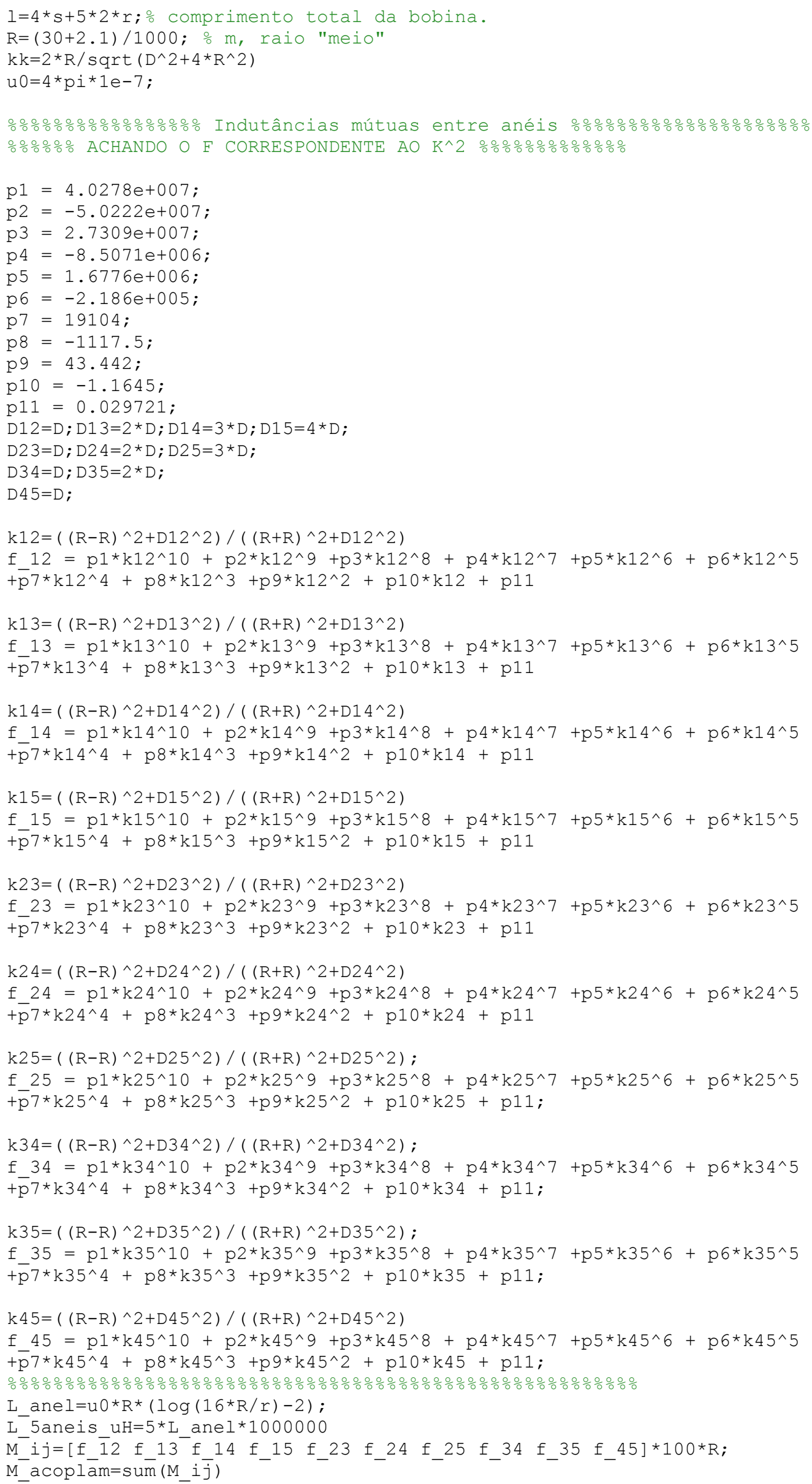


L_acopl=L_5aneis_uH+M_acoplam

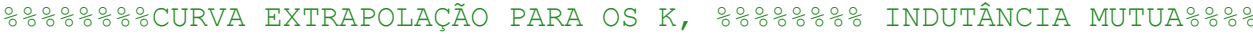
$\mathrm{k}$ cuadr $=0.01: 0.01: 0.22$;

$\mathrm{f}=\left[\begin{array}{llllllll}0.021474 & 0.017315 & 0.014937 & 0.013284 & 0.012026 & 0.011017 & 0.010179\end{array}\right.$

$\begin{array}{llllllllll}0.009464 & 0.008843 & 0.008297 & 0.00781 & 0.007371 & 0.006974 & 0.006611 & 0.006278\end{array}$

$0.005970 .0056850 .005420 .0051730 .0049410 .0047230 .004518]$;

plot ( $k$ cuadr, f)

gridon

\section{Programa para calcular o campo magnético máximo no centro da bobina} usando Biot Savart.

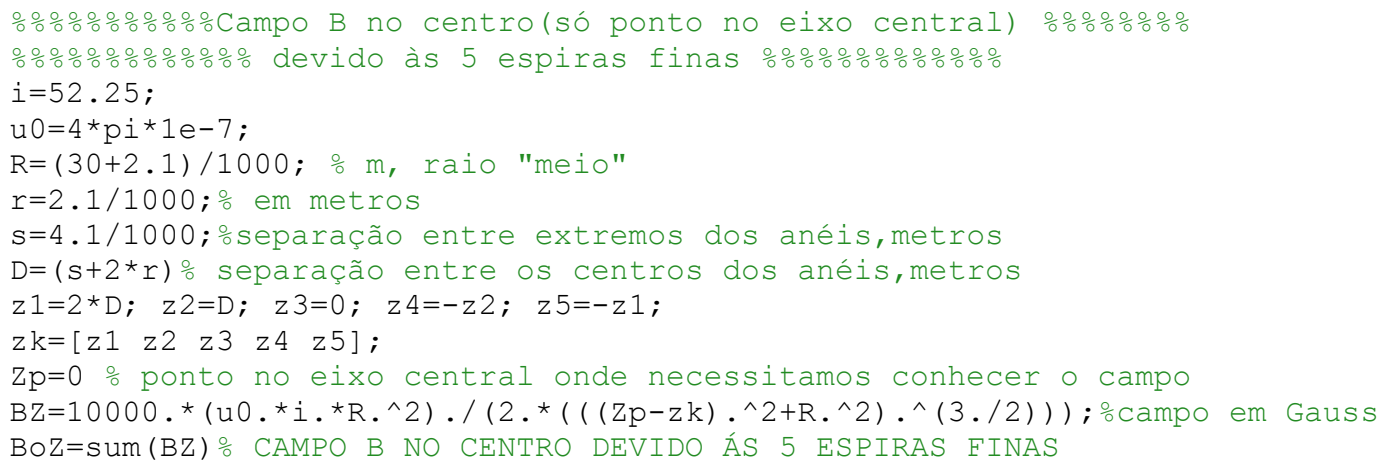

\section{E. Programa para obter a curva do campo magnético B devido às espiras em qualquer ponto do eixo central.}

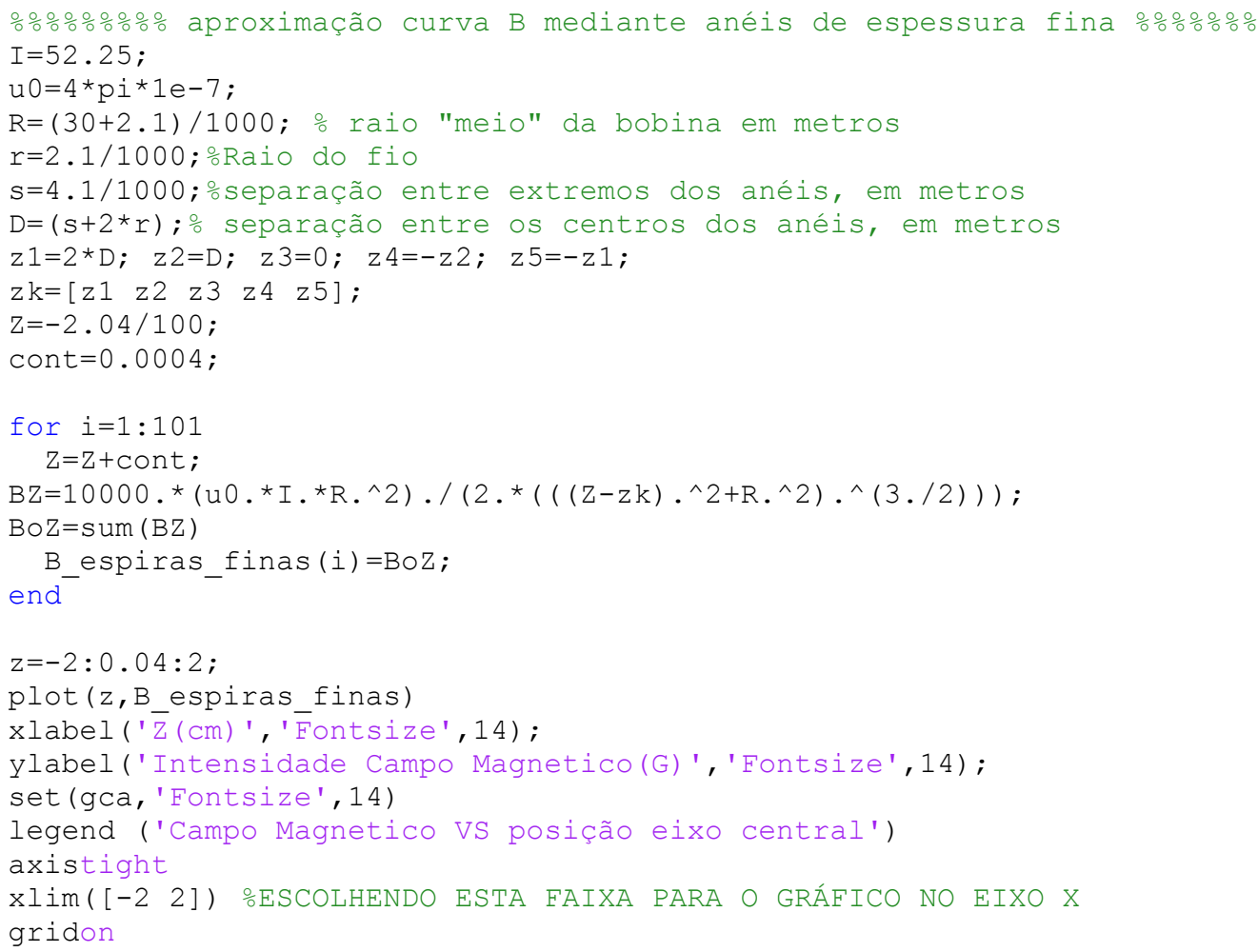

